WBS: 1 2.2.3.3

QA: L

SCPB: N/A

Cóver Sheet

Page 1 of 3

Civilian Radioactive Waste Management System Management and Operating Contractor

\title{
EMPLACED WASTE PACKAGE STRUCTURAL CAPABILITY THROUGH TIME REPORT
}

Document Identifier BBAA00000-01717-5705-00001 REV 00

\author{
Revision 00 \\ June 14, 1996 \\ Prepared for:
}

U.S. Department of Energy

Yucca Mountain Site Characterization Project Office

P.O. Box 98608

Las Vegas, NV 89109-8608

Prepared by:

TRW Environmental Safety Systems, Inc.

101 Convention Center Drive

Las Vegas, NV 89109

Under Contract Number

Contract \#: DE-AC01-91RW00134 
Emplace Waste Package Structural Capability Through Time Report

DI: BBAA00000-01717-5705-00001 REV 00
Cover Sheet

Page 2 of 3

PREPARED BY:

Sot M. Bennet

S. M. Bennett

Waste Package Design

CRWMS M\&O, Nevada Site

Joker lough

Z. Ceylon

Waste Package Design

CRWMS M\&O, Nevada Site

APPROVED BY:
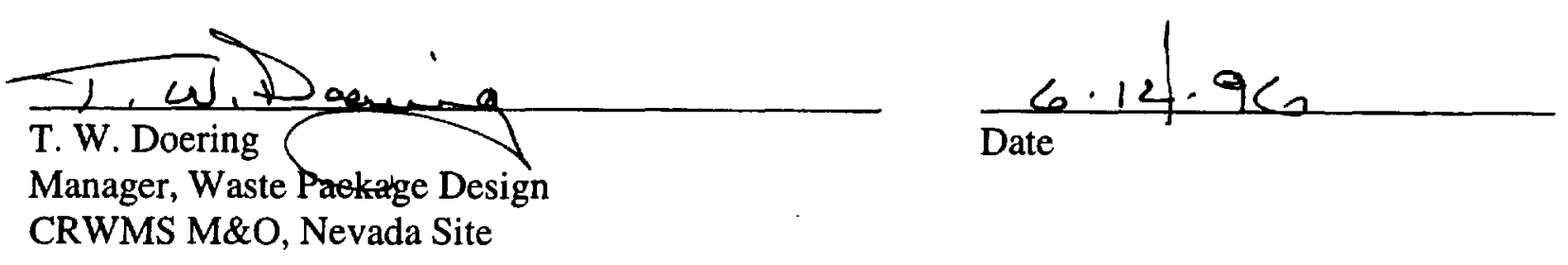

Heal A. Bunt ar

H. A. Benton

Department Manager, Waste Package Development CRWMS M\&O, Nevada Site
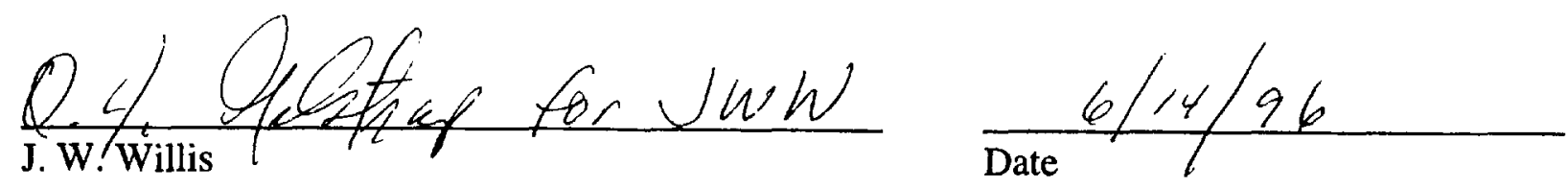

Manager, Quality Assurance

CRWMS M\&O, Nevada Site

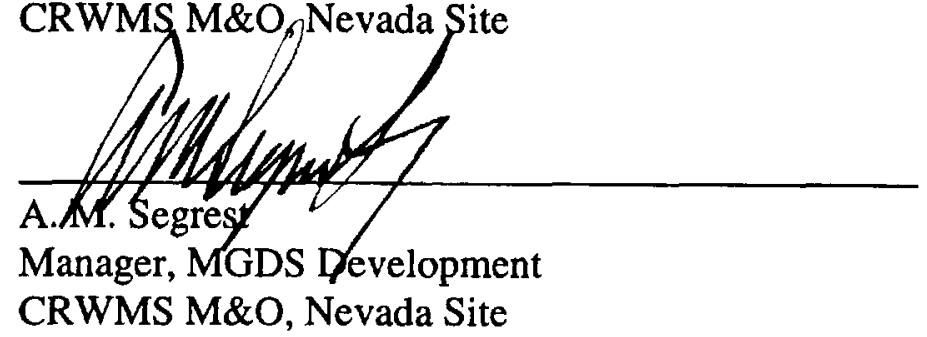

$6 / 14 / 96$

Date

Date

$06 / 14 / 96$

$6 / 14 / 96$

Date

Date

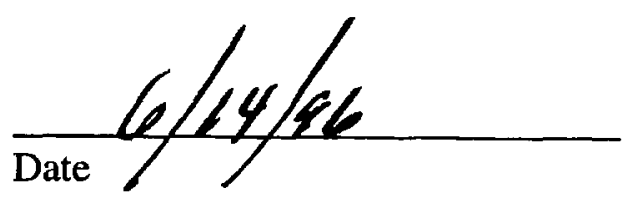




\section{REVIEW SIGNATURES}

The following individuals performed the Technical Document Review required by QAP-3-5, Sections 5.3.2 through 5.3.7. Their signatures below indicate concurrence, required in Section 5.3.5, that any mandatory comments made during the review were resolved satisfactorily, and that resolutions were reflected in the completed report.

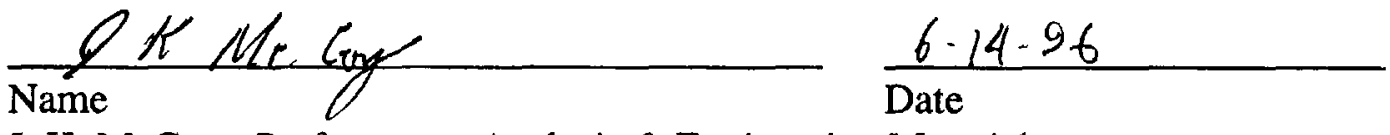

J. K. McCoy - Performance Analysis \& Engineering Materials
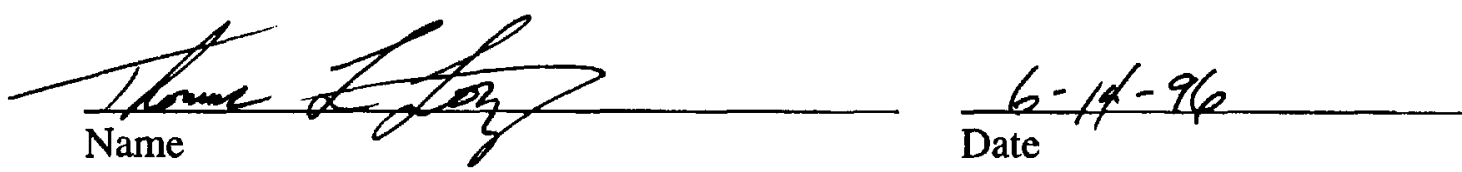

T. L. Lotz - Engineering Drawing Development

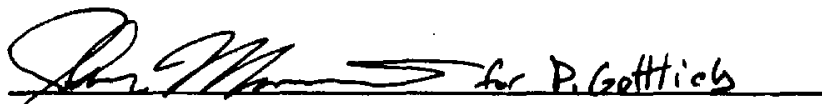

Name

P. Gottlieb - Waste Package Risk Analysis

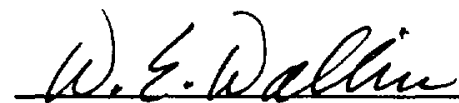

Name

W. E. Wallin - Product Checking Group

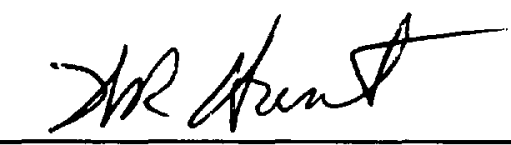

Name

W. R. Hunt - Quality Assurance

$\frac{6-14 \cdot 96}{\text { Date }}$

Date

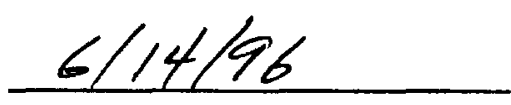

Date

$$
6-14-86
$$

Date 


\section{EXECUTIVE SUMMARY}

The Emplaced Waste Package Structural Capability Through Time Report is Waste Package Development fiscal year 1996 Deliverable Item No. ALT6204.

The objective of this document is to provide a basis for time dependent structural analyses. This report focuses on waste package component thinning and how that relates to structural failure mechanisms. A short review is included in this report that demonstrates how the component thinning results could be used in determining the relative and finite structural failure times. The correlation to failure time is based on Total System Performance Assessment (TSPA)-95 models which are now being updated and improved. It is planned that the structural results generated in this report will be used along with the new corrosion models to quantify the anticipated times of failure of various waste package components. These degradation levels cover all three phases of the repository: operations, substantially complete containment, and isolation. The major outputs of the analyses performed are given in terms of thinning of the waste package component materials, see Assumption 2.3-1. When the corrosion models are updated, the conditions analyzed may be related more accurately to time, thus providing data needed for determining the probability of spent nuclear fuel (SNF) release for performance assessment.

The waste package analyzed for this report is an unconfirmed preliminary Advanced Uncanistered Fuel waste package which provides for the disposal of spent nuclear fuel assemblies. The design uses a basket consisting of carbon steel tubes fitted into an array of interlocking stainless steel-boron plates, then surrounded by barriers of Alloy 625 and A 516 carbon steel. The design is illustrated in Figure 3.1-1.

\section{Structural Analyses:}

The purpose of this technical report is to present the results of structural analyses performed to determine the structural capabilities of a waste package at various levels of degradation. Most of the analyses were performed using the ANSYS finite element code. Evaluations of dynamic loadings were performed as transient dynamic analyses and response spectrum analyses. The analyses determined the onset of structural failure under the following conditions:

Reduced thickness of the outer barrier (A 516) and inner barrier (Alloy 625) structurally loaded by backfill. The waste package maintains containment even when the entire A 516 outer barrier and more than half of the inner barrier have been removed, (9.5 $\mathrm{mm}$ of the original $20 \mathrm{~mm}$ remains). This corresponds to a mean barrier failure time of greater than 100,000 years for static loading.

Reduced thickness of spent nuclear fuel basket plates structurally loaded by spent fuel. The criticality control plates of the basket continue to support the load of the fuel even when all of the carbon steel tubes and more than one third of the original stainless steel-boron material has been removed, ( $4.5 \mathrm{~mm}$ of the original $7 \mathrm{~mm}$ remains). This corresponds to a plate failure time of greater than 2000 years following the first breach of the containment barriers. 
Rock impact on barriers. The maximum rock size able to strike a package without breaching the barriers versus remaining barrier thickness was determined. The waste package can withstand the impact of a $350 \mathrm{~kg}$ rock falling from a height of 2.4 meters even with the outer barrier completely removed. Complete degradation of the outer barrier will take in excess of 100,000 years to occur.

Seismic. The waste package has the capability to withstand Yucca Mountain earthquakes even with the outer barrier completely removed and with the basket beginning to degrade. The waste package will still be capable of withstanding a seismic event for between 30 to 340 years following breach of the containment barriers.

Spent nuclear fuel assembly capability to be self-supporting if basket structure is completely removed. Analyses showed that a spent nuclear fuel assembly can support the load of backfill and other assemblies stacked above it without rupturing of its fuel rods, even if the waste package basket is completely removed.

\section{Barrier Capability Under Static Loading:}

The static analyses of the waste package barriers included the a sensitivity study of the effects of three parameters on barrier performance. The first parameter investigated was the effect of taking structural credit for the basket assembly when analyzing the barriers. The second parameter studied was the effect of the presence of emplacement drift backfill on the barrier stresses. The final parameter examined was the effect of the difference in mass between the original material and the degradation products.

The effect of taking structural credit for the basket assembly when analyzing the barriers was found to be significant, especially when there was substantial thinning of the barriers. With the basket assembly supporting the barriers, the barriers were able to retain containment until the barriers had degraded almost entirely ( $2 \mathrm{~mm}$ inner barrier thickness remaining from original thickness of $20 \mathrm{~mm}$ ), and the basket components had begun to thin. With no support from the basket assembly, the barriers were still capable of retaining containment until the outer barrier had degraded completely and the inner barrier had thinned to $9.5 \mathrm{~mm}$ from its original thickness of $20 \mathrm{~mm}$. This amount of degradation will take in excess of 100,000 years. Because anticipated manufacturing tolerances may allow significant barrier deflections before contact is established between the inner barrier and the basket assembly, it is reasonable to expect that analyzing the barriers without support from the basket assembly is more representative of actual conditions. Therefore, the limiting degradation for retaining containment under static loading is complete degradation of the outer barrier and thinning of the inner barrier to $9.5 \mathrm{~mm}$ from an original material thickness of $20 \mathrm{~mm}$.

The effects of backfill and the mass difference between original materials and degradation products were found to have only minor effects on the results, causing the barrier thickness at failure to vary by only a few millimeters $(6.5 \mathrm{~mm}$ to $9.5 \mathrm{~mm})$. 


\section{Basket Capability Under Static Loading:}

The basket assembly is made up of four different components; tubes, interlocking criticality control plates, side guides, and corner guides. The configuration of these basket components can be seen in Figure 3.1-1. In performing these analyses, it was determined that the two basket components critical to maintaining the spent fuel configuration under static loading are the side guides and the criticality control plates. It was found that the criticality control plates were capable of maintaining the spent fuel configuration without the support of the tubes. The tubes are, however, provided for thermal performance and provide additional support for the basket assembly to survive possible handling events. The corner guides are required in order to maintain the spent fuel configuration. They are made of the same material (A 516) and have the same thickness as the side guides, but are under less load. Therefore, they will have to thin more than the side guides before failure would occur.

The side guides are part of the design for thermal performance and for maintaining the basket configuration. They are located between the tubes and the inner barrier. A sketch of a side guide can be seen in Attachment I-14. Based on the loadings analyzed, the capability of the degrading basket to withstand static loading will be limited by the side guide. The side guide can withstand static loading until it has thinned $6.2 \mathrm{~mm}$ to $3.8 \mathrm{~mm}$ from its original thickness of $10 \mathrm{~mm}$. The time at which the side guide will fail ranges from 44 years to 560 years following breach of the barriers. When this level of degradation has been reached, the side guide will no longer be capable of supporting the load, and the entire basket structure will shift downward until the criticality control plates and fuel are resting on the inner barrier. The tubes, made of the same material as the side guide (A 516) and having an original thickness of $5 \mathrm{~mm}$, would have completely degraded when this occurs. Following failure of the side guides, corner guide failure may occur, having a similar but less severe impact.

After the guides and tubes have degraded, the criticality control plates will be the only remaining basket structure. The limiting locations for structural capability in the criticality control plates are the horizontal plates under the peripheral spent nuclear fuel assemblies. The plates in these locations will be capable of sustaining the bending load until they have thinned $2.5 \mathrm{~mm}$ to $4.5 \mathrm{~mm}$ from an original thickness of $7 \mathrm{~mm}$. This will take between 2000 and 8500 years following breach of the barriers. When this occurs, fuel assemblies on the upper side of the basket will load the fuel assemblies on the lower side, likely accelerating complete collapse of the basket structure.

\section{Barrier Capability Under Rock Impact Loading:}

Dynamic analyses simulating rocks falling onto the waste package have been performed to determine how the critical rock size will vary as the waste package barriers degrade. The critical rock size is defined as the size and mass of rock that will cause stresses in the barriers equal to defined stress allowables for the component materials. The range of barrier thicknesses ranged from original thickness of the barriers to complete degradation of the outer barrier and an inner barrier thickness of $10 \mathrm{~mm}$, half of the original thickness of $20 \mathrm{~mm}$. The results of the evaluations were: 
Level of Degradation

Original Thicknesses

Outer Barrier Thinned $50 \mathrm{~mm}$

Outer Barrier Thinned $75 \mathrm{~mm}$

Complete Outer Barrier Degradation

Inner Barrier Thinned $10 \mathrm{~mm}$
Critical Rock Size

$8000 \mathrm{~kg}, 1.90 \mathrm{~m}$ diameter

$2500 \mathrm{~kg}, 1.29 \mathrm{~m}$ diameter

$1000 \mathrm{~kg}, 0.95 \mathrm{~m}$ diameter

$350 \mathrm{~kg}, 0.67 \mathrm{~m}$ diameter

$50 \mathrm{~kg}, 0.35 \mathrm{~m}$ diameter $\frac{\text { Year }}{0}$

23,000

$-54,000$

$>100,000$

$» 100,000$

Thus, a rapid reduction in the capability of the barriers to withstand rock impact loading was observed as the barriers thinned.

\section{Waste Package Capability During Seismic Events:}

Evaluations of seismic accelerations on waste packages at various levels of degradation were performed. The input is defined as a constant acceleration in a critical frequency range. The acceleration used, $0.66 \mathrm{~g}$, came from earthquake data which was obtained from strong motion recording stations near Yucca Mountain. ${ }^{[1]}$ Results indicated that with complete degradation of the outer barrier, inner barrier thinning of $18 \mathrm{~mm}$, and carbon steel basket component thinning of $5 \mathrm{~mm}$, the waste package was still capable of containing waste and maintaining fuel assembly configuration in the basket assembly. For this condition, the side guide is an important component. Thinning of the side guide can be expected to reach this level of degradation between 30 and 340 years following breach of the containment barriers. Component failure due to seismic loading occurred when 3.5 $\mathrm{mm}$ was removed from the criticality control plates, half of the original thickness. Therefore, the critical level of degradation for seismic loading is bounded by these two cases.

\section{Spent Nuclear Fuel Structural Capabilities:}

Evaluations were performed to determine if degradation products will structurally load the spent nuclear fuel assemblies. These calculations were necessary because the degradation products occupy a greater volume than the original materials. The results of the volume calculations showed that the volume of the degradation products was insufficient to fill all of the void space in the tubes of the basket assembly. Therefore, the fuel rods will not experience compression loads due to degradation products.

Evaluations were also performed to determine if the fuel rods in the spent nuclear fuel assemblies are capable of withstanding static loads after complete collapse of the basket assembly and barriers. Fuel rods from the fuel assemblies on the bottom side of the waste package were analyzed because they will be under the highest loading. The results of the analysis indicated that the maximum bending stress was $57.2 \mathrm{MPa}$. With an allowable stress intensity of $348.2 \mathrm{MPa}$ for the fuel rod cladding material (including effects of radiation), the margin of safety is 5.1. Therefore, the fuel assemblies are capable of withstanding the static load following complete collapse of the waste package barriers and basket assembly without rupture of the fuel rods. 


\section{Table of Contents}

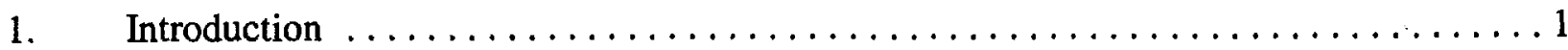

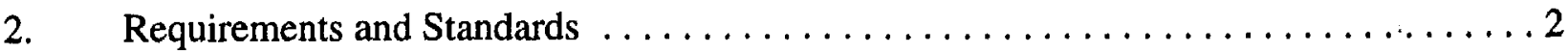

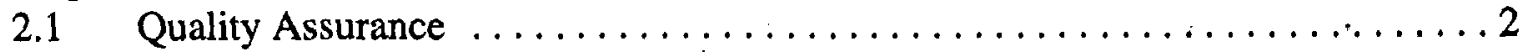

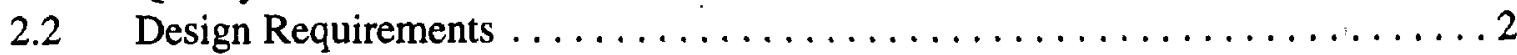

2.2.1 Waste Package Development Technical Document ............ 2

2.2.2 Engineered Barrier Design Requirements Document (EBDRD) . . . . . . 3

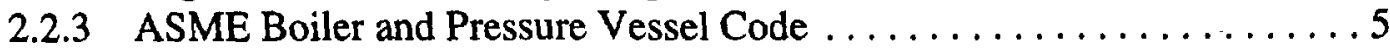

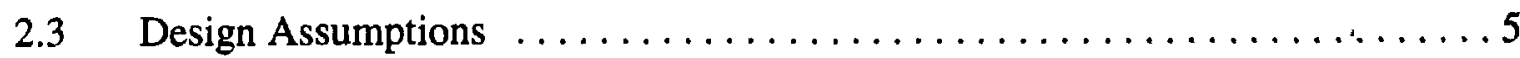

3. Waste Package Analyses of Structural Capability Through Time . . . . . . . . . 7

3.1 Waste Package Design Description $\ldots \ldots \ldots \ldots \ldots \ldots \ldots \ldots \ldots \ldots$

3.2 Static Analyses . . . . . . . . . . . . . . . . . . . . . . . . 11

3.2.1 Analysis of Containment Barriers . . . . . . . . . . . . . . 11

3.2.1.1 Barrier Analysis Taking Structural Credit for Basket . . . . . . 11

3.2.1.2 Barrier Analysis With No Structural Support from Basket . . . . 20

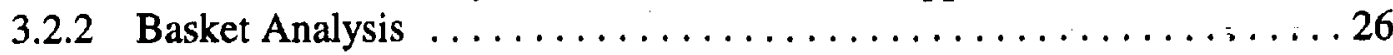

3.2.2.1 Analysis of Side Guide for Static Analyses . . . . . . . . 26

3.2.2.2 Static Analysis of Criticality Control Plates $\ldots \ldots \ldots \ldots 33$

3.2.2.3 Tube Analysis . . . . . . . . . . . . . . . . 36

3.2.2.4 Corner Guide Analysis . . . . . . . . . . . . . . . 36

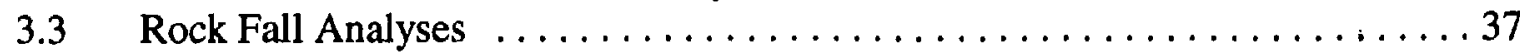

3.3.1 Finite-Element Model Development ................. 37

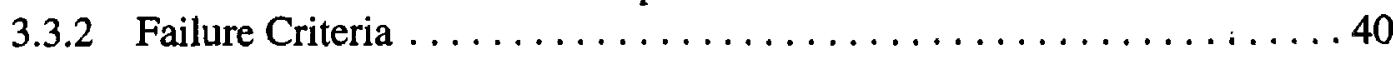

3.3 .3 Results .............................41

3.4 Seismic Analyses $\ldots \ldots \ldots \ldots \ldots \ldots \ldots \ldots \ldots \ldots \ldots \ldots \ldots \ldots \ldots \ldots \ldots$

3.4.1 Finite-Element Model Development . . . . . . . . . . . . 44

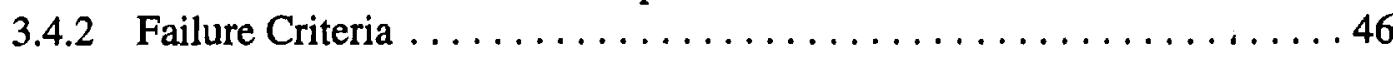

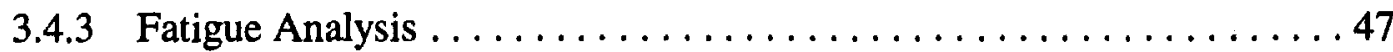

3.4 .4 Results ................................. 48

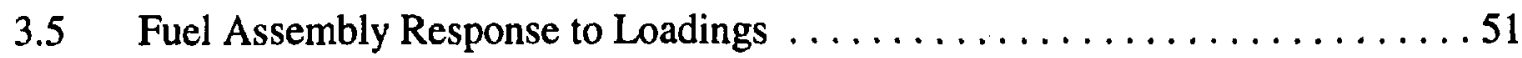

3.5.1 Effect of Degradation Products on Fuel Assemblies . . . . . . . . . 51

3.5.2 Static Load on Fuel Assemblies Due to Complete Degradation of WP . 52

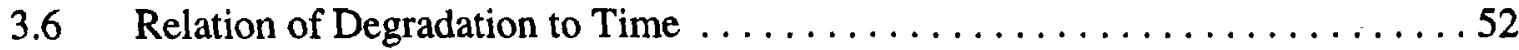

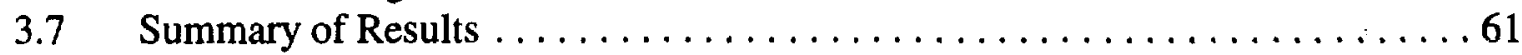

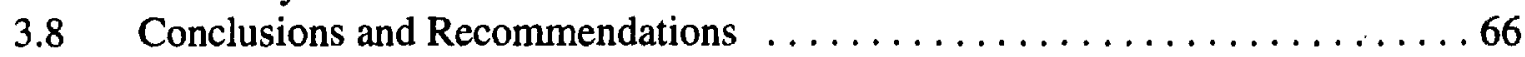

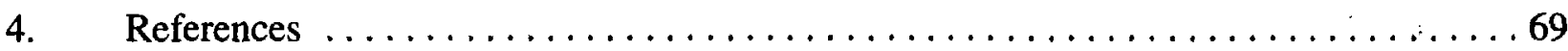

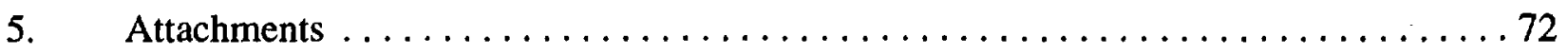




\section{List of Figures}

Figure 3.1-1. Exploded View of 21 PWR AUCF WP $\ldots \ldots \ldots \ldots \ldots \ldots \ldots \ldots \ldots \ldots$

Figure 3.2-1. Half Symmetry Waste Package Model with No Degradation ............ 12

Figure 3.2-2. Quarter Symmetry Waste Package Model with High Degree of Degradation . . . 13

Figure 3.2-3. Inner Barrier Stresses vs. Basket Thinning with $2 \mathrm{~mm}$ Inner Barrier Thickness

Remaining, Basket Provides Structural Support ................... 17

Figure 3.2-4. Inner Barrier Stresses vs. Basket Thinning with $1 \mathrm{~mm}$ Inner Barrier Thickness

Remaining, Basket Provides Structural Support ................... 18

Figure 3.2-5. Quarter Symmetry Waste Package Model with No Structural Credit for Basket

..........................................21

Figure 3.2-6. Inner Barrier Stresses vs. Inner Barrier Thinning, No Structural Support from Basket,

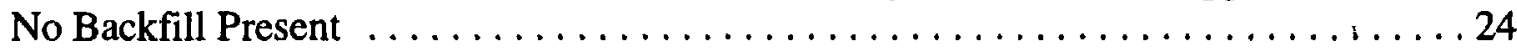

Figure 3.2-7. Inner Barrier Stresses vs. Inner Barrier Thinning, No Structural Support from Basket,

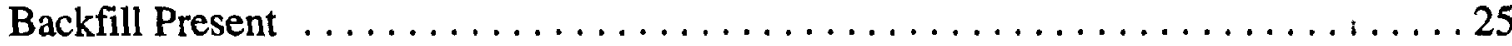

Figure 3.2-8. Quarter Symmetry Side Guide Model .................... 27

Figure 3.2-9. Side Guide Stresses vs. Side Guide Thinning, No Backfill Present . . . . . . 30

Figure 3.2-10. Side Guide Stresses vs. Side Guide Thinning, Backfill Present .......... 32

Figure $3.2-11$. Criticality Control Plate Buckling $\ldots \ldots \ldots \ldots \ldots \ldots \ldots \ldots \ldots \ldots \ldots \ldots$

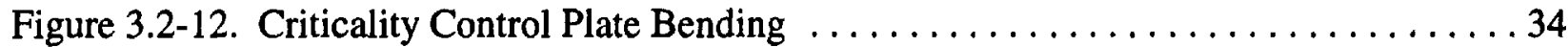

Figure 3.3-1. Finite-Element Model for Rock Fall Analyses

(Zero Degradation Model Shown Just Prior to Rock Impact) $\ldots \ldots \ldots \ldots \ldots \ldots \ldots$

Figure 3.3-2. Emplacement Drift Tunnel Geometry ....................... 40

Figure 3.3-3. Critical Rock Mass vs. Degradation of Containment Barriers $\ldots \ldots \ldots \ldots \ldots 43$

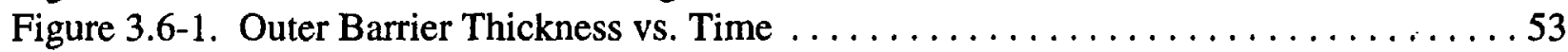




\section{List of Tables}

Table 2.2-1. Application of 1992 ASME Boiler and Pressure Vessel Code ............ 5

Table 3.1-1. Waste Package Components .............................9

Table 3.2-1. Evaluations Performed Taking Structural Credit For Basket $\ldots \ldots \ldots \ldots \ldots \ldots 15$

Table 3.2-2. Results of Evaluations Taking Structural Credit For Basket $\ldots \ldots \ldots \ldots \ldots \ldots 16$

Table 3.2-3. Calculated Failure Points . ............................. 19

Table 3.2-4. Barrier Evaluations with No Structural Credit From Basket $\ldots \ldots \ldots \ldots \ldots \ldots 22$

Table 3.2-5. Results of Barrier Evaluations with No Structural Support from Basket . . . . . 22

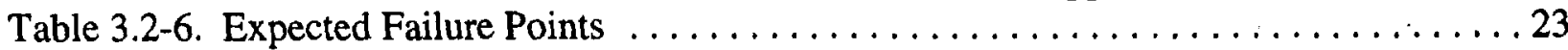

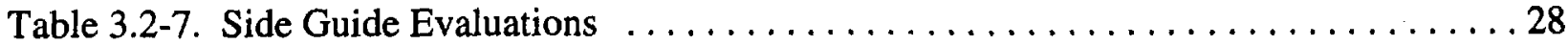

Table 3.2-8. Stress Results of Side Guide Evaluations . . . . . . . . . . . . . . . . . . 29

Table 3.2-9. Side Guide Expected Failure Points . . . . . . . . . . . . . . . . . 30

Table 3.2-10. Results of Buckling Evaluation of Criticality Control Plates .............. 34

Table 3.2-11. Results of Bending Evaluation of Criticality Control Plates $\ldots \ldots \ldots \ldots \ldots . .36$

Table 3.3-1. Emplacement Drift Rock Fall Parameters $\ldots \ldots \ldots \ldots \ldots \ldots \ldots \ldots \ldots . \ldots 40$

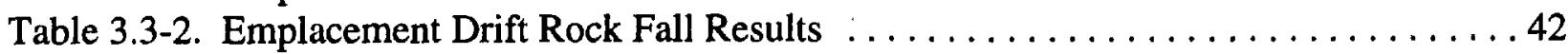

Table 3.4-1. Design Stresses (Room Temperature) $\ldots \ldots \ldots \ldots \ldots \ldots \ldots \ldots \ldots \ldots . \ldots \ldots$

Table 3.4-2. Calculated Allowable Stress Limits (Room Temperature) . . . . . . . . . . . . 46

Table 3.4-3. Backfill Masses Based on Level of Degradation . . . . . . . . . . . . . . . . 47

Table 3.4-4. Stress Peaks and Allowables for Fatigue Analysis . . . . . . . . . . . . . . 48

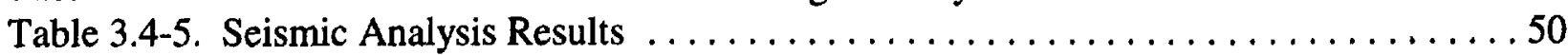

Table 3.6-1. Inner Barrier Thickness with Respect to Time $\ldots \ldots \ldots \ldots \ldots \ldots \ldots \ldots \ldots 5$

Table 3.6-2. Critical Rock Mass With Respect to Time ..................... 56

Table 3.6-3. Side guide thickness as a function of WP breach time and time since WP

breach for the TSPA-95 83 MTU/acre, low infiltration, no-backfill case .........5 57

Table 3.6-4. Side guide thickness as a function of WP breach time and time since WP

breach for the TSPA-95 $83 \mathrm{MTU} / \mathrm{acre}$, low infiltration, backfill case . . . . . . . . . 58

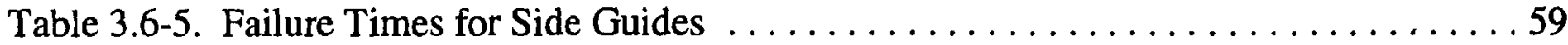

Table 3.6-6. Criticality Control Plate Times to Failure $\ldots \ldots \ldots \ldots \ldots \ldots \ldots \ldots \ldots \ldots 6$

Table 3.7-1. Summary of Results, Barrier Static Analyses ....................6. 62

Table 3.7-2. Summary of Results, Basket Component Static Analyses . . . . . . . . . . . 63

Table 3.7-3. Summary of Results, Rock Fall Analyses ....................... 64 


\section{List of Acronyms and Abbreviations}

$\begin{array}{ll}\text { ASME } & \text { American Society of Mechanical Engineers } \\ \text { ASTM } & \text { American Society for Testing and Materials } \\ \text { AUCF } & \text { Advanced Uncanistered Fuel } \\ \text { CDA } & \text { Controlled Design Assumptions (document) } \\ \text { CFR } & \text { Code of Federal Regulations } \\ \text { CRWMS } & \text { Civilian Radioactive Waste Management System } \\ \text { DI\# } & \text { Document Identifier Number } \\ \text { DOE } & \text { Department of Energy } \\ \text { EBDRD } & \text { Engineered Barrier Design Requirements Document } \\ \text { ESF } & \text { Exploratory Studies Facility } \\ \text { FEA } & \text { Finite Element Analysis } \\ \text { IB } & \text { Inner Barrier } \\ \text { LLNL } & \text { Lawrence Livermore National Laboratory } \\ \text { MGDS } & \text { Mined Geologic Disposal System } \\ \text { MGDS-RD } & \text { Mined Geologic Disposal System-Requirements Document } \\ \text { M\&O } & \text { Management and Operating Contractor } \\ \text { NLP } & \text { Nevada Line Procedure } \\ \text { OB } & \text { Outer Barrier } \\ \text { PGA } & \text { Peak Ground Acceleration } \\ \text { PWR } & \text { Pressurized Water Reactor } \\ \text { QA } & \text { Quality Assurance } \\ \text { QAP } & \text { Quality Administrative Procedure } \\ \text { QARD } & \text { Quality Assurance Requirements and Description (document) } \\ \text { SNF } & \text { Spent Nuclear Fuel } \\ \text { SS-B } & \text { Stainless Steel-Boron } \\ \text { TBD/V/R } & \text { To-Be-Determined/To-Be-Verified/To-Be-Resolved } \\ \text { TDPP } & \text { Technical Document Preparation Plan } \\ \text { TSPA } & \text { Total System Performance Assessment } \\ \text { WP } & \text { Waste Package } \\ \text { WPDD } & \text { Waste Package Development Department } \\ \text { YMP } & \text { Yucca Mountain Site Characterization Project } \\ & \end{array}$




\section{Introduction}

The Emplaced Waste Package Structural Capability Through Time Report is Waste Package Development fiscal year 1996 Deliverable Item No. ALT6204. The objective of the report is to provide an initial set of structural analyses of the waste package (WP) barriers and basket assembly while including the effects of degradation (i.e., general thinning) through time. These types of analyses are required as described on page 23 of the Waste Package Development Technical Document. $^{[2]}$

This document provides analyses of both normal conditions and off-normal conditions. Analyses have been performed on waste packages with degradation levels ranging from no degradation to degradation levels at which containment will be lost. Additional calculations have been performed to analyze spent nuclear fuel (SNF) assemblies after there has been complete waste package degradation. These degradation levels cover all three phases of the repository: operations, substantially complete containment, and isolation. The outputs of the analyses performed are reported in terms of the amount of degradation in the waste package materials. This report will review degradation rates with time; additional studies are underway that will better quantify the behavior of the engineered barrier segment through time.

The design input and data used for this document are unqualified except for the data obtained from the American Society of Mechanical Engineers (ASME) Boiler and Pressure Vessel Code and American Society for Testing and Materials (ASTM) Standard Specifications.

The current preliminary waste package design ${ }^{[17]}$, which is unconfirmed, uses a basket consisting of carbon steel tubes fitted into an array of interlocking stainless steel-boron plates, then surrounded by barriers of Alloy 625 and A 516, see Figure 3.1-1. The results of this report provide a base for time dependent structural analyses and serve as inputs in determining the expected time of failure of the waste package barriers and basket assembly. Determination of the expected time of failure of the barriers provides a basis for determining the probability of SNF release for performance assessment. The results of the basket failure analyses may assist in determining the potential for internal criticality during collapse of the waste package basket assembly. Analysis of the failure modes of the basket assembly predict how failure of the basket assembly occurs and what the configuration of waste package internals will be following collapse of the basket assembly.

The scope of this document covers static loading on the WP (with and without emplacement drift backfill), rock impact loading, and seismic loading. Also within the scope of this document is analysis of the SNF assemblies under loading following degradation of the waste package components. For static and seismic loading, the focus is on determining the level of component thinning at which failure of the barriers and basket will occur. For rock impact loading, the focus is on determining the rock size and mass which will cause failure at various levels of component thinning. For SNF assembly analyses, the focus is on determining if the fuel rod cladding can withstand loadings without breaching. 


\section{Requirements and Standards}

\subsection{Quality Assurance}

The Quality Assurance (QA) program applies to the development of this technical document. The activities described can impact the proper functioning of the MGDS waste package; the waste package has been identified as an MGDS Q-List item important to safety and waste isolation. ${ }^{[3]}$ The waste package is on the Q-List by direct inclusion by the DOE; a Quality Administrative Procedure (QAP)-2-3 evaluation has yet to be conducted. There are no applicable determination of importance evaluations in accordance with Nevada Line Procedure, NLP-2-0. The preparation, review, and content of this technical document are covered by three Waste Package Development QAP-2-0 work control Activity Evaluations: 1. Develop Technical Documents ${ }^{[4]} ; 2$. Formal Review of Technical Documents $^{[3]}$; and 3. Perform Criticality, Thermal, Structural, and Shielding Analyses. ${ }^{[6]}$ The Activity Evaluations determine the activities to be subject to Quality Assurance Requirements and Description $^{[7]}$ (QARD) controls. The Activity Evaluations Develop Technical Documents ${ }^{[4]}$ and Formal Review of Technical Documents ${ }^{[5]}$ determined that Management and Operating Contractor (M\&O) QAP-3-5 would be followed in the development, review, and approval, and any subsequent revision of the document. Accordingly, a Technical Document Preparation Plan (TDPP) for this document ${ }^{[8]}$ was developed, issued, and utilized to guide its preparation. Other applicable procedural controls not specifically discussed in the TDPP are listed in the above mentioned QAP-2-0 evaluations.

The Activity Evaluation Perform Criticality, Thermal, Structural, and Shielding Analyses ${ }^{[6]}$ determined that M\&O QAP-3-9 would be followed for the performance of all calculations performed

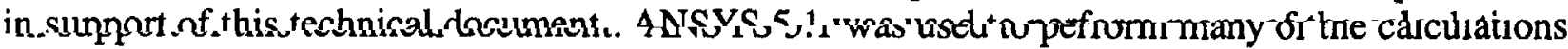
in support of this technical document. Use of this computer software in these calculations is controlled in accordance with QAP-3-9 and the QAP-SI-series procedures.

This document will be controlled in accordance with M\&O QAP-6-1, and QA records generated will be handled in accordance with M\&O QAP-17-1. Data and assumptions which are identified in this document are for preliminary design and shall be treated as unqualified; these data and assumptions will require subsequent qualification (or superseding data and assumptions) as the waste package design proceeds. This document will not directly support any construction, fabrication, or procurement activity and therefore is not required to be procedurally controlled as TBV (to be verified). In addition, the data and assumptions associated with this analysis are not required to be procedurally controlled as TBV. However, use of any data from this analysis for input into documents supporting procurement, fabrication, or construction is required to be controlled as TBV in accordance with the appropriate procedures.

\subsection{Design Requirements}

\subsubsection{Waste Package Development Technical Document ${ }^{[2]}$}

Section 4.2.4.3 of the Waste Package Development Technical Document contains a listing of design analyses required for waste package design. The analyses reported in this document were performed to fulfill the requirement that evaluations be performed to evaluate the long term effects due to 
thinning of the barriers from degradation and from long term external loading. External loadings include seismic loads and loads from rock fall onto the waste package prior to backfilling of the drifts.

\subsubsection{Engineered Barrier Design Requirements Document (EBDRD) ${ }^{[9]}$}

The EBDRD contains several requirements which relate to static, rock fall, and seismic analyses considered in this document. The following requirements are applicable; however, it is not the intent of these analyses to show direct compliance with the following requirements. The analyses reported in this report investigate the effects of degradation on waste package performance.

"The Engineered Barrier Segment shall maintain performance under rock-induced loading (TBD)."

[EBDRD 3.7.F]

Requirement 3.7.F is addressed by performing analyses of rock falls onto the waste package, see Section 3.3.

"Packages for SNF and HLW shall be designed so that the in situ chemical, physical, and nuclear properties of the waste package and its interactions with the emplacement environment do not compromise the function of the waste packages or the performance of the underground facility or the geologic setting."

[EBDRD 3.7.1.A]

With regard to Requirement 3.7.1.A, the analyses performed in support of this report examine the physical properties of the WP and its ability to function properly in the emplacement environment as it degrades, see Sections 3.2, 3.3, and 3.4.

"The design of waste packages shall include, but not be limited to, consideration of the following factors: solubility, oxidation/reduction reactions, corrosion, hydriding, gas generation, thermal effects, mechanical strength, mechanical stress, radiolysis, radiation damage, radionuclide retardation, leaching, fire and explosion hazards, thermal loads, and synergistic interactions."

[EBDRD 3.7.1.B]

Requirement 3.7.1.B items addressed in this report are considerations of corrosion, mechanical strength, and mechanical stress. The purpose of this document is to report the results of structural analyses while taking into account the effects of corrosion.

"The waste package shall contribute to limiting the dispersal of radioactive waste materials in the event of accidents or other dynamic effects."

[EBDRD 3.7.1.H]

Requirements 3.7.1.H is addressed in Sections 3.3 and 3.4 of this report where the structural performance during rock fall and seismic loadings are analyzed. 
"Containment of radioactive material within the waste packages shall be substantially complete (TBD) for a period of years (TBD) after permanent closure of the geologic repository."

[EBDRD 3.7.1.I]

Requirement 3.7.1.I is addressed in Sections 3.2, 3.3, and 3.4 of this report. All analyses were performed to help determine the duration of waste containment.

"Seismic loads (TBD) shall not decrease the postclosure performance of the waste form."

[EBDRD 3.7.1.1.G]

Requirement 3.7.1.1.G is addressed in Section 3.4, Seismic Analyses.

"The container shall contain the radioactive waste materials during all normal handling and emplacement operations and, in the event of accidents or other dynamic effects, contribute to limiting dispersal of the waste. The container shall also have the mechanical integrity to sustain routine handling and transportation loads (TBD)."

[EBDRD 3.7.1.2.A]

The requirement 3.7.1.2.A items which are addressed are that the waste package shall contribute to limiting dispersal of waste in the event of accidents or dynamic effects. These requirements are addressed in Sections 3.3 and 3.4.

"The container shall contribute to the waste package such that containment of the enclosed radionuclides is substantially complete (TBD) during the containment period of not less than 300 to 1,000 years (TBR) after permanent closure of the geologic repository."

[EBDRD 3.7.1.2.B]

"The container shall contribute (TBD) to controlling the release of radionuclides during the period of isolation."

[EBDRD 3.7.1.2.C]

Requirements 3.7.1.2.B and 3.7.1.2.C are addressed in Sections 3.2, 3.3, and 3.4 of this report. All analyses were performed to help determine the duration of waste containment.

"The container shall be designed so that neither its in situ chemical, physical and nuclear properties, nor its interactions with the waste form and the emplacement environment, compromise the function of the waste package or the performance of the natural barriers or engineered barriers."

[EBDRD 3.7.1.2.G]

With regard to Requirement 3.7.1.2.G, the analyses performed in support of this report examine the physical properties of the WP and its ability to function properly in the emplacement environment as it degrades, see Sections 3.2, 3.3, and 3.4. 
"The internal structure of the waste package shall be configured to accommodate the spent fuel waste form, provide mechanical stability of the waste form, and facilitate loading of the waste form into the waste package."

[EBDRD 3.7.1.3.B]

The requirement 3.7.1.3.B item addressed is that the internal structure of the waste package shall be configured to provide mechanical stability of the waste form. This requirement is addressed in Section 3.2.2, Basket Analyses, and in Section 3.4, Seismic Analyses.

\subsubsection{ASME Boiler and Pressure Vessel Code ${ }^{[10,11,12,18]}$}

There are no codes or standards which directly apply to the design of disposal containers. However, the ASME Boiler and Pressure Vessel Code has been chosen as a guide for setting stress limits for the waste package components. Applications of Subsections of Section III of the 1992 ASME Boiler and Pressure Vessel Code have been categorized in Table 2.2-1.

Table 2.2-1. Application of 1992 ASME Boiler and Pressure Vessel Code

\begin{tabular}{||c|c|c|c||}
\hline Analysis Type & Component & $\begin{array}{c}\text { Section III, } \\
\text { Subsection Applied }\end{array}$ & Service Limits* \\
\hline \multirow{2}{*}{ Static } & Barriers & Subsection $\mathrm{NB}^{[10]}$ & Level A \\
\cline { 2 - 4 } & Basket & Subsection $\mathrm{NG}^{[1]}$ & Level A \\
\hline \multirow{3}{*}{ Seismic } & Barriers & $\begin{array}{c}\text { Subsection } \mathrm{NB}^{[10]} \\
\text { Appendix F }\end{array}$ & Level D \\
\cline { 2 - 4 } & Basket & $\begin{array}{c}\text { Subsection } \mathrm{NG}^{[1]]} \\
\text { Appendix } \mathrm{F}^{[12]}\end{array}$ & Level D \\
\hline \multirow{2}{*}{ Rock Fall } & Barriers & $\begin{array}{c}\text { Subsection } \mathrm{NB}^{[10]} \\
\text { Appendix } \mathrm{F}^{[12]}\end{array}$ & Level D \\
\hline
\end{tabular}

*Level A Service Limits are for normal operation, Level D Service Limits are for off-normal conditions.

Section II of the 1992 ASME Boiler and Pressure Vessel Code, Reference 18, was used as a source of material properties. It contains material design stresses, $S_{m}$, which were used with the other sections listed in Table 2.2-1 to determine allowable stress limits.

\subsection{Design Assumptions}

In the course of developing this document, several assumptions were made regarding the static loading on the barriers, static loading on the basket components, rock fall accidents, seismic acceleration of the waste package, and static loading on SNF assemblies. These assumptions along with the assumptions contained in the Controlled Design Assumptions (CDA) Document ${ }^{[13]}$ (TBV- 
221-DD) are identified below. Documents which use data from this document as input must carry this TBV forward if they are developed in support of construction, fabrication, or procurement.

2.3-1 Degradation is modeled as uniform general material thinning. The Waste Package Development Technical Document discusses evaluations of "... long term effects relating to thinning of the barrier(s) due to corrosion ....". ${ }^{[2]}$ For some materials, pitting may be a more probable mode of degradation, however, general thinning results in weakening of the component which is the reason for modeling degradation.

2.3-2 The seismic design values for peak ground acceleration (PGA) are given in Table 2 on page 13 of the document Seismic Design Inputs for the Exploratory Studies Facility at Yucca Mountain. ${ }^{[1]}$ The ground motion reduction factors as a function of depth for Exploratory Studies Facility (ESF) Design are also provided in Table 3 on page 17 of the same document. Instead of using the reduction factors for changing depth, the subsurface peak ground acceleration is conservatively assumed to be $0.66 \mathrm{~g}$. The frequency range of seismic input is also selected from a recommended design spectrum from $0.1 \mathrm{~Hz}$ to $100 \mathrm{~Hz}$ in Figure C-18 on page C-26. ${ }^{[1]}$ It should be noted that the PGA value of $0.66 \mathrm{~g}$ is higher than the $0.4 \mathrm{~g}$ PGA currently specified as the design basis earthquake for the WP in CDA Assumption EBDRD 3.7.1.1.G, which was based on an earlier recommendation for ESF design. ${ }^{[13]}$

The relevant assumptions from the $\mathrm{CDA}^{[13]}$ are as follows:

Assumption Identifier: Key 011 Subject: Horizontal In-Drift Emplacement

Waste packages will be emplaced in-drift in a horizontal mode.

Assumption Identifier: $\underline{\text { Key } 046}$ Subject: $\underline{\text { Backfill in Emplacement Drifts }}$

Current design assumes no backfill in emplacement drifts. Options for backfill will be considered based on ongoing and future backfill studies.

Assumption Identifier: EBDRD 3.7.F Subject: Rock-Induced Waste Package Loading

The waste package must be able to withstand a uniform external pressure of $0.50 \mathrm{MPa}$ and a dynamic load of $50 \mathrm{kN}$ and still maintain structural integrity.

Assumption Identifier: EBDRD 3.7.1.I Subject: Waste Package Substantially Complete Containment

Containment of radioactive material within the Waste Packages shall be substantially complete for at least a thousand years after permanent closure of the geological repository (i.e., fewer than $1 \%$ of the waste packages shall be breached within the first 1000 years after permanent closure of the geologic repository). 
Assumption Identifier: EBDRD 3.7.1.1.G Subject:

Post Closure Seismic Loads on Waste Package

Waste package seismic design for postclosure (through the substantially complete containment phase) performance shall be compatible with Design Basis Earthquake for surface and subsurface repository. Potential Repository peak accelerations for design are currently estimated at $0.75 \mathrm{~g}$ for surface and $0.4 \mathrm{~g}$ for subsurface.

Assumption Identifier: EBDRD 3.7.1.2.B Subject: $\quad$ Container Substantially Complete Containment

B. The container shall contribute to the waste package such that containment of the enclosed radionuclides is substantially complete for 1000 years (with less than $1 \%$ of the waste packages failing within 1000 years after permanent closure of the geologic repository) and with a mean waste package lifetime well in excess of 1000 years.

Assumption Identifier: EBDRD 3.7.1.2.C Subject: $\quad$ Controlled Release During Period of Isolation

The container shall contribute to controlling the release rate of radionuclides during the period of isolation.

Assumption Identifier: EBDRD 3.7.2.B Subject: Backfill Permeability

(In case backfill is used)

BACKFILL PERMEABILITY

The requirements for backfill placed in other underground openings in the repository are addressed in the Repository Design Requirements Document.

B. The backfill permeability shall not have an adverse effect on the long-term performance of the WP.

\section{Waste Package Analyses of Structural Capability Through Time}

The purpose of the analyses reported in this document was to analyze the advanced uncanistered fuel (AUCF) waste package for its structural capability through time. To demonstrate how the component thinning results could be used in determining the relative and finite failure times, a short review is included in this report, see Section 3.6. To support time dependent evaluation, the component load capacity is evaluated. The approach taken for performing these analyses was to analyze the WP while representing degradation by material thinning, see Assumption 2.3-1. The temperatures of waste package components at various levels of degradation was not directly imposed for this first evaluation. Only after detailed time dependence is defined can specific temperatures be applied. For this reason, room temperature $\left(20^{\circ} \mathrm{C}\right)$ structural material properties are used in these analyses. The impact of using room temperature material properties is small because while 
allowable stresses would decrease with increasing temperature, stress results would also decrease due to the decrease in the elastic modulus. ${ }^{[14,15,16]}$ Therefore, for this initial set of calculations, use of room temperature properties is adequate.

The term 'degradation products' is used throughout Section 3. This term refers to the oxides formed during degradation. In the formation of oxides, oxygen and hydrogen combine with the metal (iron). The added weight of the oxygen and hydrogen cause the oxides to be heavier than the original materials, thus in some evaluations in Section 3, a mass ratio is applied to account for this increase. However, the mass increase applies only to waste package components. The loading due to the fuel assemblies remains constant for all levels of waste package degradation because the fuel assemblies are expected to degrade at a much slower rate than the waste package components.

\subsection{Waste Package Design Description}

The AUCF WP consists of two containment barriers which hold a basket assembly. The basket assembly is composed of carbon steel tubes in an array of interlocking stainless steel boron plates. Around the outside of the basket assembly, there are carbon steel side guides and corner guides. The carbon steel tubes protect the fuel assemblies from damage in the case of accidents and maintain the configuration of the stainless steel-boron plates which are used for criticality control. The side guides and corner guides hold the basket in place in the inner barrier, providing structural support and a conduction path for temperature control. The inner barrier is made of a corrosion resistant material for long life. The thick outer barrier is made of a corrosion allowance material, initially providing high strength and protection for the inner barrier. The components which make up the AUCF WP are listed in Table 3.1-1 along with their materials and dimensions. Figure 3.1-1 is an exploded view of the 21 pressurized water reactor (PWR) fuel assembly AUCF WP. Sketches of individual components and subassemblies are included in Attachments I-1 through I-14. 
Table 3.1-1. Waste Package Components

\begin{tabular}{|c|c|c|c|}
\hline Component & Material $^{[17]}$ & $\begin{array}{l}\text { Dimensions } \\
\text { (in meters) }\end{array}$ & Source \\
\hline Outer Barrier & A 516 Grade 70 & $\begin{array}{l}\text { Length }=5.335 \\
\text { ID }=1.4619 \\
\text { Thickness }=0.100 \\
\text { Skirt ID }=1.5419 \\
\text { Skirt Length }=0.225 \\
\text { Skirt Thick. }=0.060\end{array}$ & Attachment I-1 \\
\hline Outer Barrier Lid & A 516 Grade 70 & $\begin{array}{l}\text { Dia. }=1.4679 \\
\text { Thickness }=0.110\end{array}$ & Attachment I-2 \\
\hline Inner Barrier & Alloy 625 & $\begin{array}{l}\text { Length }=4.635 \\
\text { ID }=1.4219 \\
\text { Thickness }=0.020\end{array}$ & Attachment I-3 \\
\hline Inner Barrier Lid & Alloy 625 & $\begin{array}{l}\text { Dia. }=1.4279 \\
\text { Thickness }=0.025\end{array}$ & Attachment I-4 \\
\hline $\begin{array}{l}\text { A-Plate } \\
\text { B-Plate }\end{array}$ & 316B6A & $\begin{array}{l}\text { Length }=1.1338 \\
\text { Width }=1.2205 \\
\text { Thickness }=0.007\end{array}$ & $\begin{array}{l}\text { Attachment I-5 } \\
\text { Attachment I-6 }\end{array}$ \\
\hline C-Plate & $316 \mathrm{~B} 6 \mathrm{~A}$ & $\begin{array}{l}\text { Length }=1.1338 \\
\text { Width }=0.7295 \\
\text { Thick. }=0.007\end{array}$ & Attachment I-7 \\
\hline A-Guide & A 516 Grade 70 & $\begin{array}{l}\text { Length }=1.1288 \\
\text { Width }=0.7295 \\
\text { Thick. }=0.010\end{array}$ & Attachment I-8 \\
\hline B-Guide & A 516 Grade 70 & $\begin{array}{l}\text { Length }=1.1288 \\
\text { Width }=0.0809 \\
\text { Thickness }=0.010\end{array}$ & Attachment I-9 \\
\hline Corner Guide & A 516 Grade 70 & $\begin{array}{l}\text { Length }=1.1338 \\
\text { Width }=0.2455 \\
\text { Thickness }=0.010\end{array}$ & Attachment I-10 \\
\hline Stiffener & A 516 Grade 70 & $\begin{array}{l}\text { Length }=0.2294 \\
\text { Width }=0.2294 \\
\text { Thickness }=0.010\end{array}$ & Attachment I-11 \\
\hline Side Cover & A 516 Grade 70 & $\begin{array}{l}\text { Width }=0.7295 \\
\text { Radius }=0.7109 \\
\text { Thickness }=0.010\end{array}$ & Attachment I-12 \\
\hline Tube & A 516 Grade 70 & $\begin{array}{l}\text { Length }=4.575 \\
\text { Side }=0.2385 \\
\text { Thickness }=0.005\end{array}$ & Attachment I-13 \\
\hline
\end{tabular}

ID = inner diameter, $\mathrm{OD}=$ outer diameter 


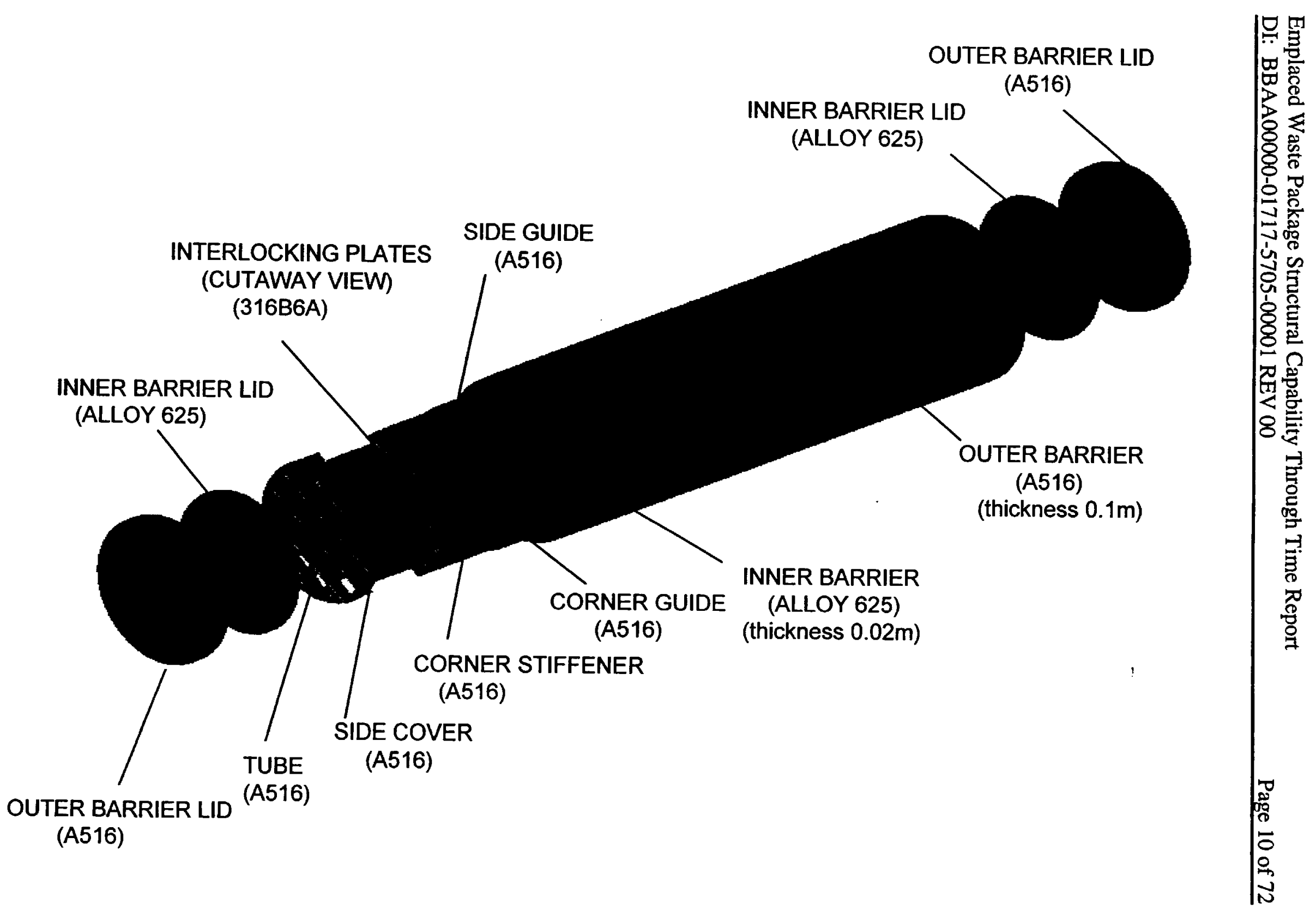

Figure 3.1-1. Exploded View of 21 PWR AUCF WP 


\subsection{Static Analyses}

\subsubsection{Analysis of Containment Barriers}

Two different sets of barrier analyses were performed. In the first set of analyses, the basket assembly was rigidly connected to the inner barrier, providing structural support to the barrier. The first set of analyses are described in Section 3.2.1.1. Current designs do not include connections between the basket and barriers, and manufacturing tolerances may leave gaps between the basket and barriers, thus reducing the amount of structural support provided by the basket to the barriers. Therefore, in the second set of analyses, the barriers were analyzed with the basket omitted, thus providing no structural support to the barriers. The second set of analyses is described in Section 3.2.1.2. In both sets of analyses, the waste package is assumed to be emplaced in a horizontal mode, see Controlled Design Assumptions Key 011. ${ }^{[13]}$

\subsubsection{Barrier Analysis Taking Structural Credit for Basket}

\subsection{Description of Model}

Two models were used to evaluate waste package barriers receiving structural support from the basket assembly. Both were three dimensional solid models. One was a half symmetry model (see Figure 3.2-1) which took advantage of the symmetry of the waste package along its axis. ${ }^{[14]}$ Using the symmetry allowed the computer solutions to solve faster and reduced the sizes of the output files. As the barriers were being thinned to represent degradation (see Assumption 2.3-1), better element resolution was desired, so a quarter symmetry model (see Figure 3.2-2) was developed, ${ }^{[14]}$ allowing greater detail without increasing solution times or output file sizes. The geometries of the models were taken from sketches generated by Waste Package Development, Attachments I-1 through I-14. The WP components included in each model were the outer barrier and lids, inner barrier and lids, side guides, corner guides, criticality control plates, and tubes. Loads on the waste package included the individual component weights, the SNF assembly load, and, when present, the backfill load. The WP emplacement supports were represented by radial displacement constraints. 


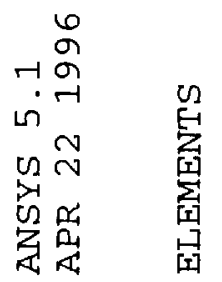

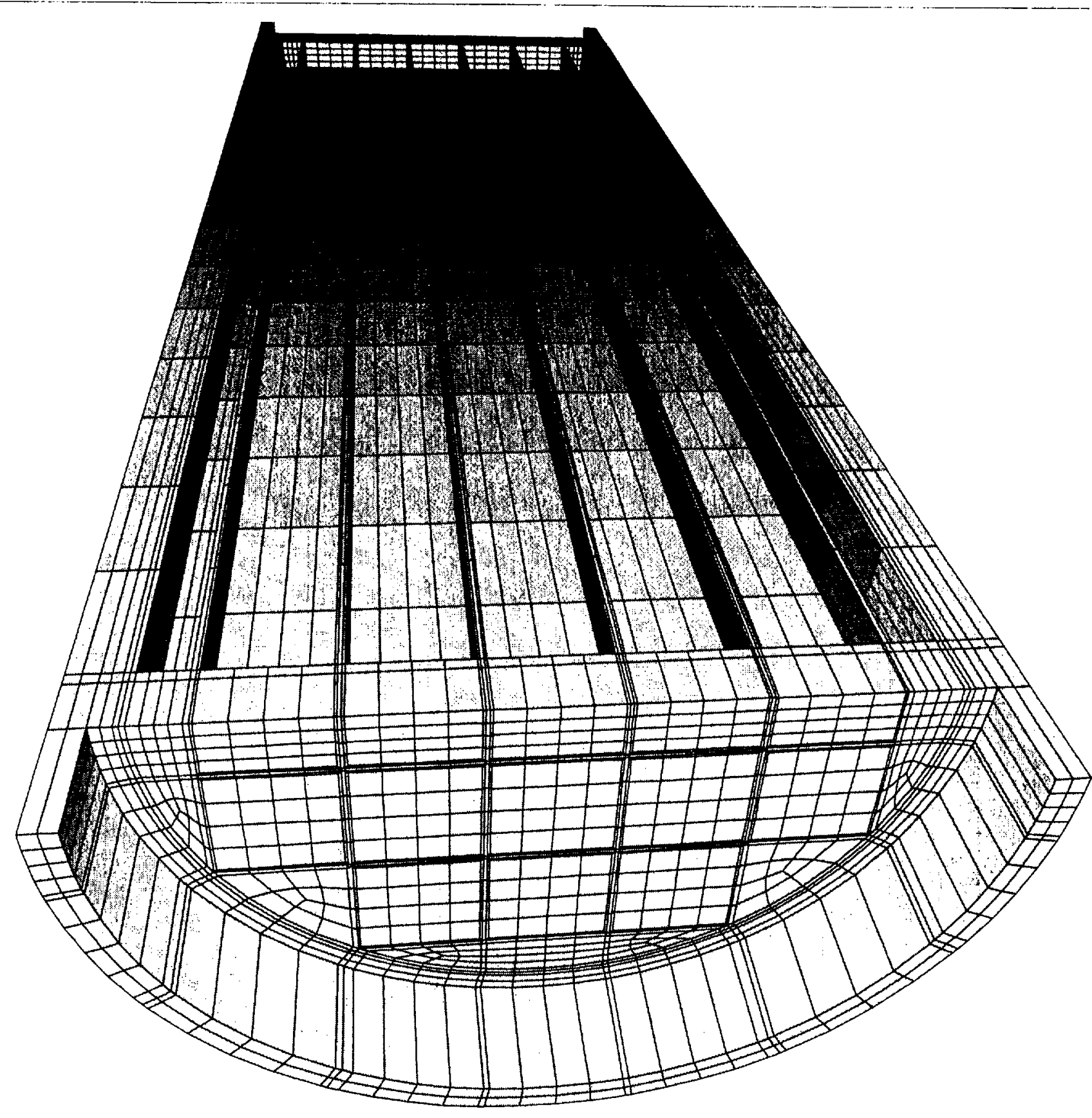




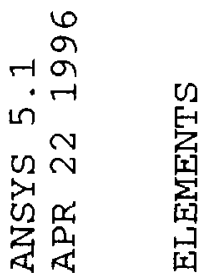

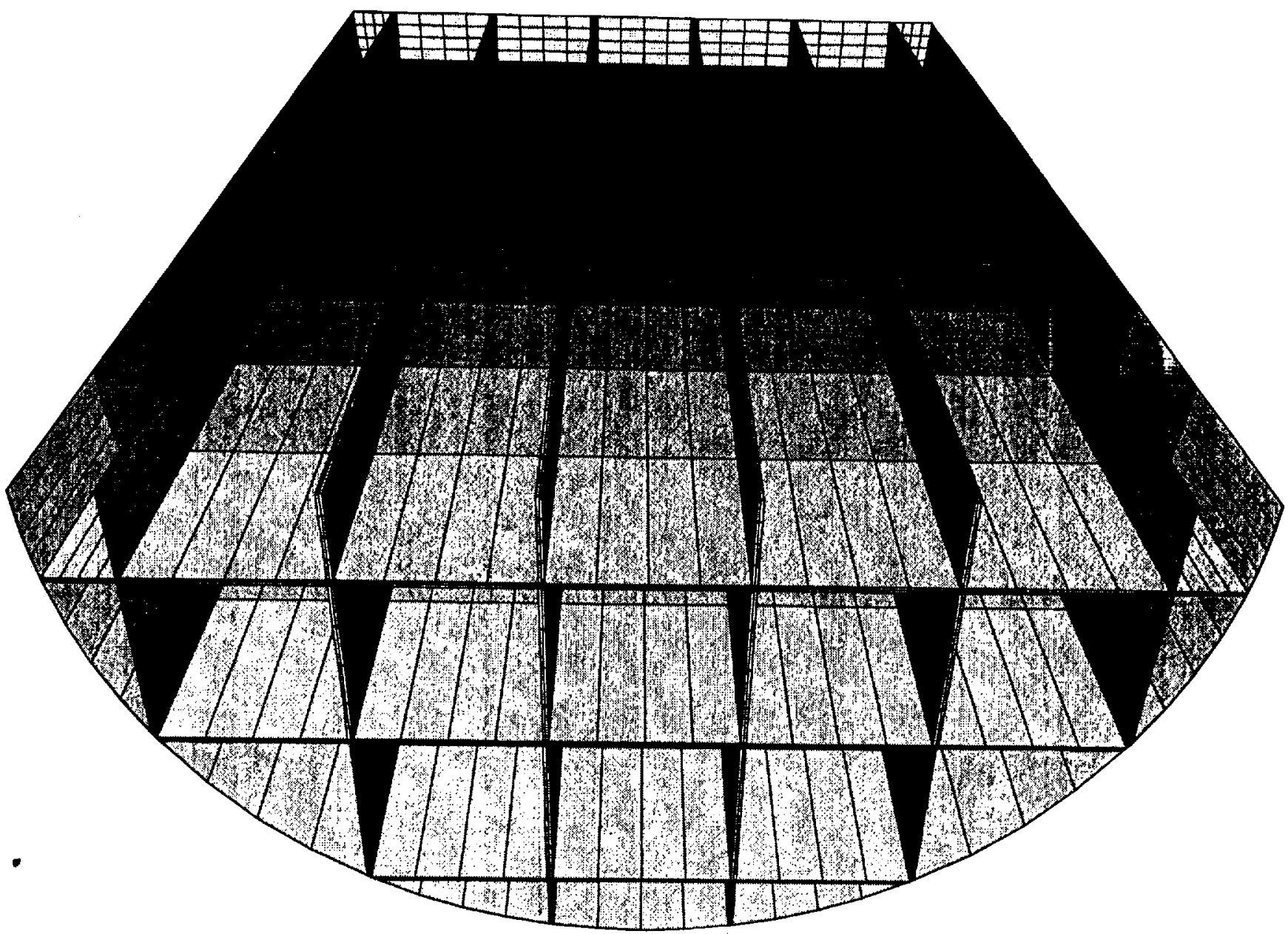




\subsection{Description of Computer Evaluations Performed}

The first computer evaluations performed made use of half symmetry models representing waste packages with little or no degradation. The evaluations performed with the half symmetry models indicated that barrier stresses were low until the entire outer barrier and nearly all of the inner barrier had degraded. Use of the quarter symmetry computer models was then initiated to increase the resolution of the model and the accuracy of the solutions.

The level of inner barrier thinning at which the basket will begin to thin is not yet known. Therefore, evaluations of barrier thinning were performed with and without basket thinning. Four loading conditions were analyzed. ${ }^{[14]}$

LC1. Backfill present.

Mass of degradation products equal to mass of original materials.

LC2. No backfill present.

Mass of degradation products equal to mass of original materials.

LC3. Backfill present.

Degradation product mass/original material mass $=1.61 .^{[14]}$

LC4. No backfill present.

Degradation product mass/original material mass $=1.61{ }^{[14]}$

The evaluations of loading condition 1 were performed first. The barrier failure points of the evaluations of loading condition 1 were then used for the initial evaluations of loading conditions 2 and 3 in order to start closer to the failure point and reduce the number of analyses required. The barrier failure points of the evaluations of loading condition 2 were used for the initial evaluation of loading condition 4. Table 3.2-1 contains a list of the evaluations performed, including the key parameters defining each case.

\subsection{Evaluation Results of Barriers With Structural Support From Basket}

The results of the evaluations are given in Table 3.2-2. In Table 3.2-2, Pm represents primary membrane stress, and $\mathrm{Pm}+\mathrm{Pb}$ represents primary membrane plus primary bending stress. The allowable stresses listed in the table are for the inner barrier material as determined from the appropriate ASME Boiler and Pressure Vessel Code subsection listed in Table 2.2-1.

$$
\text { Pm Allowable }=\mathrm{S}_{\mathrm{m}}{ }^{[10]} \quad \mathrm{Pm}+\mathrm{Pb} \text { Allowable }=1.5 \mathrm{~S}_{\mathrm{m}}{ }^{[10]}
$$

For Alloy 625: $\mathrm{S}_{\mathrm{m}}=36.6 \mathrm{ksi}^{[18]}(252 \mathrm{MPa})$

$\mathrm{Pm}$ Allowable $=252 \mathrm{MPa} \quad \mathrm{Pm}+\mathrm{Pb}$ Allowable $=379 \mathrm{MPa}$

Figures 3.2-3 and 3.2-4 are plots of the inner barrier stress levels versus basket thinning for evaluations performed with remaining inner barrier thicknesses of $2 \mathrm{~mm}$ and $1 \mathrm{~mm}$ respectively. 
Emplaced Waste Package Structural Capability Through Time Report

DI: BBAA00000-01717-5705-00001 REV 00

Page 15 of 72

Table 3.2-1. Evaluations Performed Taking Structural Credit For Basket

\begin{tabular}{|c|c|c|c|c|c|}
\hline Case No. & $\begin{array}{l}\text { Thinning of } \\
\mathrm{OB}(\mathrm{mm})\end{array}$ & $\begin{array}{l}\text { Thinning of } \\
\text { IB (mm) }\end{array}$ & $\begin{array}{l}\text { Thinning of } \\
\text { Basket (mm) }\end{array}$ & $\begin{array}{l}\text { Model } \\
\text { Symmetry }\end{array}$ & $\begin{array}{c}\text { Loading Condition } \\
\text { (Refer to Section 3.2.1.1.2) }\end{array}$ \\
\hline 1 & 0 & 0 & 0 & Half & LC1 \\
\hline 2 & 50 & 0 & 0 & Half & LC1 \\
\hline 3 & 100 & 0 & 0 & Half & LC1 \\
\hline 4 & 100 & 10 & 0 & Half & LC1 \\
\hline 5 & 100 & 15 & 0 & Half & $\mathrm{LCl}$ \\
\hline 6 & 100 & 18 & 0 & Half & LC1 \\
\hline 7 & 100 & 19 & 0 & Half & LC1 \\
\hline 8 & 100 & 19 & 5 & Half & LC1 \\
\hline 9 & 100 & 18 & 0 & Quarter & LC1 \\
\hline 10 & 100 & 18 & 5 & Quarter & $\mathrm{LCl}$ \\
\hline 11 & 100 & 18 & 8 & Quarter & LC1 \\
\hline 12 & 100 & 19 & 0 & Quarter & LC1 \\
\hline 13 & 100 & 19 & 2.5 & Quarter & LC1 \\
\hline 14 & 100 & 19 & 4 & Quarter & LC1 \\
\hline 15 & 100 & 19 & 4.5 & Quarter & LC1 \\
\hline 16 & 100 & 19 & 5 & Quarter & LC1 \\
\hline 17 & 100 & 18 & 8 & Quarter & LC2 \\
\hline 18 & 100 & 18 & 8.5 & Quarter & LC2 \\
\hline 19 & 100 & 19 & 4 & Quarter & LC2 \\
\hline 20 & 100 & 19 & 5 & Quarter & LC2 \\
\hline 21 & 100 & 18 & 5 & Quarter & LC3 \\
\hline 22 & 100 & 18 & 8 & Quarter & LC3 \\
\hline 23 & 100 & 19 & 4.5 & Quarter & LC3 \\
\hline 24 & 100 & 19 & 5 & Quarter & LC3 \\
\hline 25 & 100 & 18 & 5 & Quarter & LC4 \\
\hline 26 & 100 & 18 & 8 & Quarter & LC4 \\
\hline 27 & 100 & 19 & 4 & Quarter & LC4 \\
\hline 28 & 100 & 19 & 4.5 & Quarter & $\mathrm{LC} 4$ \\
\hline
\end{tabular}


Emplaced Waste Package Structural Capability Through Time Report

DI: BBAA00000-01717-5705-00001 REV 00

Page 16 of 72

Table 3.2-2. Results of Evaluations Taking Structural Credit For Basket

\begin{tabular}{|c|c|c|c|c|c|}
\hline Case No. & $\begin{array}{c}\text { Inner Barrier } \\
\text { Pm (MPa) }\end{array}$ & $\begin{array}{c}\text { Inner Barrier } \\
\mathrm{Pm}+\mathrm{Pb}(\mathrm{MPa})\end{array}$ & $\begin{array}{l}\text { Pm Allowable } \\
(\mathrm{MPa})\end{array}$ & $\begin{array}{c}\mathrm{Pm}+\mathrm{Pb} \text { Allowable } \\
(\mathrm{MPa})\end{array}$ & Failure \\
\hline 1 & 3.6 & 4.4 & 252 & 379 & No \\
\hline 2 & 5.0 & 6.5 & 252 & 379 & No \\
\hline 3 & 1.9 & 7.1 & 252 & 379 & No \\
\hline 4 & 5.6 & 8.5 & 252 & 379 & No \\
\hline 5 & 9.1 & 12 & 252 & 379 & No \\
\hline 6 & 19 & 47 & 252 & 379 & No \\
\hline 7 & 59 & 130 & 252 & 379 & No \\
\hline 8 & 119 & 245 & 252 & 379 & No \\
\hline 9 & 29 & 59 & 252 & 379 & No \\
\hline 10 & 87 & 251 & 252 & 379 & No \\
\hline 11 & 139 & 376 & 252 & 379 & Yes* \\
\hline 12 & 97 & 101 & 252 & 379 & No \\
\hline 13 & 82 & 160 & 252 & 379 & No \\
\hline 14 & 102 & 228 & 252 & 379 & No \\
\hline 15 & 95 & 313 & 252 & 379 & No \\
\hline 16 & 155 & 518 & 252 & 379 & Yes \\
\hline 17 & 135 & 363 & 252 & 379 & No \\
\hline 18 & 144 & 385 & 252 & 379 & Yes \\
\hline 19 & 98 & 321 & 252 & 379 & No \\
\hline 20 & 194 & 625 & 252 & 379 & Yes \\
\hline 21 & 96 & 274 & 252 & 379 & No \\
\hline 22 & 162 & 435 & 252 & 379 & Yes \\
\hline 23 & 137 & 319 & 252 & 379 & No \\
\hline 24 & 173 & 556 & 252 & 379 & Yes \\
\hline 25 & 108 & 303 & 252 & 379 & No \\
\hline 26 & 155 & 415 & 252 & 379 & Yes \\
\hline 27 & 106 & 348 & 252 & 379 & No \\
\hline 28 & 147 & 478 & 252 & 379 & Yes \\
\hline
\end{tabular}

*The close proximity of $\mathrm{Pm}+\mathrm{Pb}$ with the allowable indicates that this is the failure point. 


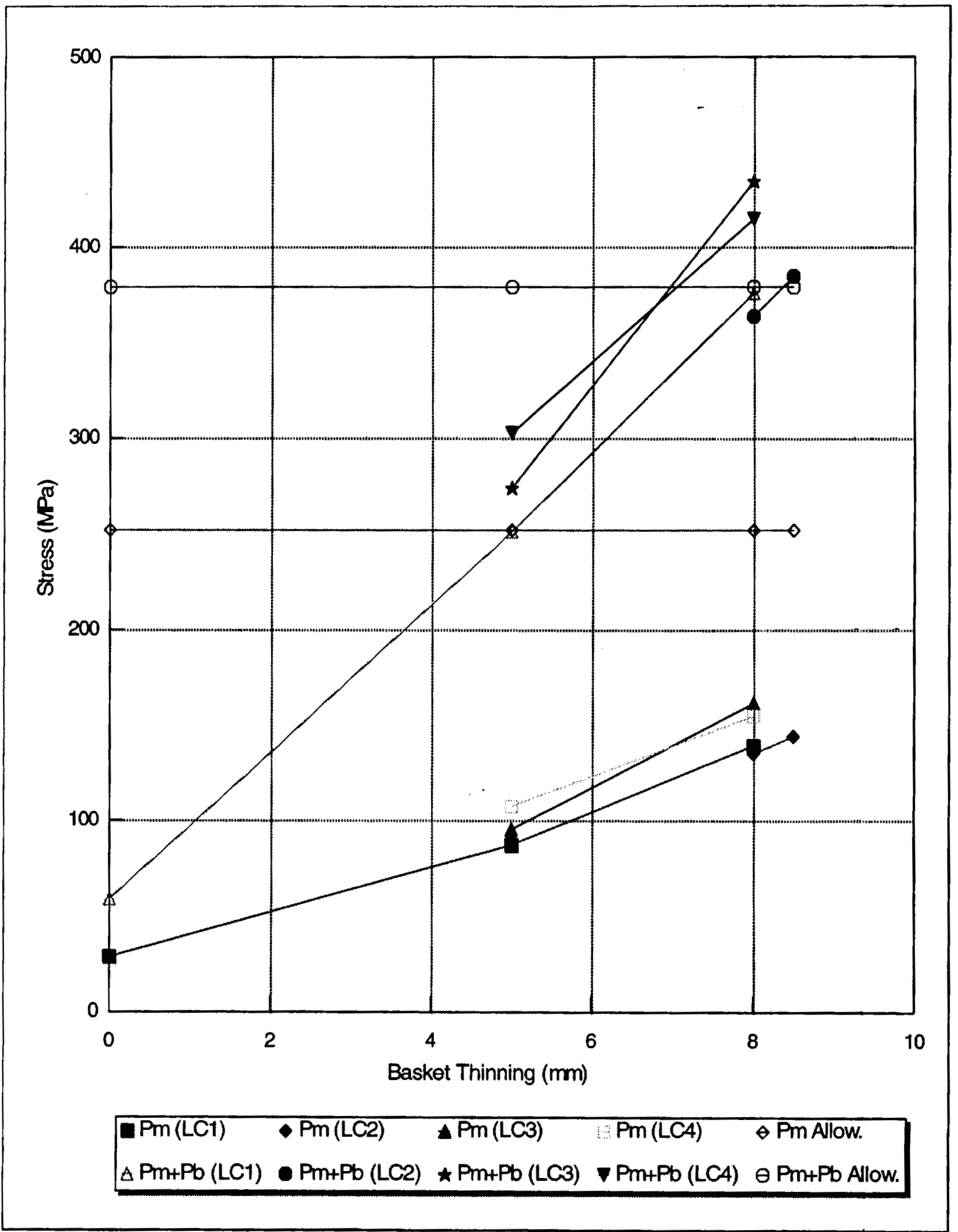

Figure 3.2-3. Inner Barrier Stresses vs. Basket Thinning with $2 \mathrm{~mm}$ Inner Barrier Thickness Remaining, Basket Provides Structural Support 
Emplaced Waste Package Structural Capability Through Time Report

DI: BBAA00000-01717-5705-00001 REV 00

Page 18 of 72

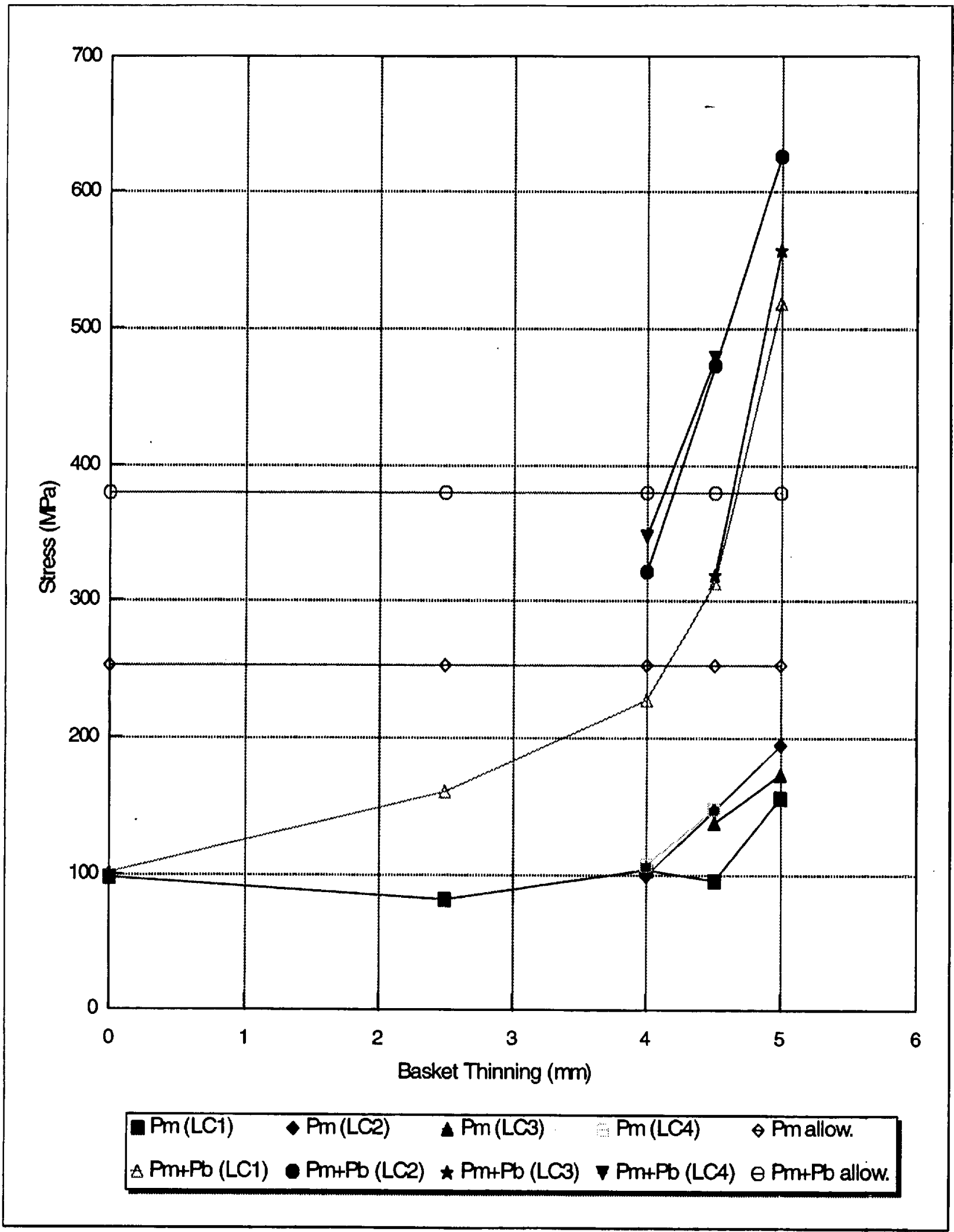

Figure 3.2-4. Inner Barrier Stresses vs. Basket Thinning with $1 \mathrm{~mm}$ Inner Barrier Thickness Remaining, Basket Provides Structural Support 


\subsection{Conclusions}

Each of the four loading conditions analyzed is plotted as a separate curve in Figures 3.2-3 and 3.2-4, each having a different failure point. On these plots, the inner barrier faiture points are defined as the amount of basket thinning at which the stress curve crosses its corresponding allowable stress limit; i.e., $\mathrm{Pm}$ curve crosses $\mathrm{Pm}$ allowable or $\mathrm{Pm}+\mathrm{Pb}$ curve crosses $\mathrm{Pm}+\mathrm{Pb}$ allowable. These failure points have been determined from Figures 3.2-3 and 3.2-4 and tabulated in Table 3.2-3.

Table 3.2-3. Calculated Failure Points

\begin{tabular}{|c|c|c|c|}
\hline $\begin{array}{l}\text { Presence of } \\
\text { Backfill }\end{array}$ & $\begin{array}{l}\text { Loading Condition } \\
\text { (Refer to Section 3.2.1.1.2) }\end{array}$ & $\begin{array}{c}\text { Inner Barrier } \\
\text { Thinning }\end{array}$ & Basket Component Thinning at Failure \\
\hline \multirow{2}{*}{$\begin{array}{l}\text { Backfill } \\
\text { Present }\end{array}$} & LCl & $18 \mathrm{~mm}$ & $\begin{array}{l}5 \mathrm{~mm} \text { Tube Thinning } \\
8.0 \mathrm{~mm} \text { Guide Thinning* } \\
3.0 \mathrm{~mm} \text { Criticality Control Plate Thinning* }\end{array}$ \\
\hline & LC3 & $18 \mathrm{~mm}$ & $\begin{array}{l}5 \mathrm{~mm} \text { Tube Thinning } \\
7.0 \mathrm{~mm} \text { Guide Thinning* } \\
2.0 \mathrm{~mm} \text { Criticality Control Plate Thinning }\end{array}$ \\
\hline \multirow{2}{*}{$\begin{array}{l}\text { No Backfill } \\
\text { Present }\end{array}$} & LC2 & $18 \mathrm{~mm}$ & $\begin{array}{l}5 \mathrm{~mm} \text { Tube Thinning } \\
8.4 \mathrm{~mm} \text { Guide Thinning* } \\
3.4 \mathrm{~mm} \text { Criticality Control Plate Thinning* }\end{array}$ \\
\hline & LC4 & $18 \mathrm{~mm}$ & $\begin{array}{l}5 \mathrm{~mm} \text { Tube Thinning } \\
7.0 \mathrm{~mm} \text { Guide Thinning } \\
2.0 \mathrm{~mm} \text { Criticality Control Plate Thinning }\end{array}$ \\
\hline \multirow{2}{*}{$\begin{array}{l}\text { Backfill } \\
\text { Present }\end{array}$} & $\mathrm{LC} 1$ & $19 \mathrm{~mm}$ & $\begin{array}{l}\text { 4.7 mm Tube Thinning } \\
4.7 \mathrm{~mm} \text { Guide Thinning } \\
0 \mathrm{~mm} \text { Criticality Control Plate Thinning }\end{array}$ \\
\hline & LC3 & $19 \mathrm{~mm}$ & $\begin{array}{l}\text { 4.6 mm Tube Thinning } \\
\text { 4.6 mm Guide Thinning } \\
0 \mathrm{~mm} \text { Criticality Control Plate Thinning }\end{array}$ \\
\hline \multirow{2}{*}{$\begin{array}{l}\text { No Backfill } \\
\text { Present }\end{array}$} & $\mathrm{LC} 2$ & $19 \mathrm{~mm}$ & $\begin{array}{l}4.2 \mathrm{~mm} \text { Tube Thinning** } \\
4.2 \mathrm{~mm} \text { Guide Thinning } \\
0 \mathrm{~mm} \text { Criticality Control Plate Thinning }\end{array}$ \\
\hline & LC4 & $19 \mathrm{~mm}$ & $\begin{array}{l}4.1 \mathrm{~mm} \text { Tube Thinning** } \\
4.1 \mathrm{~mm} \text { Guide Thinning } \\
0 \mathrm{~mm} \text { Criticality Control Plate Thinning }\end{array}$ \\
\hline
\end{tabular}

*The thinning of this component required for barrier failure exceeds the thinning required for failure of the component itself, see Table 3.2-9 and Table 3.2-11. Therefore, the basket will fail prior to this level of thinning and may no longer provide support for the barrier.

**Note that the failure point for the case of no backfill and $19 \mathrm{~mm}$ of inner barrier thinning comes sooner than the same case with backfill, the opposite of what might have been expected. With no backfill, inward barrier deflections due to the weight of the attached basket assembly cause outward bulging of the barrier between contact points with the basket assembly, thus increasing peak stresses. When backfill is applied, although the global deformation of the barrier is increased, outward bulging is decreased, thus reducing the peak stresses. This phenomenon is observed as occurring for two different loading cases. 


\subsubsection{Barrier Analysis With No Structural Support from Basket}

\subsection{Description of Model}

The models used to perform these analyse ${ }^{[14]}$ were similar to the quarter symmetry models used to perform the barrier analyses in which structural credit was taken for the basket, see Section 3.2.1.1.1. The difference is that the basket components present in the previous analyses have been removed. However, the loads on the barrier due to the weights of the basket assembly and the SNF assemblies were still applied. The outer barrier was not included in these analyses because earlier analyses reported in Section 3.2.1.1 indicated that failure of the inner barrier would not occur until well after the outer barrier had completely degraded. A plot of the model is included in Figure 3.2-5.

\subsection{Description of Evaluations Performed}

Barrier analyses in which no structural credit was taken for the basket components were performed for various levels of inner barrier degradation. Three loading conditions were analyzed. ${ }^{[14]}$

LC1. No backfill present.

Degradation products do not load barriers. ${ }^{[14]}$

LC2. Backfill present.

Mass of degradation products equal to mass of original materials.

LC3. Backfill present.

Degradation products mass/original material mass $=1.61 .^{[14]}$

Because previous evaluations reported in Section 3.2.1.1 indicated that stresses in the inner barrier will be very small prior to complete degradation of the outer barrier, the evaluations performed in this set of analyses were begun with cases of complete degradation of the outer barrier and no degradation of the inner barrier. Successive evaluations attempted to precisely determine the level of inner barrier thinning at which failure would occur.

Table 3.2-4 contains descriptions of the evaluations performed. Results of these evaluations are given in Section 3.2.1.2.3. 


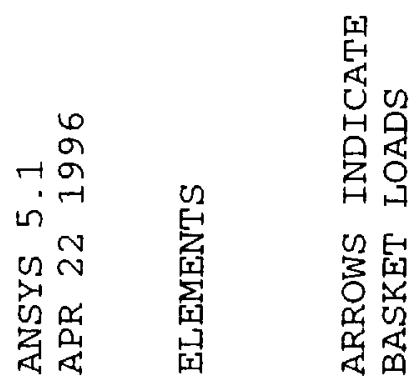

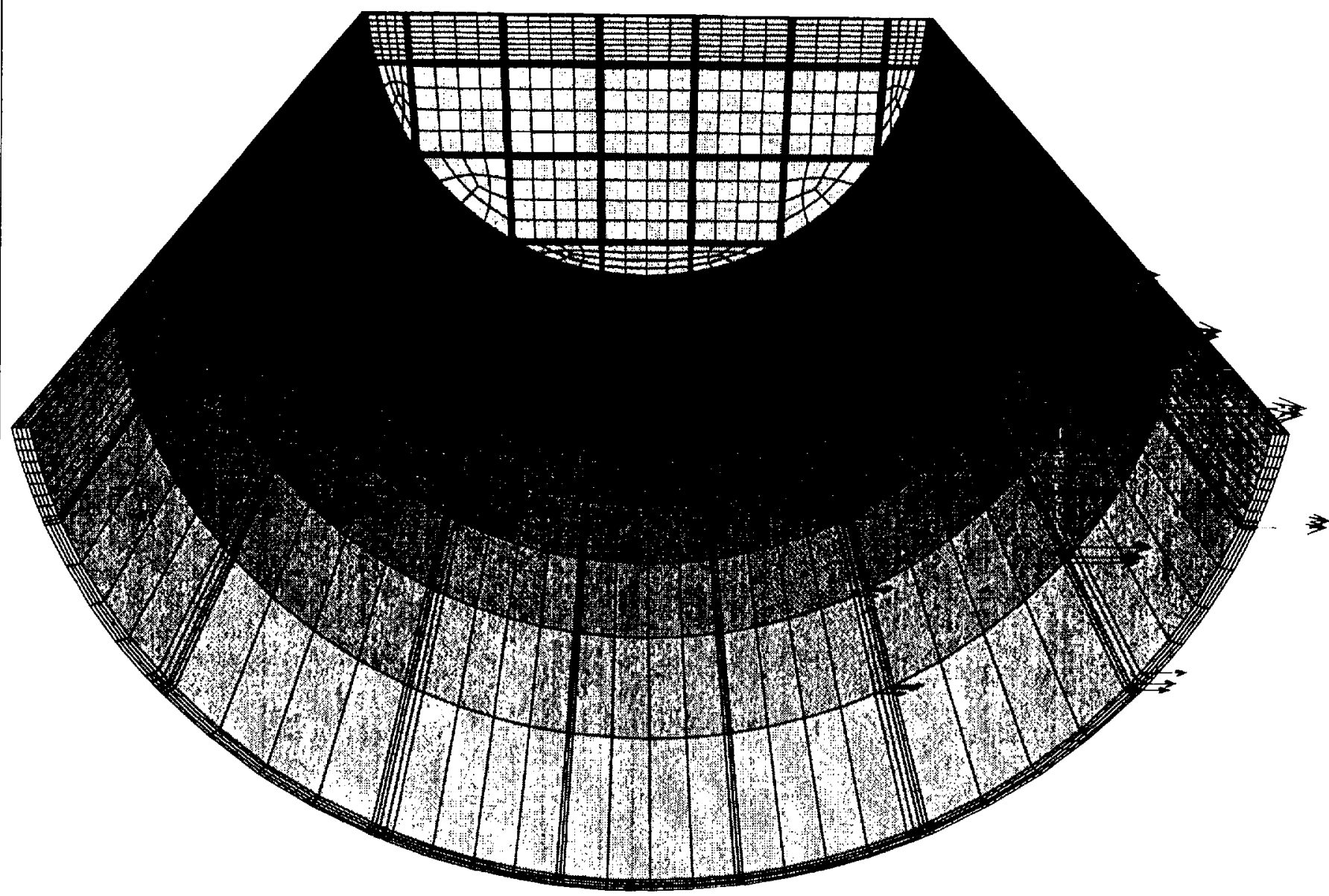


Table 3.2-4. Barrier Evaluations with No Structural Credit From Basket

\begin{tabular}{|c|c|c|c|c|}
\hline Case No. & $\begin{array}{c}\text { Thinning of OB } \\
(\mathrm{mm})\end{array}$ & $\begin{array}{c}\text { Thinning of IB } \\
(\mathrm{mm})\end{array}$ & Backfill & $\begin{array}{c}\text { Loading Condition } \\
(\text { Refer to Section 3.2.1.2.2) }\end{array}$ \\
\hline 1 & 100 & 0 & No & LC1 \\
\hline 2 & 100 & 10 & No & LC1 \\
\hline 3 & 100 & 15 & No & LC1 \\
\hline 4 & 100 & 14 & No & LC1 \\
\hline 5 & 100 & 0 & Yes & LC2 \\
\hline 6 & 100 & 10 & Yes \\
\hline 7 & 100 & 12 & Yes & LC2 \\
\hline 8 & 100 & 11 & Yes & LC2 \\
\hline 9 & 100 & 0 & Yes & LC3 \\
\hline 10 & 100 & 10 & Yes & LC3 \\
\hline 11 & 100 & 11 & Yes & \\
\hline
\end{tabular}

\subsection{Results of Barrier Evaluations with No Structural Support from Basket}

The results of the evaluations listed in Table 3.2-4 are given in Table 3.2-5. The failure criteria are the same as those given in Section 3.2.1.1.3.

Table 3.2-5. Results of Barrier Evaluations with No Structural Support from Basket

\begin{tabular}{||c|c|c|c|c|c||}
\hline Case No. & $\begin{array}{c}\text { Inner Barrier } \\
\mathrm{Pm}(\mathrm{MPa})\end{array}$ & $\begin{array}{c}\text { Inner Barrier } \\
\mathrm{Pm}+\mathrm{Pb}(\mathrm{MPa})\end{array}$ & $\begin{array}{c}\text { Pm Allowable } \\
(\mathrm{MPa})\end{array}$ & $\begin{array}{c}\text { Pm+Pb Allowable } \\
(\mathrm{MPa})\end{array}$ & Barrier Failure \\
\hline 1 & 11 & 58 & 252 & 379 & No \\
\hline 2 & 28 & 178 & 252 & 379 & No \\
\hline 3 & 71 & 538 & 252 & 379 & Yes \\
\hline 4 & 52 & 404 & 252 & 379 & Yes \\
\hline 5 & 19 & 97 & 252 & 379 & No \\
\hline 6 & 55 & 306 & 252 & 379 & No \\
\hline 7 & 81 & 444 & 252 & 379 & Yes \\
\hline 8 & 66 & 365 & 252 & 379 & No \\
\hline 9 & 22 & 108 & 252 & 379 & No \\
\hline 10 & 63 & 345 & 252 & 379 & No \\
\hline 11 & 75 & 412 & 252 & 379 & Yes \\
\hline
\end{tabular}


Figures 3.2-6 is a plot of stress in the inner barrier versus inner barrier thinning with no backfill present. Figures 3.2-7 is a plot of stress in the inner barrier versus inner barrier thinning with backfill present. In Figure 3.2-7, there are separate curves for loading conditions 2 and 3 described in Section 3.2.1.2.2.

\subsection{Conclusions}

Barrier failure points have been determined from Figures 3.2-6 and 3.2-7. On these plots, the inner barrier failure points are defined as the amount of inner barrier thinning at which either stress curve crosses its corresponding allowable stress limit, i.e. $\mathrm{Pm}$ curve crosses $\mathrm{Pm}$ allowable or $\mathrm{Pm}+\mathrm{Pb}$ curve crosses $\mathrm{Pm}+\mathrm{Pb}$ allowable. Table 3.2-6 lists the conditions and expected barrier failure points for the analyses in which the basket did not provide structural support to the barrier.

Table 3.2-6. Expected Failure Points

\begin{tabular}{||l|c|c|c||}
\hline Presence of Backfill & $\begin{array}{c}\text { Loading Condition } \\
\text { (Refer to Section 3.2.1.2.2) }\end{array}$ & $\begin{array}{c}\text { Inner Barrier } \\
\text { Thinning } \\
\text { at Failure Point }\end{array}$ & $\begin{array}{c}\text { Inner Barrier } \\
\text { Thickness } \\
\text { Remaining }\end{array}$ \\
\hline No Backfill Present & LC1 & $13.5 \mathrm{~mm}$ & $6.5 \mathrm{~mm}$ \\
\hline \multirow{2}{*}{ Backfill Present } & LC2 & $11.2 \mathrm{~mm}$ & $8.8 \mathrm{~mm}$ \\
\cline { 2 - 4 } & LC3 & $10.5 \mathrm{~mm}$ & $9.5 \mathrm{~mm}$ \\
\hline
\end{tabular}




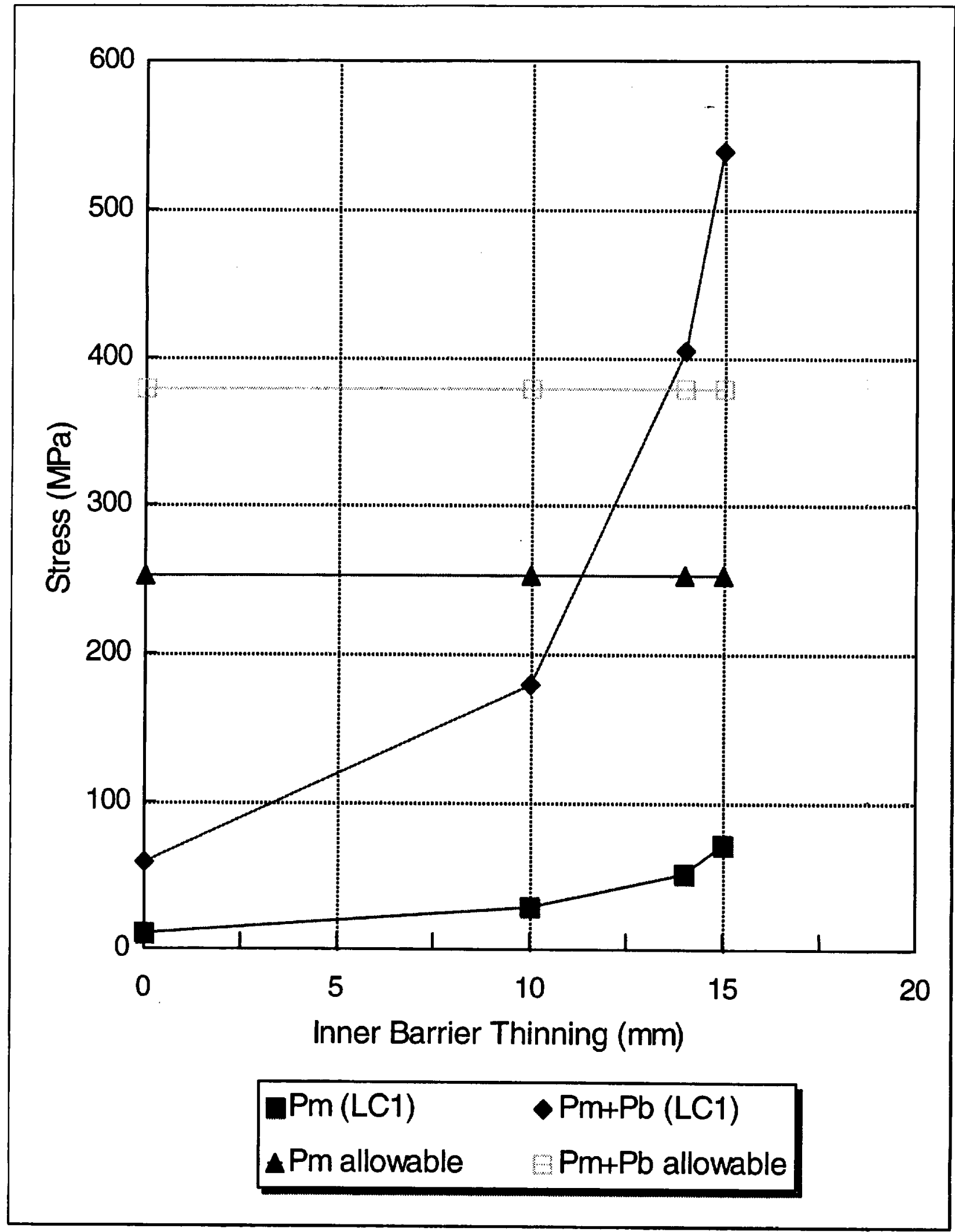

Figure 3.2-6. Inner Barrier Stresses vs. Inner Barrier Thinning, No Structural Support from Basket, No Backfill Present 


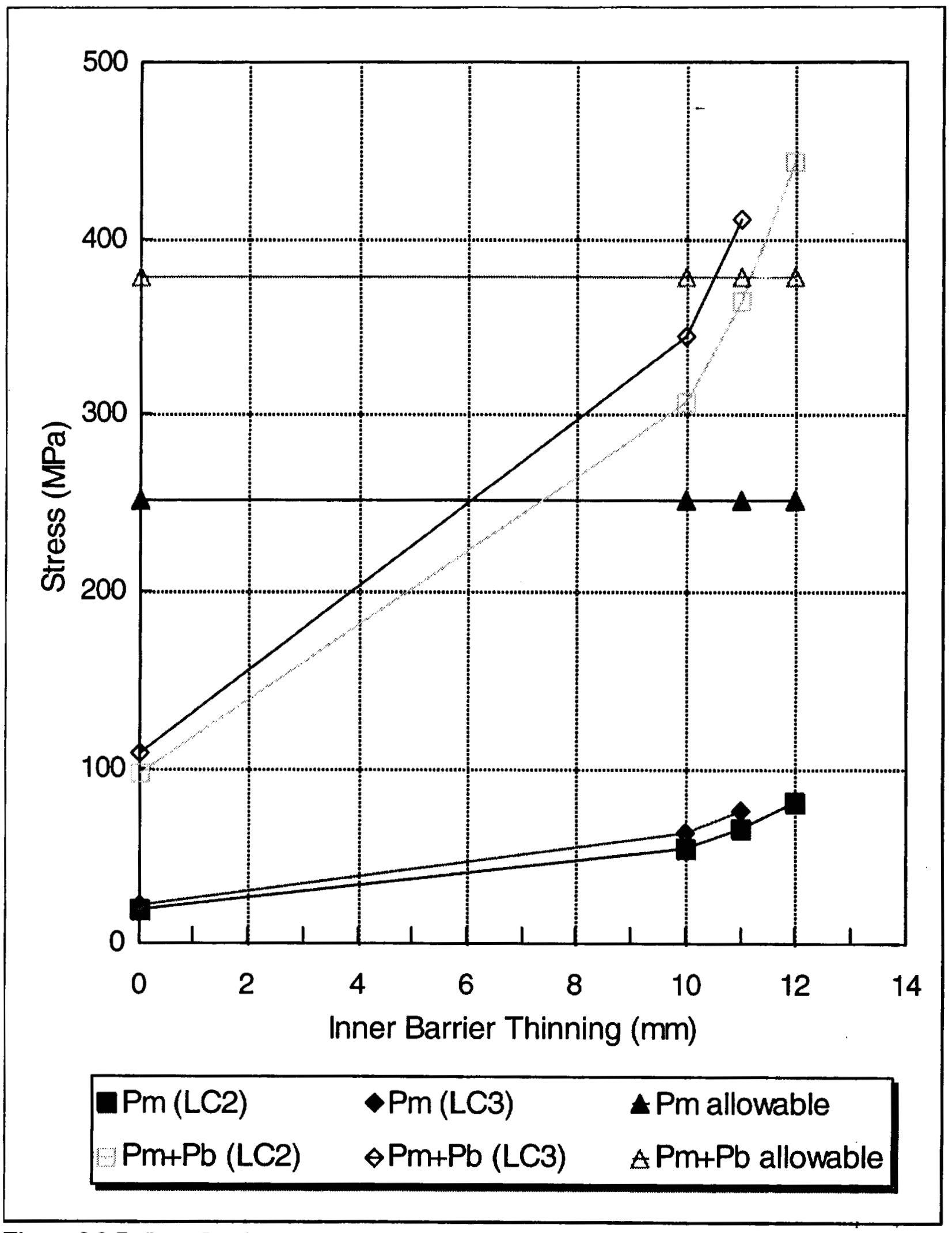

Figure 3.2-7. Inner Barrier Stresses vs. Inner Barrier Thinning, No Structural Support from Basket, Backfill Present 


\subsubsection{Basket Analysis}

\subsubsection{Analysis of Side Guide for Static Analyses}

The side guide is a basket component which is located between the tubes and inner barrier, see Figure 3.1-1. The side guide is a subassembly comprised of the A-Guide and two B-Guides. Sketches of the A-Guide, B-Guide, and side guide weldment can be found in Attachments I-8, I-9, and I-14. The side guides have a dual purpose. For thermal performance, they provide a conduction path from the tubes to the barrier. For structural performance, they maintain the basket configuration. These analyses were performed to determine the level of side guide thinning at which the side guides will no longer be capable of maintaining the basket configuration.

\subsection{Description of Analysis Performed}

The analysis of the side guide was performed using a three-dimensional solid finite-element model. ${ }^{[14]}$ The geometry of the model was defined by dimensions taken from Attachments I-8, I-9, and I-14. The model takes advantage of the symmetry of the part in two planes and is therefore a quarter symmetry model. A plot of the model is provided in Figure 3.2-8. The failure criteria applied were those for Level A service limits, see Table 2.2-1. Level A service limits are to be applied against the results of elastic analyses, therefore, elastic material properties are used. Degradation of the side guide is modeled as general thinning of the component, see Assumption 2.31. The loads of the waste package components above the side guide, which varies with the amount of degradation, are applied to the upper surface of the side guide. ${ }^{[14]}$ The evaluations which were performed are listed in Table 3.2-7. Initial evaluations, cases 1 through 8 in Table 3.2-7, were performed with a load based on the mass of the original materials rather than the mass of the degradation products. Later evaluations, cases 9 and 10, were performed with a load based on the mass of the degradation products. Because all of the analyses were performed using elastic material properties, the stresses vary linearly with the load. Therefore, the stresses can be scaled by the ratio of the loads. The appropriate scaling factors for the cases with backfill and without backfill were calculated in Reference 14. Scaling case 1 yields the same results as case 9 , and scaling case 5 yields the same results as case 10, thus verifying the scaling factors, see Table 3.2-8. 


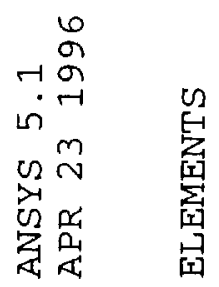


Table 3.2-7. Side Guide Evaluations

\begin{tabular}{|c|c|c|}
\hline Case No. & Side Guide Thinning (mm) & Backfill \\
\hline 1 & 0 & - yes \\
\hline 2 & 5 & yes \\
\hline 3 & 7.5 & yes \\
\hline 4 & 6.5 & yes \\
\hline 5 & 0 & no \\
\hline 6 & 5 & no \\
\hline 7 & 7 & no \\
\hline 8 & 8 & no \\
\hline $9 *$ & 0 & yes \\
\hline $10^{*}$ & 0 & no \\
\hline
\end{tabular}

${ }^{*}$ Case 9 and 10 are the same as Case 1 and 5 respectively with the exception that the loading has been adjusted for the difference in mass between the original materials and the degradation products.

\subsection{Results of Side Guide Evaluations}

The results of the evaluation performed are given in Table 3.2-8 and plotted in Figures 3.2-9 and 3.2-10. Figure 3.2-9 is a plot of side guide stress versus side guide thinning when no backfill is present, and Figure 3.2-10 is a plot of side guide stress versus side guide thinning when backfill is present. The primary membrane stress $(\mathrm{Pm})$ and the primary membrane plus bending stress $(\mathrm{Pm}+\mathrm{Pb})$ are plotted in each figure, along with the corresponding stress limits. Failure of the side guide occurs at the level of side guide thinning at which the stress curve crosses its corresponding limit, i.e. $\mathrm{Pm}$ curve crosses $\mathrm{Pm}$ allowable or $\mathrm{Pm}+\mathrm{Pb}$ curve crosses $\mathrm{Pm}+\mathrm{Pb}$ allowable. The failure points determined from Figures 3.2-9 and 3.2-10 are tabulated in Table 3.2-9. 
Table 3.2-8. Stress Results of Side Guide Evaluations

\begin{tabular}{|c|c|c|c|c|c|c|c|}
\hline Case No. & $\begin{array}{c}\text { Degradation } \\
(\mathrm{mm})\end{array}$ & Backfill & $\begin{array}{c}\mathrm{Pm} \\
(\mathrm{MPa})\end{array}$ & $\begin{array}{c}\mathrm{Pm}+\mathrm{Pb} \\
(\mathrm{MPa})\end{array}$ & $\begin{array}{c}\text { Pm } \\
\text { Allowable } \\
(\mathrm{MPa})\end{array}$ & $\begin{array}{c}\text { Pm+Pb } \\
\text { Allowable } \\
\text { (MPa) }\end{array}$ & Failure \\
\hline 1 & 0 & Yes & 3.2 & 18.9 & 161 & 241 & No \\
\hline 2 & 5 & Yes & 45.6 & 101 & 161 & 241 & No \\
\hline 3 & 7.5 & Yes & 87.7 & 421 & 161 & 241 & Yes \\
\hline 4 & 6.5 & Yes & 66.3 & 215 & 161 & 241 & No \\
\hline 5 & 0 & No & 2.1 & 12.2 & 161 & 241 & No \\
\hline 6 & 5 & No & 29.4 & 65.2 & 161 & 241 & No \\
\hline 7 & 7 & No & 48.9 & 188 & 161 & 241 & No \\
\hline 8 & 8 & No & 66.4 & 417 & 161 & 241 & Yes \\
\hline 9 & 0 & Yes & 3.8 & 22.3 & 161 & 241 & No \\
\hline $1(\text { scaled })^{*}$ & 0 & Yes & 3.8 & 22.3 & 161 & 241 & No \\
\hline 10 & 0 & No & 2.4 & 13.9 & 161 & 241 & No \\
\hline 5 (scaled)* & 0 & No & 2.4 & 13.9 & 161 & 241 & No \\
\hline 2 (scaled)* $^{*}$ & 5 & Yes & 53.9 & 119 & 161 & 241 & No \\
\hline 3 (scaled)* & 7.5 & Yes & 104 & 498 & 161 & 241 & Yes \\
\hline 4 (scaled)* $^{*}$ & 6.5 & Yes & 78.4 & 254 & 161 & 241 & Yes \\
\hline 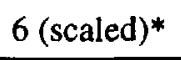 & 5 & No & 33.5 & 74.2 & 161 & 241 & No \\
\hline 7 (scaled $)^{*}$ & 7 & No & 55.6 & 214 & 161 & 241 & No \\
\hline 8 (scaled)* & 8 & No & 75.6 & 475 & 161 & 241 & Yes \\
\hline
\end{tabular}

*The scaling ratios are 1.182 with backfill present and 1.138 with no backfill present. ${ }^{[14]}$

\subsection{Conclusions}

Based on the results of the analyses performed, and using Figures 3.2-9 and 3.2-10, the levels of side guide thinning at which side guide failure will occur have been determined. These results are tabulated in Table 3.2-9. 
Table 3.2-9. Side Guide Expected Failure Points

\begin{tabular}{|c|c|c|c|}
\hline $\begin{array}{l}\text { Loading } \\
\text { Condition }\end{array}$ & $\begin{array}{c}\text { Adjustment for Mass Difference } \\
\text { between Original Materials and } \\
\text { Degradation Products }\end{array}$ & $\begin{array}{l}\text { Side Guide Degradation } \\
\text { Required for Failure }\end{array}$ & $\begin{array}{l}\text { Critical Side } \\
\text { Guide Thickness }\end{array}$ \\
\hline \multirow{2}{*}{$\begin{array}{l}\text { Without } \\
\text { Backfill }\end{array}$} & None & $7.2 \mathrm{~mm}$ & $2.8 \mathrm{~mm}$ \\
\hline & Scaled by 1.138 & $7.1 \mathrm{~mm}$ & $2.9 \mathrm{~mm}$ \\
\hline \multirow{2}{*}{$\begin{array}{l}\text { With } \\
\text { Backfill }\end{array}$} & None & $6.6 \mathrm{~mm}$ & $3.4 \mathrm{~mm}$ \\
\hline & Scaled by 1.182 & $6.2 \mathrm{~mm}$ & $3.8 \mathrm{~mm}$ \\
\hline
\end{tabular}




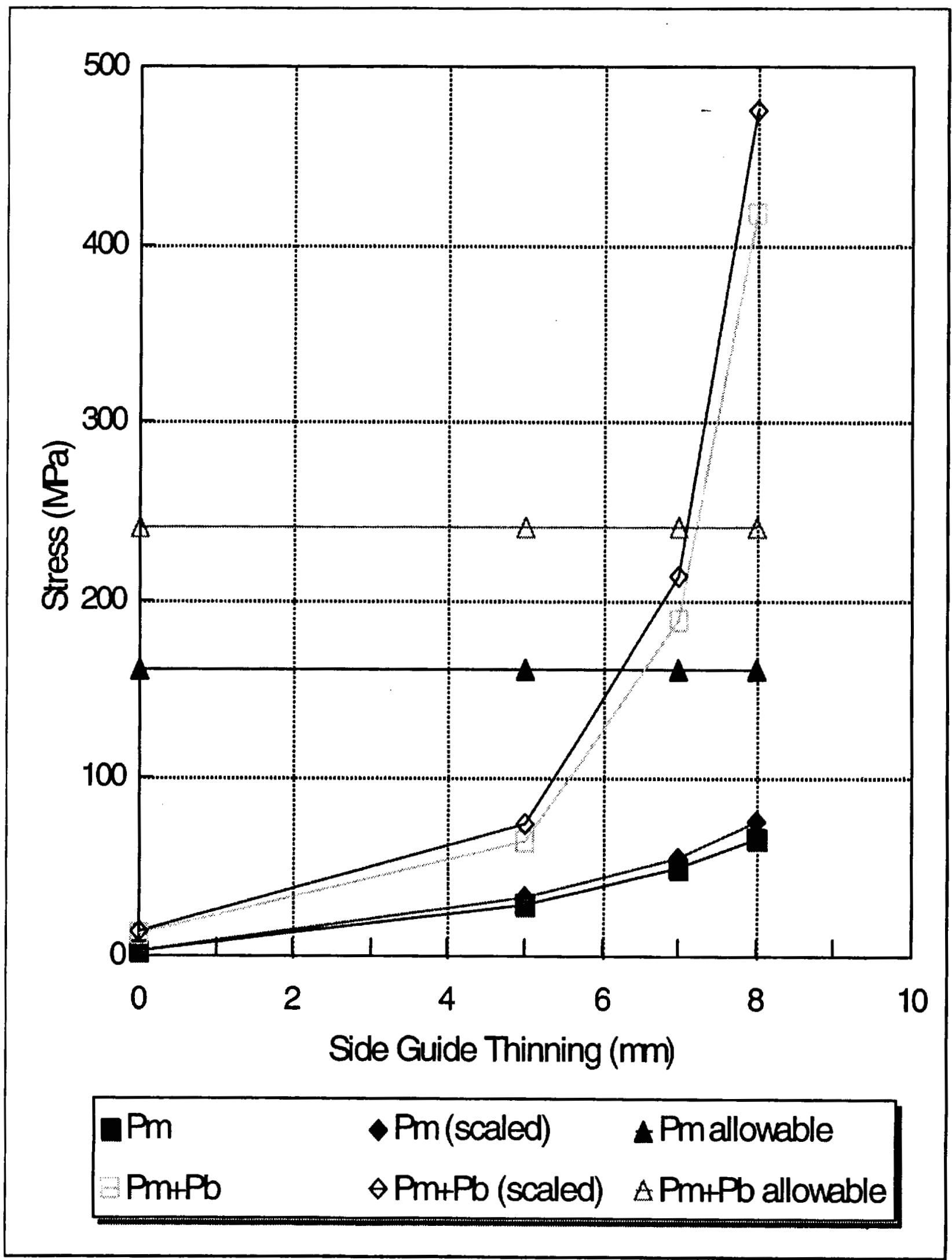

Figure 3.2-9. Side Guide Stresses vs. Side Guide Thinning, No Backfill Present 


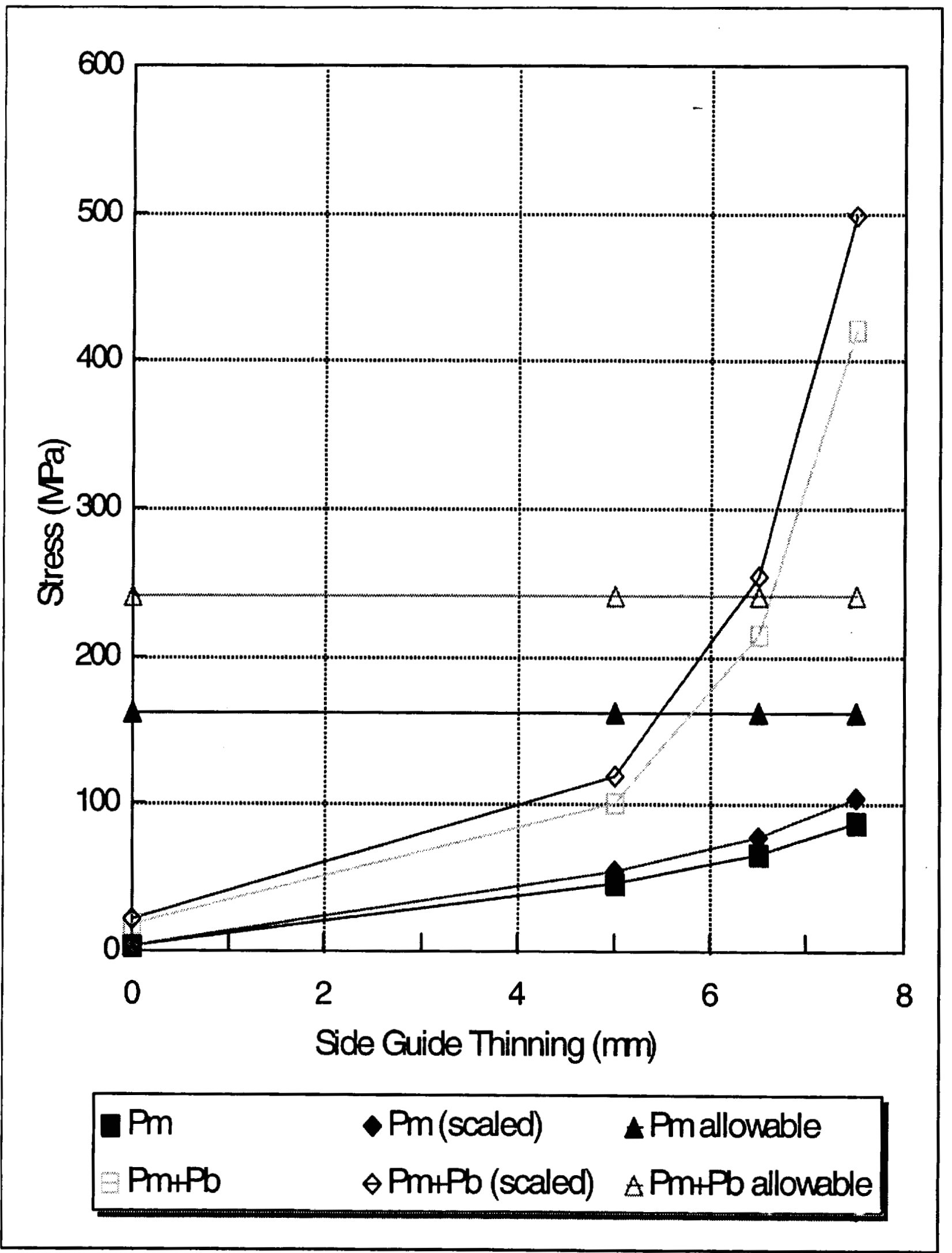

Figure 3.2-10. Side Guide Stresses vs. Side Guide Thinning, Backfill Present 


\subsubsection{Static Analysis of Criticality Control Plates}

\subsection{Buckling Analysis of Vertical Plates}

One possible failure mechanism for vertical criticality control plates is buckling. The buckling analysis of the criticality control plates was conservatively performed for conditions where there has been complete degradation of the carbon steel tubes. ${ }^{114]}$ The equation used for the buckling analysis of the plates is Euler's Formula for pin-ended columns. ${ }^{[19, \text { p. 529] }}$

$$
\mathrm{P}_{\mathrm{cr}}=\pi^{2} \mathrm{EI} / \mathrm{L}^{2}
$$

Equation 3.2-1

where: $P_{c r}=$ critical buckling load

$\mathrm{E}=$ elastic modulus

$\mathrm{I}=$ moment of inertia about bending axis

$\mathbf{L}=$ column height

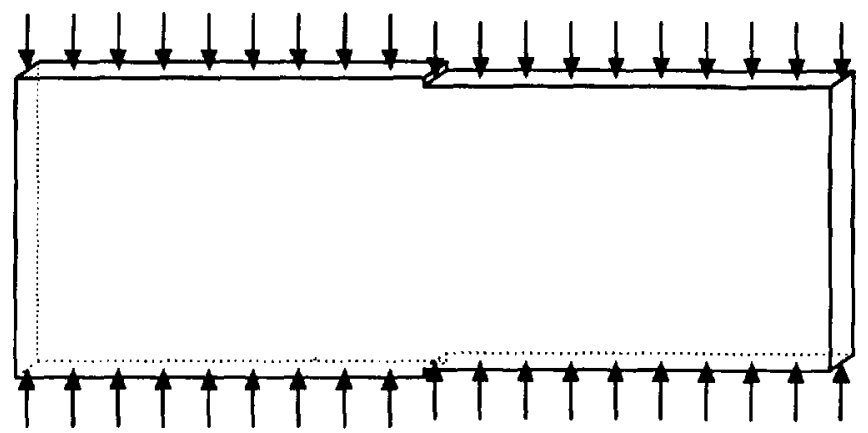

Figure 3.2-11. Criticality Control Plate Buckling

Because of the slots cut in the interlocking plates, the actual conditions are that half of the plate has fixed ends and half has free ends. The half of the plate which has free ends can be expected to behave somewhat like a pin-ended column because the movement of the ends will be limited by the connection to the fixed ended plate and contact with the fuel.

For a rectangular cross section, the moment of inertia, $\mathrm{I}$, is calculated by the equation ${ }^{[19]}$ :

$$
\mathrm{I}=(1 / 12) \mathrm{bh}^{3}
$$

$$
\text { where: } \begin{aligned}
b & =\text { plate width } \\
h & =\text { plate thickness }
\end{aligned}
$$

Substituting Equation 3.2-2 into Equation 3.2-1, and solving for plate thickness, the following equation is obtained.

$$
\mathrm{h}=\left(12 \mathrm{P}_{\mathrm{cr}} \mathrm{L}^{2} / \pi^{2} \mathrm{~Eb}\right)^{(1 / 3)}
$$


If $\mathrm{P}_{\mathrm{cr}}$ is set equal to the load present on the plate, the resulting plate thickness will be the critical thickness for buckling. Four different loads were applied to the plate to examine the effects of two loading parameters. The loading conditions were: ${ }^{[14]}$

LC1. No backfill present. ${ }^{[14]}$

Mass of degradation products equal to mass of original materials.

LC2. No backfill present. ${ }^{[14]}$

Degradation product mass/original material mass $=1.61 .^{[14]}$

LC3. Backfill present.

Mass of degradation products equal to mass of original materials.

LC4. Backfill present.

Degradation product mass/original material mass $=1.61 .^{[14]}$

The buckling loads on the criticality control plates and critical plate thicknesses are given in Table 3.2-10.

Table 3.2-10. Results of Buckling Evaluation of Criticality Control Plates ${ }^{[14]}$

\begin{tabular}{||c|c|c|c|c||}
\hline $\begin{array}{c}\text { Backfill } \\
\text { Presence }\end{array}$ & $\begin{array}{c}\text { Loading } \\
\text { Condition }\end{array}$ & $\begin{array}{c}\text { Buckling Load } \\
(\mathrm{N})\end{array}$ & $\begin{array}{c}\text { Critical Plate } \\
\text { Thickness, } \mathrm{h}\end{array}$ & $\begin{array}{c}\text { Critical Plate } \\
\text { Thinning }\end{array}$ \\
\hline \multirow{2}{*}{$\begin{array}{c}\text { Without } \\
\text { Backfill }\end{array}$} & LC1 & 11,750 & $0.00155 \mathrm{~m}$ & $0.00545 \mathrm{~m}$ \\
\cline { 2 - 5 } & LC2 & $(14,249-118,357 \mathrm{~h})^{*}$ & $0.00164 \mathrm{~m}$ & $0.00536 \mathrm{~m}$ \\
\hline \multirow{2}{*}{$\begin{array}{c}\text { With } \\
\text { Backfill }\end{array}$} & LC3 & 19,466 & $0.00183 \mathrm{~m}$ & $0.00517 \mathrm{~m}$ \\
\cline { 2 - 5 } & LC4 & $(23,982-118,357 \mathrm{~h})^{*}$ & $0.00195 \mathrm{~m}$ & $0.00505 \mathrm{~m}$ \\
\hline
\end{tabular}

*Solved iteratively ${ }^{[14]}, \mathrm{h}=$ critical plate thickness.

\subsection{Bending Analysis of Horizontal Plate}

Another possible failure mechanism for the criticality control plates is bending due to the SNF assembly load. The critical location in the waste package for bending of a criticality control plate is in a peripheral location where the plate is loaded as a cantilever beam because there is no connection between the criticality control plate and the side guide. The problem is treated as a cantilever beam which is fixed at one end and is under an evenly distributed load, see Figure 3.2-12. The load consists of the weight of the plate itself plus one fourth of the sum of the weight of a fuel assembly and the weight of a tube. The fuel assembly and tube weights are divided by four because there are four plates along the length. 


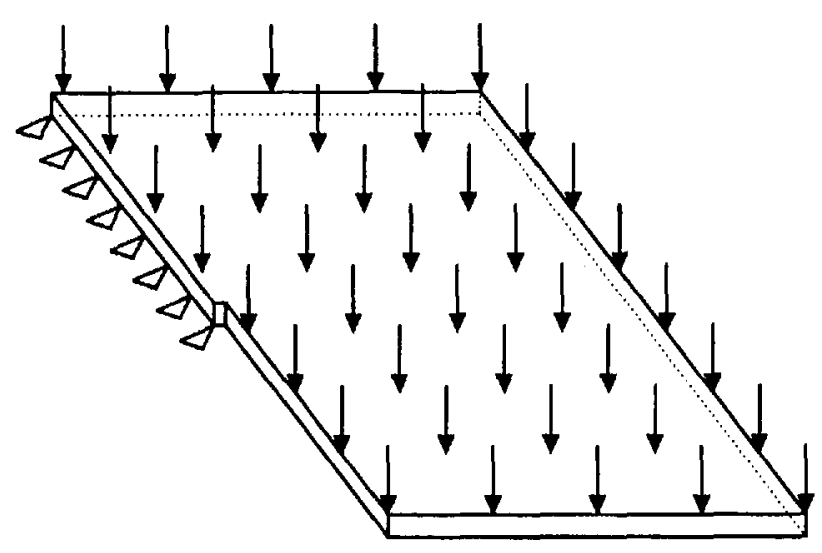

Figure 3.2-12. Criticality Control Plate Bending

The stress in the plate can be found with the equation:

$$
\sigma=\mathrm{Mc} / \mathrm{I} \quad(\text { Reference } 19, \mathrm{p} .157)
$$

Equation 3.2-4

where: $\quad c=h / 2$

$\mathrm{h}=$ plate thickness

$$
\begin{aligned}
\mathrm{I}=(1 / 12) \mathrm{bh}^{3} \\
\quad \mathrm{~b}=\text { plate length minus slot length }
\end{aligned}
$$

The maximum moment is at the fixed end and is determined by the following equation:

$$
M=w L^{2} / 2 \text { (Reference 20, p. 3-136) }
$$

Equation 3.2-7

where: $\quad w=$ the distributed load

$L=$ the cantilever length

Substituting Equations 3.2-5, 3.2-6, and 3.2-7 into Equation 3.2-4 and solving for thickness, $h$, yields:

$$
h=L(3 w / b \sigma)^{0.5}
$$

If the stress limit for $\mathrm{Pm}+\mathrm{Pb}, 173 \mathrm{MPa},{ }^{[14]}$ is input for stress, $\sigma$, then the resulting thickness is the critical thickness for bending. Two loading conditions were analyzed. ${ }^{[14]}$

LC1. Mass of degradation products equal to mass of original materials.

LC2. Degradation product mass/original material mass $=1.61 .^{[14]}$

The distributed bending loads and critical plate thicknesses are reported in Table 3.2-11. ${ }^{[14]}$ 
Table 3.2-11. Results of Bending Evaluation of Criticality Control Plates

\begin{tabular}{||c|c|c|c||}
\hline Loading Condition & $\begin{array}{c}\text { Bending } \\
\text { Load }\end{array}$ & $\begin{array}{c}\text { Critical Plate } \\
\text { Thickness, } \mathrm{h}\end{array}$ & $\begin{array}{c}\text { Critical Plate } \\
\text { Thinning }\end{array}$ \\
\hline LC1 & $10,432 \mathrm{~N} / \mathrm{m}$ & $0.0043 \mathrm{~m}$ & $0.0027 \mathrm{~m}$ \\
\hline LC2 & $(11,904-54,440 \mathrm{~h}) \mathrm{N} / \mathrm{m}^{*}$ & $0.0045 \mathrm{~m}$ & $0.0025 \mathrm{~m}$ \\
\hline
\end{tabular}

${ }^{*}$ Solved iteratively ${ }^{[14]}, \mathrm{h}=$ critical plate thickness.

The results of these calculations indicate that if the worst case mass for degradation products is considered, the bending stresses in the criticality control plate will exceed Level A Service Limits ${ }^{[1]}$ after it has thinned $2.5 \mathrm{~mm}$. If the loading on the plate is based on the masses of the original materials, the bending stresses do not exceed the limits until the plate has thinned $2.7 \mathrm{~mm}$.

\subsubsection{Tube Analysis}

The tubes will degrade before the criticality control plates. ${ }^{[14]}$ In analyzing the criticality control plates, it was determined that the plates could maintain the basket and SNF assembly configuration without structural support from the tubes. Failure of the tubes will, therefore, not cause collapse of the basket, so no specific analysis is performed for the tubes. Failure of the criticality control plates is analyzed in Section 3.2.2.2.

\subsubsection{Corner Guide Analysis}

The thickness of the corner guide will always be equal to the side guide thickness because they are originally equal in thickness, and they are made of the same material. The side guide is under higher loading, so it will fail before the corner guide. Therefore, no specific analysis is performed for the corner guides. Failure of the side guides is analyzed in Section 3.2.2.1. 


\subsection{Rock Fall Analyses}

\subsubsection{Finite-Element Model Development}

A three-dimensional finite-element model of the 21 PWR AUCF Tube WP (including inner and outer barriers), shown in Figure 3.3-1, has been developed in accordance with the WP conceptual designs. The model includes a $1.5 \mathrm{~m}$ section of the containment barriers in the midspan of the WP. This length is approximately equal to the spacing between emplacement supports. ${ }^{[15]}$ This region of the WP experiences the highest stresses due to rock fall since the contact is reached between the rock and the WP at the mid-length. The combination of kinetic-strain energy and linear bending stress relations, as given in Equation 3.3-1, reveals that the stress on a beam is inversely proportional to the square root of the beam length. ${ }^{[15]}$

$$
\frac{1}{2} m v^{2}=\left(\frac{4 \sigma I}{c L}\right)^{2} \frac{L^{3}}{96 E I}
$$

where: $\quad \mathrm{m}=$ mass of rock

$\mathrm{v}=$ velocity of rock

$\sigma=$ bending stress on barriers

$\mathrm{L}=$ length of the WP

$\mathrm{E}=$ modulus of elasticity of barrier materials

$I=$ area moment of inertia of barriers

$\mathrm{c}=$ containment barrier outer radius

The physical interpretation of this relation is that if the volume of a beam is decreased, less kinetic energy can be absorbed as strain energy in the beam. Since the middle section of the WP provides a smaller volume than the WP total volume, the finite-element model is conservative.

A transient dynamic analysis was performed with gravitational acceleration as the only load on the system. There is one support location at each end, along the section length of the WP. These boundary conditions provide a conservative approach for the simulation of the WP length used in this analysis. 


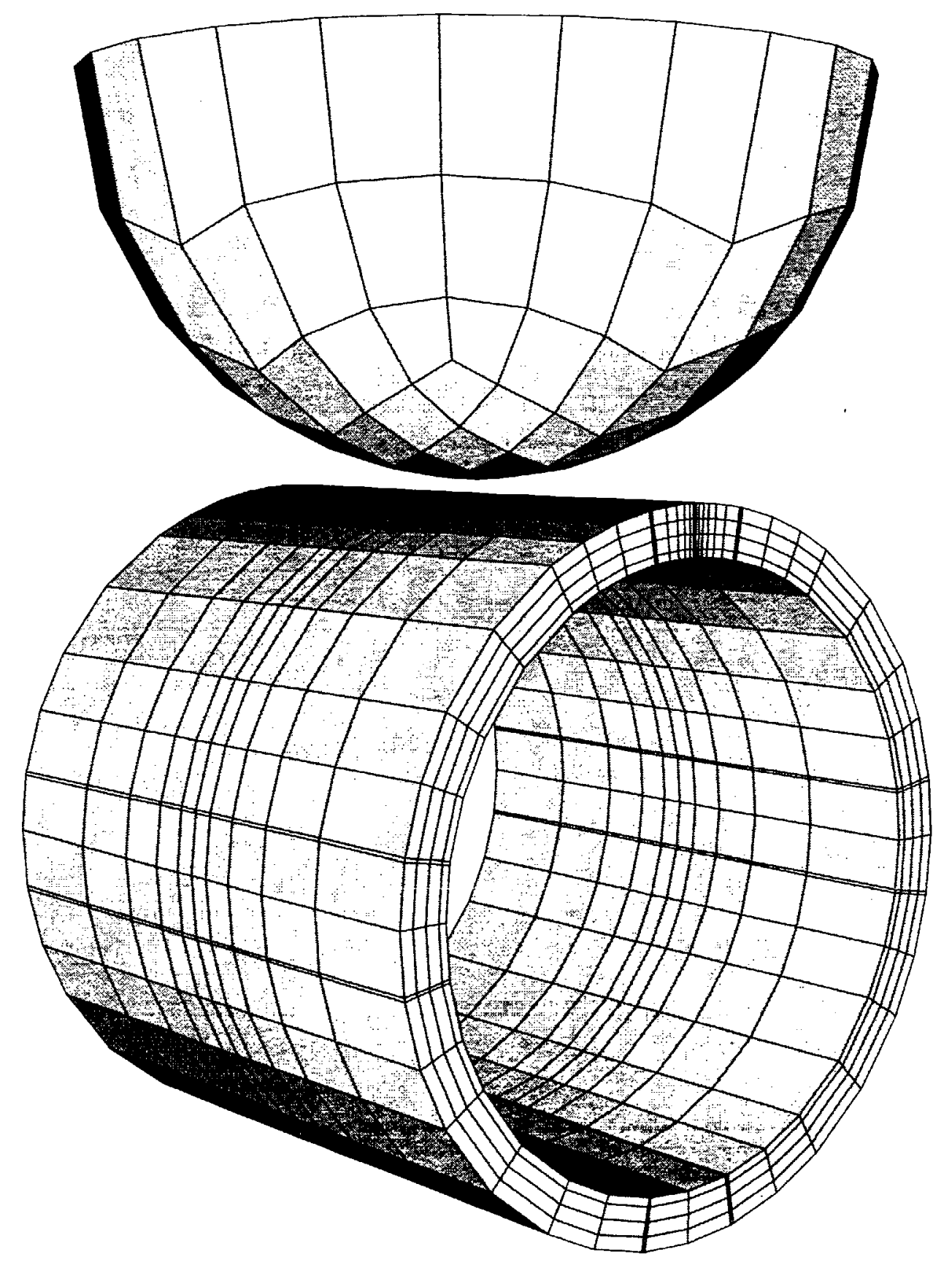

ANSYS 5.1

MAR 131996

DISPLACEMENT

$\mathrm{STEP}=3$

SUB $=37$

TIME $=0.7$

Figure 3.3-1. Finite-Element Model for Rock Fall Analyses (Zero Degradation Model Shown Just Prior to Rock Impact) 
For the present WP conceptual designs, the outer and inner barriers of 21 PWR WP are fabricated as one piece. However, material properties are unique to each specific material. The materials called out for the barriers are listed in Table 3.1-1:

Outer barrier: ASTM A 516 carbon steel (grade 70)

Inner barrier: Alloy 625

A spherical geometry was selected for the rock because the impact of a sphere will result in a global distribution of stress onto the WP, whereas a sharp-wedge geometry would deform the pointed region of the rock as a result of high stress concentration at the impact point. ${ }^{[15]}$ The spherical rock provides a conservative approach to the problem since the most severe effect of impact on the WP will be determined without any failure on the rock surface, i.e. crumbling of the rock. In order to perform the finite-element analysis (FEA) evaluations, the radius of the rock was varied to simulate different rock sizes. These rock sizes are provided for different containment barrier levels of degradation in Table 3.3-1.

In order to determine the effect of WP static weight in the FEA, the maximum bending moment and resulting stress magnitudes are calculated on the 21 PWR AUCF WP due to its own weight which is conservatively applied as a point load at the center of the span. ${ }^{[15]}$ The summation of the resulting stress magnitude with the stress obtained from the finite-element solutions for dynamic loading on the waste packages is determined to be approximately the same as the stress obtained solely from the finite-element solutions for dynamic loading on the waste packages. Thus, the weight of the fuel assemblies and basket are not included in this analysis since the static load on the WP due to the fuel assemblies and basket is found to be much less than the dynamic impact load.

Degradation of the outer and inner barriers is treated as general thinning of the material (Assumption 2.3-1). Furthermore, degradation of the inner barrier does not begin until the outer barrier is completely degraded. ${ }^{[15]}$

The drop height of the rock is calculated from the given dimensions of the emplacement drift tunnel. ${ }^{[2]}$ Figure 3.3-2 depicts the emplacement drift tunnel geometry. Since the pedestal support has not been designed yet, the dimensions of "rail car emplacement concept" are used to calculate the rock fall height ${ }^{[22]}$ The fall height is the distance from the top surface of the WP to the bottom of the rock, as tabulated in Table 3.3-1.

The geometry of the rock and emplacement drift tunnel is defined by the following parameters (Figure 3.3-2):

$D=$ Emplacement drift tunnel diameter $=5.0 \mathrm{~m}^{[2]]}$

$r_{1}=$ WP containment barrier outer radius

$r_{2}=$ Rock radius (determined by finite-element analysis for different levels of degradation in the WP)

$k=$ Distance from the bottom of the emplacement drift tunnel to the bottom of the WP $\mathrm{P}^{[15]}$

$\mathrm{h}=$ Rock fall height

$y=$ Distance from the WP center to the rock center 
These parameters are calculated for different barrier thickness values and presented in Table 3.3-1.

Table 3.3-1. Emplacement Drift Rock Fall Parameters

\begin{tabular}{||l|c|c|c|c|c||}
\hline & \multicolumn{5}{|c||}{ Percent Degradation (Thinning) } \\
\hline Outer Barrier Degradation & $0 \%$ & $50 \%$ & $75 \%$ & $100 \%$ & $100 \%$ \\
\hline Inner Barrier Degradation & $0 \%$ & $0 \%$ & $0 \%$ & $0 \%$ & $50 \%$ \\
\hline $\begin{array}{l}\text { WP Containment Barrier } \\
\text { Outer Radius }\left(r_{1}\right)\end{array}$ & $0.8310 \mathrm{~m}$ & $0.7809 \mathrm{~m}$ & $0.75595 \mathrm{~m}$ & $0.73095 \mathrm{~m}$ & $0.72095 \mathrm{~m}$ \\
\hline Rock Radius $\left(r_{2}\right)$ & $0.9526 \mathrm{~m}$ & $0.64642 \mathrm{~m}$ & $0.47629 \mathrm{~m}$ & $0.33566 \mathrm{~m}$ & $0.17547 \mathrm{~m}$ \\
\hline Rock Fall Height $(\mathrm{h})$ & $2.2280 \mathrm{~m}$ & $2.3282 \mathrm{~m}$ & $2.3781 \mathrm{~m}$ & $2.4281 \mathrm{~m}$ & $2.4481 \mathrm{~m}$ \\
\hline $\begin{array}{l}\text { Distance from WP Center to } \\
\text { Rock Center }(\mathrm{y})\end{array}$ & $4.0116 \mathrm{~m}$ & $3.75552 \mathrm{~m}$ & $3.61034 \mathrm{~m}$ & $3.49471 \mathrm{~m}$ & $3.34452 \mathrm{~m}$ \\
\hline
\end{tabular}

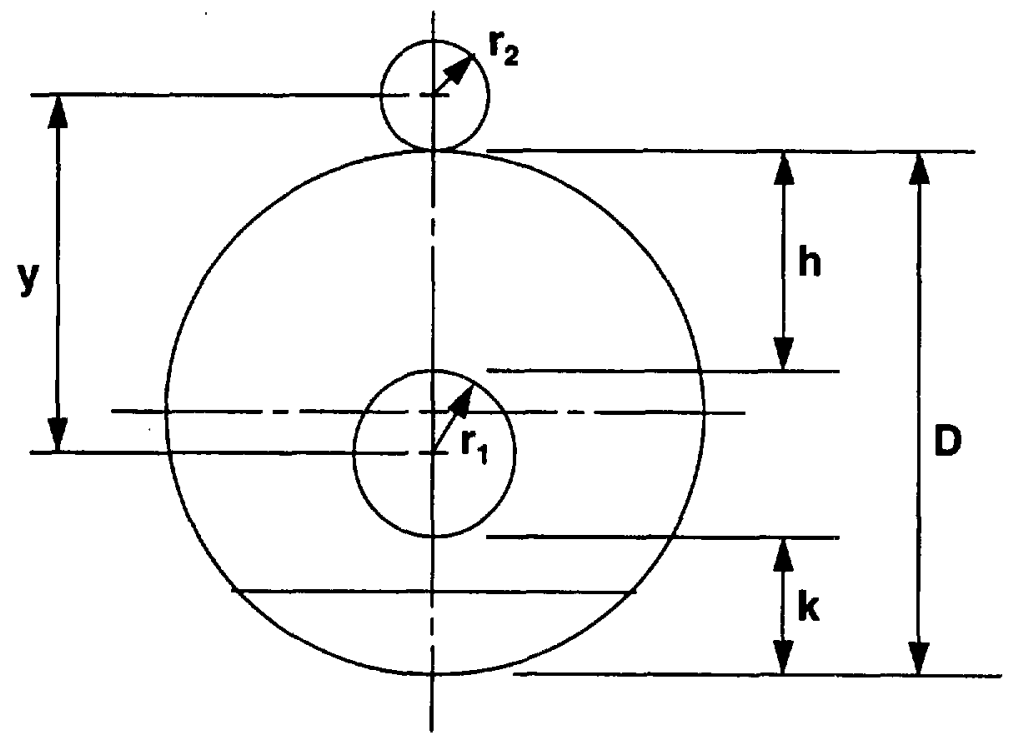

Figure 3.3-2. Emplacement Drift Tunnel Geometry

\subsubsection{Failure Criteria}

The criteria for the failure analysis of containment barriers are obtained from the ASME Boiler and Pressure Vessel Code. $S_{\mathrm{u}}$ is defined as the ultimate tensile strength of the materials and the failure criteria for the plastic analysis are described in the ASME Boiler and Pressure Vessel Code as follows: ${ }^{[10,12 \text { Article F-1341.2] }}$ 
The general primary membrane stress intensity shall not exceed $0.7 \mathrm{~S}_{\mathrm{v}}$ and the maximum primary stress intensity at any location shall not exceed $0.90 \mathrm{~S}_{\mathrm{u}}$. Therefore,

Maximum Membrane Stress $<0.7 \mathrm{~S}_{\mathrm{u}}$

Maximum Membrane + Bending Stress $<0.9 \mathrm{~S}_{\mathrm{u}}$

will be satisfied for both outer and inner barriers of the WP.

For the outer barrier material, A 516 carbon steel, $\mathrm{S}_{\mathrm{u}}=485 \mathrm{MPa}{ }^{[23]}$ Therefore, the outer barrier failure criteria are specified as follows:

Maximum Membrane Stress $<0.7^{*}(485)=339.5 \mathrm{MPa}$

Maximum Membrane + Bending Stress $<0.9^{*}(485)=436.5 \mathrm{MPa}$

For the inner barrier material, Alloy $625, \mathrm{~S}_{\mathrm{u}}=758 \mathrm{MPa} \cdot{ }^{[24]}$ Therefore, the inner barrier failure criteria are specified as follows:

Maximum Membrane Stress $<0.7 *(758)=530.6 \mathrm{MPa}$

Maximum Membrane + Bending Stress $<0.9 *(758)=682.2 \mathrm{MPa}$

The margin of safety for the stress magnitudes is defined as follows: ${ }^{[25, \mathrm{p} .11]}$

margin of safety $=\left(\mathrm{S}_{\text {allowable }} / \sigma\right)-1$

where $\sigma$ is the maximum stress on the containment barriers.

\subsubsection{Results}

The maximum membrane and membrane plus bending stress magnitudes are expected to occur along the impact line between the rock and the WP due to excessive local deformation of the containment barriers in the region of impact. It has been verified by a separate ANSYS evaluation that the impact line between the rock and the WP is the location of the stress path which gives the maximum membrane and membrane plus bending stresses. ${ }^{[15]}$ Therefore, the stress path along the line of impact is used through the thickness of the outer and inner barriers for all degradation levels of this analysis.

The failure criteria were explained in Section 3.3.2. Thus, the maximum stresses from the ANSYS solution are compared to the stress allowables in order to determine the critical rock sizes for different degradation levels in the WP containment barriers. Table 3.3-2 presents the maximum values of the membrane stress, membrane plus bending stress, and allowable stress magnitudes. A comparison of allowable stresses with the maximum stresses shows that there is no failure in the material for different levels of degradation of the outer and inner barriers. The margin of safety values were calculated according to the relation given in Section 3.3.2 and provided in the same table. Since the margin of safety values are small, the degradation levels given in Table 3.3-2 are considered to be limiting. The allowable rock size and mass values are also given in the same table. 
Table 3.3-2. Emplacement Drift Rock Fall Results

\begin{tabular}{|c|c|c|c|c|c|}
\hline \multirow{2}{*}{$\begin{array}{l}\text { Barrier Analysis at Different } \\
\text { Levels of Degradation } \\
\text { Outer Barrier Degradation }\end{array}$} & \multicolumn{5}{|c|}{$\begin{array}{l}\text { Percent Degradation (General Thinning of Outer Barrier, Pitting of Inner Barrier). } \\
\text { The outer barrier degrades completely prior to any pitting on the inner barrier. }\end{array}$} \\
\hline & $0 \%$ & $50 \%$ & $75 \%$ & $-100 \%$ & $100 \%$ \\
\hline Inner Barrier Degradation & $0 \%$ & $0 \%$ & $0 \%$ & $0 \%$ & $50 \%$ \\
\hline Membrane Stress in Outer Barrier & 236.0 & 234.1 & 174.4 & N/A & N/A \\
\hline $\begin{array}{l}\text { Membrane Stress Allowable in } \\
\text { Outer Barrier } \\
\text { Margin of Safety }\end{array}$ & $\begin{array}{r}339.5 \\
0.439\end{array}$ & $\begin{array}{l}339.5 \\
0.450 \\
\end{array}$ & $\begin{array}{l}339.5 \\
0.947 \\
\end{array}$ & N/A & N/A \\
\hline $\begin{array}{l}\text { Membrane Plus Bending Stress in } \\
\text { Outer Barrier }\end{array}$ & 432.9 & 432.6 & 429.0 & N/A & N/A \\
\hline $\begin{array}{l}\text { Membrane Plus Bending Stress } \\
\text { Allowable in Outer Barrier } \\
\text { Margin of Safety }\end{array}$ & $\begin{array}{l}436.5 \\
0.008\end{array}$ & $\begin{array}{l}436.5 \\
0.009\end{array}$ & $\begin{array}{l}436.5 \\
0.017 \\
\end{array}$ & N/A & N/A \\
\hline Membrane Stress in Inner Barrier & 442.0 & 421.9 & 352.8 & 151.1 & 90.7 \\
\hline $\begin{array}{l}\text { Membrane Stress Allowable in } \\
\text { Inner Barrier } \\
\text { Margin of Safety }\end{array}$ & $\begin{array}{l}530.6 \\
0.200 \\
\end{array}$ & $\begin{array}{l}530.6 \\
0.258 \\
\end{array}$ & $\begin{array}{l}530.6 \\
0.504\end{array}$ & $\begin{array}{l}530.6 \\
2.512 \\
\end{array}$ & $\begin{array}{l}530.6 \\
4.850 \\
\end{array}$ \\
\hline $\begin{array}{l}\text { Membrane Plus Bending Stress in } \\
\text { Inner Barrier }\end{array}$ & 492.3 & 505.2 & 498.3 & 677.0 & 675.8 \\
\hline $\begin{array}{l}\text { Membrane Plus Bending Stress } \\
\text { Allowable in Inner Barrier } \\
\text { Margin of Safety }\end{array}$ & $\begin{array}{l}682.2 \\
0.386 \\
\end{array}$ & $\begin{array}{l}682.2 \\
0.350\end{array}$ & $\begin{array}{l}682.2 \\
0.369 \\
\end{array}$ & $\begin{array}{l}682.2 \\
0.008\end{array}$ & $\begin{array}{l}682.2 \\
0.009 \\
\end{array}$ \\
\hline $\begin{array}{l}\text { Allowable Rock Mass that does } \\
\text { not Breach Containment Barriers } \\
(\mathrm{kg})\end{array}$ & 8,000 & 2,500 & 1,000 & 350 & 50 \\
\hline $\begin{array}{l}\text { Rock Size Diameter for Allowable } \\
\text { Rock Mass Values (m) }\end{array}$ & 1.90 & 1.29 & 0.95 & 0.67 & 0.35 \\
\hline
\end{tabular}

*All stress magnitudes are in $\mathrm{MPa}$

A plot of critical rock size versus degradation through the containment barrier thickness is provided in Figure 3.3-3. The first and second regions of the containment barrier consist of the outer and inner barriers which are $0.1 \mathrm{~m}$ and $0.02 \mathrm{~m}$ in thicknesses, respectively. 
Emplaced Waste Package Structural Capability Through Time Report

DI: BBAA00000-01717-5705-00001 REV 00

Page 43 of 72

Figure 3.3-3. Critical Rock Mass vs. Degradation of Containment Barriers

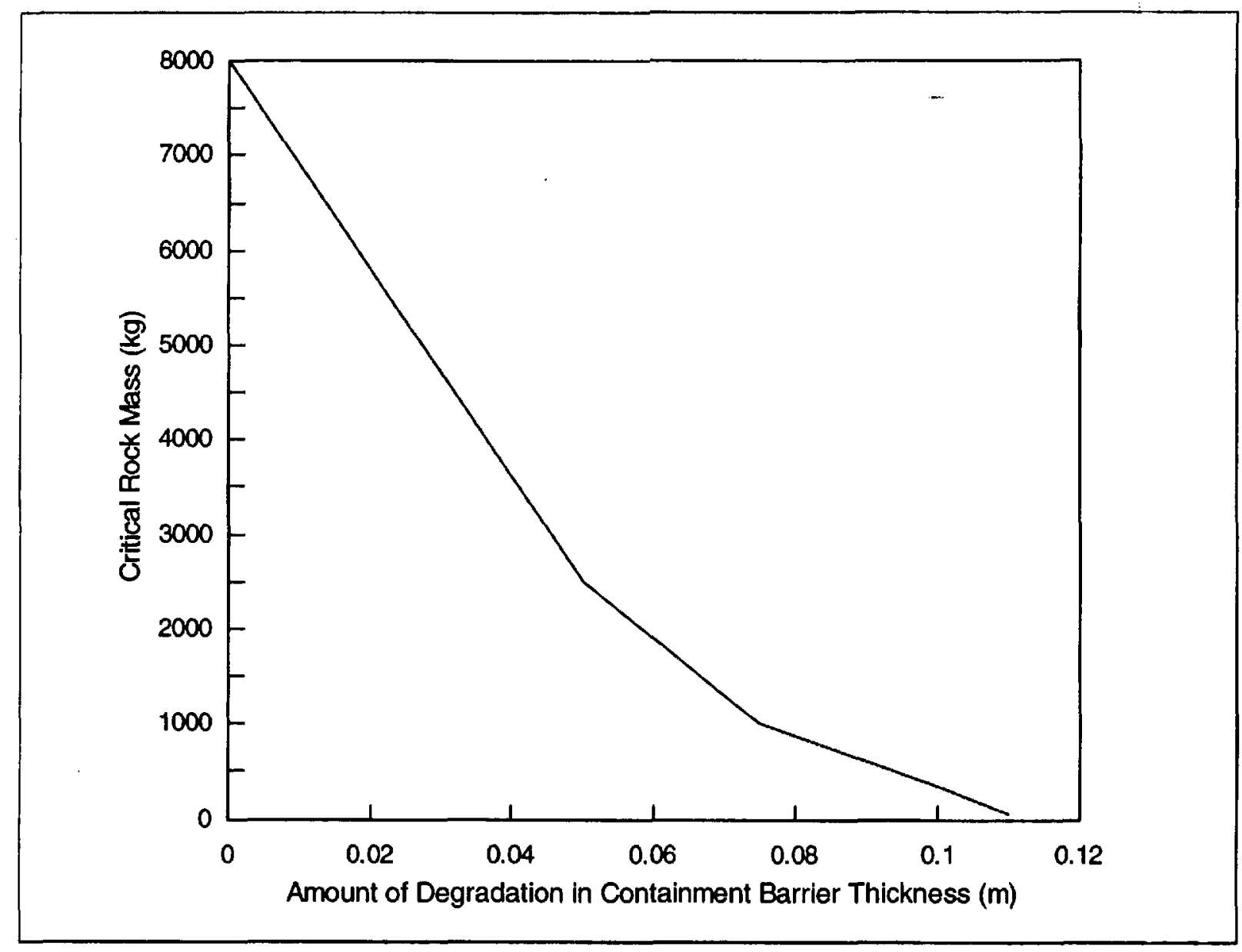




\subsection{Seismic Analyses}

\subsubsection{Finite-Element Model Development}

The ANSYS 5.1 finite-element analysis code is used for the seismic analysis of the WP under various degrees of material degradation. The models developed for this analysis are one-quarter and one-half symmetry three-dimensional finite-element models. ${ }^{[16]}$

The analysis incorporates the waste package outer barrier and lids, inner barrier and lids, basket tubes, criticality control plates, side guides, and corner guides. Material specifications of each WP component are defined by their individual property tables. The component materials are as listed in Table 3.1-1.

The waste package is modeled as a three-dimensional solid structure. The waste package rests on two pedestal supports. The supports are placed inside of the lids, leaving a span approximately half of the length of the outer barrier, excluding the skirts. The solutions were run with backfill present.

The WP is symmetric about a plane that runs along the longitudinal axis. The waste package is also symmetric at top and bottom. ${ }^{[16]}$ Taking advantage of the symmetry reduces the model size, allowing more detail in the part that is modeled. However, even with the symmetric model, the element mesh must remain somewhat coarse in order to keep solution times and output file sizes manageable. Therefore, some other simplifications have been made to the model.

- For the present WP conceptual designs, the outer and inner barriers are fabricated as one piece (the inner barrier clad to the outer barrier). Thus, there is no need for contact elements between the inner and outer barriers. It is best to avoid the use of contact elements wherever possible to prevent convergence problems and to reduce the model size and run times. While the inner and outer barriers are treated as contiguous, there is an element border between the inner and outer barrier and the appropriate material properties are used for each barrier.

- The basket components are modeled as a solid piece and also solidly connected to the inner barrier. Since the nonlinear contact elements cannot be used in a spectrum analysis, this simplification is necessary for the finite-element solution.

- The backfill load is included in the model by increasing the density of the outermost barrier for that particular solution (outer barrier when present, inner barrier for cases where the outer barrier has completely degraded). Since the additional backfill load is included in the mass of the containment barriers, this analysis is conservative compared to an analysis which could be performed without the backfill.

The pressure of SNF assemblies cannot be incorporated into the modal or response spectrum analyses in terms of external pressure since the natural frequency and mode shapes are not dependent on the external forces applied to the system. Therefore, the SNF mass is added into the basket assembly components for each seismic finite-element solution. 
The seismic loads were applied as acceleration loads at the emplacement supports. After the model was constructed, a modal solution was obtained to find the natural frequencies and mode shapes of the geometry. The results of the modal analysis were then used in a response-spectrum analysis. In the response-spectrum analysis, the seismic loads were applied to the model to determine stresses, strains and deflections. The input to the response spectrum is in the form of a table of acceleration versus frequency, thus making it a frequency-domain solution. A single-point response-spectrum is used, meaning that all supports of the model will experience the same ground movement.

A large amplitude horizontal component of the seismic input would cause the WP to move on pedestal supports along the symmetry axis. Similarly, a lateral movement on the horizontal plane would cause the WP to rotate with respect to the point of contact with the pedestal and, therefore, would not result a significant change in the stress distribution over the WP. Vertical displacement of the pedestals, however, causes bending of the WP structure in terms of both local and global deformations. Therefore, the vertical component of the acceleration is selected to be the only seismic input used in the finite-element analysis. A constant peak ground acceleration of $0.66 \mathrm{~g}$ in the vertical $y$-direction is conservatively assumed for a frequency range from $0.1 \mathrm{~Hz}$ to $100 \mathrm{~Hz}^{[1]}$ (Assumption 2.3-2).

The material properties and displacement solution to the finite-element problem are linear because of the complex nature of spectrum analysis. The ANSYS code allows only linear solution to this type of analysis. Therefore, an elastic solution is obtained and allowable material stresses are based on the failure criteria given in Sections 3.4.2 and 3.4.3.

There is no damping specified in this finite-element analysis solution. Therefore, the results are considered conservative since the stress magnitudes will be larger due to the absence of damping in the waste package structure.

The frequency range of the response spectrum covers the first eight mode shapes and corresponding natural frequencies. It is verified from the mode combination files of each case run that the first six modes of the WP have the largest scale factors for their contributions to the spectrum solution. Therefore, the subsequent modes of the WP have no significant effect in the solution.

The output from the finite-element solution consists of the participation factor table and the mode combination file. The participation factor is a combination of the normalized eigenvector, mass matrix, and a vector describing the excitation direction. The participation factor table lists the participation factors, mode coefficients, and the mass distribution for each mode. The mode coefficients are used to multiply the mode shapes to obtain the maximum response of each mode.

The final sequence of the solution process involves the combination of the maximum modal responses as specified by the mode combination file of ANSYS to calculate the overall response of the structure. The overall response consists of the overall displacements, stresses, strains, and reaction forces. 


\subsubsection{Failure Criteria}

The criteria for the failure analysis of containment barriers are obtained from the ASME Boiler and Pressure Vessel Code. $S_{u}$ and $S_{n}$ are defined as the ultimate tensile strength and design stress intensity values of the materials, respectively. The failure criteria for the elastic analysis are described in the ASME Boiler and Pressure Vessel Code as follows: ${ }^{[10,11 \text {, and } 12 \text { Article F-1331.1] }}$

The general primary membrane stress intensity shall not exceed the lesser of $2.4 \mathrm{~S}_{\mathrm{m}}$ and $0.7 \mathrm{~S}_{\mathrm{u}}$, and the primary membrane plus primary bending stress intensity $\left(\mathrm{P}_{\mathrm{b}}\right)$ shall not exceed $150 \%$ of the limit for general primary membrane stress intensity, $P_{m}$. Therefore,

$$
\begin{aligned}
& \text { Maximum Membrane Stress }<0.7 \mathrm{~S}_{\mathrm{u}} \text { or } 2.4 \mathrm{~S}_{\mathrm{m}} \\
& \text { Maximum Membrane + Bending Stress }<1.05 \mathrm{~S}_{\mathrm{u}} \text { or } 3.6 \mathrm{~S}_{\mathrm{m}}
\end{aligned}
$$

will be satisfied for all materials in the WP.

$S_{m}$ values for selected materials are given in Reference 18, Tables $2 \mathrm{~A}$ and $2 \mathrm{~B}$. For the analyses performed, the temperature used is room temperature $\left(20^{\circ} \mathrm{C}\right)$. Therefore, the limits are as follows:

Table 3.4-1. Design Stresses (Room Temperature)

\begin{tabular}{||l|c|c|}
\hline Material & $\mathrm{S}_{\mathrm{m}}(\mathrm{MPa})$ & Page of Reference 18 \\
\hline A 516 Grade 70 & 161 & Table 2A, p. 300 \\
\hline Alloy 625 & 252 & Table 2B, p. 408 \\
\hline 316B6A (316L) & 115 & Table 2A, p. 340 \\
\hline
\end{tabular}

Table 3.4-2 summarizes the failure criteria obtained from the ASME Boiler and Pressure Vessel Code.

Table 3.4-2. Calculated Allowable Stress Limits (Room Temperature)

\begin{tabular}{||l|c|c|c|c|c|c||}
\hline Material & $\begin{array}{c}\mathrm{S}_{\mathrm{m}} \\
(\mathrm{MPa})\end{array}$ & $\begin{array}{c}\mathrm{S}_{\mathrm{u}} \\
(\mathrm{MPa})\end{array}$ & $\begin{array}{c}2.4 \mathrm{~S}_{\mathrm{m}} \\
(\mathrm{MPa})\end{array}$ & $\begin{array}{c}0.7 \mathrm{~S}_{\mathrm{u}} \\
(\mathrm{MPa})\end{array}$ & $\begin{array}{c}\mathrm{P}_{\mathrm{m}} \\
(\mathrm{MPa})\end{array}$ & $\begin{array}{c}\mathrm{P}_{\mathrm{m}}+\mathrm{P}_{\mathrm{b}} \\
\left(150 \% \mathrm{P}_{\mathrm{m}}\right.\end{array}$ \\
$(\mathrm{MPa})$
\end{tabular}


The margin of safety for the stress magnitudes is defined as follows: ${ }^{[25, p .11]}$

$$
\text { margin of safety }=\left(S_{\text {allowable }} / \sigma\right)-1
$$

where $\sigma$ is the maximum stress on the containment barriers.

The calculations to adjust barrier densities to include the backfill mass are provided in Reference 16. The results of backfill input mass calculations are given in Table 3.4-3. Between $25 \%$ and $50 \%$ outer barrier degradation, the skirts corrode completely and are subtracted from the length. At $100 \%$ outer barrier degradation, the remaining portion of the outer barrier lids and the gap between the inner barrier lid and outer barrier lid are subtracted from the length.

Table 3.4-3. Backfill Masses Based on Level of Degradation

\begin{tabular}{||l|l|l|l|l|l|l||}
\hline $\begin{array}{l}\text { Level of } \\
\text { Degradation }\end{array}$ & $\begin{array}{c}\text { Depth of } \\
\text { Backfill } \\
(\mathrm{m})\end{array}$ & $\begin{array}{c}\text { Length } \\
\text { of WP } \\
(\mathrm{m})\end{array}$ & $\begin{array}{c}\text { Diameter } \\
\text { of WP } \\
(\mathrm{m})\end{array}$ & $\begin{array}{c}\text { Volume } \\
\left(\mathrm{m}^{3}\right)\end{array}$ & $\begin{array}{c}\text { Density } \\
\left(\mathrm{kg} / \mathrm{m}^{3}\right)\end{array}$ & $\begin{array}{c}\text { Backfill } \\
\text { Mass } \\
(\mathrm{kg})\end{array}$ \\
\hline OB-0, IB-0 & 0.82 & 5.335 & 1.6619 & 7.27 & 1952.45 & 14,195 \\
\hline OB-100, IB-75 & 0.82 & 4.605 & 1.4319 & 5.41 & 1952.45 & 10,557 \\
\hline OB-100,IB-90 & 0.82 & 4.599 & 1.4259 & 5.38 & 1952.45 & 10.504 \\
\hline
\end{tabular}

The adjusted density for the upper section of the inner barrier is calculated by adding the section mass with the backfill mass and outer barrier mass (one half for half symmetry is considered in the calculations, however, the same densities are used in the quarter model) and dividing the sum by the section volume.

\subsubsection{Fatigue Analysis}

Due to the cyclic nature of the problem, a fatigue analysis is also performed to determine if the WP can withstand specified cyclic loads obtained from the seismic analysis. The allowable alternating stress is obtained from the ASME Code as follows:

Upper end of the frequency range considered in analysis $=100 \mathrm{~Hz}$

Time duration for the seismic input $=50 \mathrm{sec}^{[1]}$

Thus, number of cycles $=100 * 50=5000$ cycles per seismic event

Using 5000 cycles per seismic event, the allowable alternating stress for Alloy 625 and 316B6A Stainless Steel-Boron (SS-B) is determined as $75 \mathrm{ksi}(517 \mathrm{MPa}) .{ }^{[12, \text { Fig. 1-9.2.1] }}$ The alternating stress allowable for A 516 Carbon Steel, however, is determined as $50 \mathrm{ksi}$ (345 MPa). ${ }^{[12, \text { Figure } 1-9.1]}$

The analysis for cyclic operation is described in Reference 10, Article NB-3222.4, and Reference 11, Article NG-3222.4 in such a way that one-half of the peak stress determined from the FEA is to be compared to the alternating stress allowables in order to determine the failure in the system 
due to cyclic loading. Table 3.4-4 summarizes these stress magnitudes and allowables. A comparison of these values shows that the load fluctuation is insignificant. In addition to this, the conditions stipulated in the same article related to the temperature difference effects are not evaluated in this document. Therefore, no analysis for cyclic service is required, and the peak stress limits discussed above has been satisfied by compliance with the applicable requirements of these ASME subsections.

Table 3.4-4. Stress Peaks and Allowables for Fatigue Analysis

\begin{tabular}{||l|c|c|c||}
\hline WP Components & Percent Degradation & $\begin{array}{c}\text { Peak Stress / } \\
(\mathrm{MPa})\end{array}$ & $\begin{array}{c}\text { Alternating Stress } \\
\text { Allowables (MPa) }\end{array}$ \\
\hline Outer Barrier & $100 \%$ & N/A & N/A \\
\hline Inner Barrier & $90 \%$ & 325 & 517 \\
\hline Tubes & $100 \%$ & N/A & N/A \\
\hline Guides & $50 \%$ & 175 & 345 \\
\hline SS-B Plates & $0 \%$ & 9 & 517 \\
\hline
\end{tabular}

\subsubsection{Results}

The stress path for each finite-element model is defined including the node at which the stress intensity is maximum. This procedure is applied to the outer barrier, inner barrier, tubes, guides, and the criticality control plates. The resulting membrane and membrane plus bending stress magnitudes are presented in Table 3.4-5 for four different degradation levels in the WP.

The failure criteria were explained in Section 3.4.2. Thus, the maximum stresses from the ANSYS solution are compared to the stress allowables in order to determine the critical WP dimensions for different levels of degradation. Table 3.4-5 shows the maximum values of the membrane stress, membrane plus bending stress, and allowable stress magnitudes. The FEA results of seismic analysis are presented for the WP degradation levels which are critical for failure in various WP components. The outer barrier degrades completely prior to any pitting on the inner barrier. Degradation of the basket assembly does not begin until there is full penetration of the inner barrier material due to degradation. This will occur at some intermediate level of degradation of the inner barrier because degradation does not necessarily occur as general thinning. Degradation of the basket assembly is treated as if the carbon steel tubes and an equivalent thickness of the guides will degrade prior to the beginning of degradation of the SS-B plates. ${ }^{[16]}$ Therefore, no structural credit is taken for the tubes although their masses are incorporated into the SS-B plates providing a conservative approach for analysis.

In order to determine the thickness at which the SS-B plates would fail due to seismic loads, $50 \%$ degradation of the side guide and plates was modeled (Table 3.4-5). The result of this FEA solution showed that the failure occurred in the side guides. Therefore, no further analysis was performed to determine the failure in the plates since the failure in the side guides would cause the basket assembly to lose its structural integrity and would also change the geometry of the problem. 
The first column of the Table 3.4-5 gives the results of the FEA with no degradation in the WP. The reason for observing such small magnitudes of stresses in the WP is because of the full thicknesses of the inner and outer barriers and the resulting fact that none of the natural frequencies of this structure is in the frequency range that is critical for the WP. Therefore, these negligible stresses and very high margin of safety values are presented in this table for no degradation of the WP.

A comparison of allowable stresses with the maximum stresses shows that there is no failure in the material for the first three degradation levels of the outer barrier, inner barrier, tubes, and the criticality control plates. However, the fourth level of degradation by $50 \%$ thinning of the SS-B plates results in the failure of the side guide (see Table 3.4-5, fourth column). For the same degradation level, the margin of safety for the inner barrier is determined to be $34 \%$ in terms of the allowable membrane stress. It is concluded from the results in Table 3.4-5 that the failure of the side guide takes place before any failure is observed in the inner barrier. Therefore, allowable percent degradation levels of various WP components are obtained from the third degradation level which are presented in the same table.

It is observed from Table 3.4-5 that a degradation level of $100 \%$ in the outer barrier, $90 \%$ in the inner barrier, $100 \%$ in the tubes, $50 \%$ in the guides, and $0 \%$ in the SS-B plates (which have not begun to degrade significantly at this level) will not cause failure in any component of the WP which is subjected to a seismic load of $0.66 \mathrm{~g}$ peak ground acceleration. The results of fatigue analysis also show that there is no failure in the WP for a seismic input for a time duration of 50 seconds (see Section 3.4.3). Thus, these degradation levels are acceptable in terms of the WP performance subjected to the previously described seismic load. 
Table 3.4-5. Seismic Analysis Results

\begin{tabular}{|c|c|c|c|c|}
\hline \multirow{2}{*}{\begin{tabular}{|l} 
Barrier Analysis at Different Degradation Levels \\
Outer Barrier Degradation \\
\end{tabular}} & \multicolumn{4}{|c|}{$\begin{array}{l}\text { Percent Degradation (General Thinning of Outer Barrier, Pitting of Inner } \\
\text { Barrier). } \\
\text { The outer barrier degrades completely prior to any pitting on the inner } \\
\text { barrier. }\end{array}$} \\
\hline & $0 \%$ & $100 \%$ & $100 \%$ & $100 \%$ \\
\hline Inner Barrier Degradation & $0 \%$ & $75 \%$ & $90 \%$ & $90 \%$ \\
\hline Tube Degradation & $0 \%$ & $100 \%$ & $100 \%$ & $100 \%$ \\
\hline Guide Degradation & $0 \%$ & $50 \%$ & $50 \%$ & $50 \%$ \\
\hline SS-B Plate Degradation & $0 \%$ & $0 \%$ & $0 \%$ & $50 \%$ \\
\hline Membrane Stress in Outer Barrier & 3 & N/A & N/A & N/A \\
\hline $\begin{array}{l}\text { Membrane Stress Allowable in Outer Barrier } \\
\text { Margin of Safety }\end{array}$ & $\begin{array}{c}340 \\
112.33\end{array}$ & N/A & N/A & N/A \\
\hline Membrane Plus Bending Stress in Outer Barrier & 5 & N/A & N/A & N/A \\
\hline $\begin{array}{l}\text { Membrane Plus Bending Stress Allowable in Outer Barrier } \\
\text { Margin of Safety }\end{array}$ & $\begin{array}{c}510 \\
101.00\end{array}$ & N/A & N/A & N/A \\
\hline Membrane Stress in Inner Barrier & 3 & 72 & 295 & 395 \\
\hline $\begin{array}{l}\text { Membrane Stress Allowable in Inner Barrier } \\
\text { Margin of Safety }\end{array}$ & $\begin{array}{c}531 \\
176.00\end{array}$ & $\begin{array}{l}531 \\
6.38\end{array}$ & $\begin{array}{l}531 \\
0.80\end{array}$ & $\begin{array}{l}531 \\
0.34\end{array}$ \\
\hline Membrane Plus Bending Stress in Inner Barrier & 4 & 82 & 321 & 435 \\
\hline $\begin{array}{l}\text { Membrane Plus Bending Stress Allowable in Inner Barrier } \\
\text { Margin of Safety }\end{array}$ & $\begin{array}{c}797 \\
198.25\end{array}$ & $\begin{array}{l}797 \\
8.72\end{array}$ & $\begin{array}{l}797 \\
1.48\end{array}$ & $\begin{array}{l}797 \\
0.83\end{array}$ \\
\hline Membrane Stress in Guides & 5 & 68 & 293 & 369 \\
\hline $\begin{array}{l}\text { Membrane Stress Allowable in Guides } \\
\text { Margin of Safety }\end{array}$ & $\begin{array}{c}340 \\
67.00\end{array}$ & $\begin{array}{l}340 \\
4.00\end{array}$ & $\begin{array}{l}340 \\
0.16\end{array}$ & $\begin{array}{l}340 \\
\text { fails }\end{array}$ \\
\hline Membrane Plus Bending Stress in Guides & 6 & 70 & 300 & 376 \\
\hline $\begin{array}{l}\text { Membrane Plus Bending Stress Allowable in Guides } \\
\text { Margin of Safety }\end{array}$ & $\begin{array}{l}510 \\
84.00\end{array}$ & $\begin{array}{l}510 \\
6.29\end{array}$ & $\begin{array}{l}510 \\
0.70\end{array}$ & $\begin{array}{l}510 \\
0.36\end{array}$ \\
\hline Membrane Stress in SS-B Plates & 3 & 15 & 20 & 46 \\
\hline $\begin{array}{l}\text { Membrane Stress Allowable in SS-B Plates } \\
\text { Margin of Safety }\end{array}$ & $\begin{array}{c}276 \\
91.00\end{array}$ & $\begin{array}{c}276 \\
17.40\end{array}$ & $\begin{array}{c}276 \\
12.80\end{array}$ & $\begin{array}{l}276 \\
5.00\end{array}$ \\
\hline Membrane Plus Bending Stress in SS-B Plates & 3 & 16 & 21 & 48 \\
\hline $\begin{array}{l}\text { Membrane Plus Bending Stress Allowable in SS-B Plates } \\
\text { Margin of Safety }\end{array}$ & $\begin{array}{c}414 \\
137.00 \\
\end{array}$ & $\begin{array}{r}414 \\
24.88 \\
\end{array}$ & $\begin{array}{r}414 \\
18.71 \\
\end{array}$ & $\begin{array}{l}414 \\
7.63 \\
\end{array}$ \\
\hline
\end{tabular}

*All stress magnitudes are in $\mathrm{MPa}$ 


\subsection{Fuel Assembly Response to Loadings}

\subsubsection{Effect of Degradation Products on Fuel Assemblies}

The effect of degradation products on the fuel assemblies is determined in this section of the report. The fuel assembly array of Westinghouse $17 \times 17$ is considered for this analysis. The analyses of yield for the side drop and buckling are performed for various sizes of fuel assemblies in Reference 26. The results show that allowable $g$ loads calculated for each case in this document are lowest for the $17 \times 17$ array. Therefore, the limiting fuel assembly is the $17 \times 17$ according to these structural evaluations and it is evaluated here for any potential effect of degradation products on the fuel rods. The analysis results given in Sections 3.5.1 and 3.5.2 are taken from Reference 14.

The expansion of the tubes and the plates results in the degradation products moving into void spaces in the fuel assembly. ${ }^{[14]}$ Therefore, the calculations are performed in two parts. First, the volume of expansion due to degradation is determined in the tube and plate structure. Then, the volume of the fuel assembly is calculated based on the cladding dimensions. Since there is a clearance between the fuel assembly and the tubes, this volume is also considered to be filled by degradation products. If the available space in the tubes after degradation is larger than the volume of the fuel assembly, the fuel assembly does not experience a load due to expansion in the tubes. On the other hand, an available space smaller than the fuel assembly volume causes a compressive load on the fuel assemblies.

The amount of oxidation in the carbon steel is selected as the maximum value for iron and its common degradation products. ${ }^{[14]}$ The ratio of the specific volume per mole of $\mathrm{Fe}(\mathrm{OH})_{2}$ to the iron $(\mathrm{Fe})$ is determined as 3.713. ${ }^{[27]}$ This value is used as a factor of volume expansion during degradation of the basket components.

The WP basket assembly structure expands in all directions. Therefore, the outer surface expansion of carbon steel tubes causes both surfaces of the SS-B plates to experience compressive stress. Since the plates also expand, the resulting effect of degradation is an increase in the volume of carbon steel tubes toward the center of each tube. Initial volume per unit length of the tube plus plate structure is, therefore, multiplied by the factor of 3.713 in order to calculate the final inner dimension of the initial materials plus degradation products. Thus, available space in each tube is also obtained using this dimension.

The dimensions of the fuel rod, guide tubes, and instrument tube are used to determine the volume per unit length of the fuel assembly. The calculations showed that the available volume is larger than the total volume of the fuel assembly in the tubes. Therefore, it is concluded that degradation products do not cause any load on the fuel assemblies. 


\subsubsection{Static Load on Fuel Assemblies Due to Complete Degradation of WP}

This calculation is performed to determine the effect of a static load on the fuel assemblies when the WP is completely degraded. A conservative approach is taken by selecting the fuel assembly at the bottom on the symmetry axis to analyze the maximum effect of the static load. The vertical load on one fuel rod is equal to the summation of the total weight of the WP components and fuel assemblies above the bottom fuel assembly, weight of the bottom fuel assembly itself, and the backfill load, divided by the total number of fuel rods in a $17 \times 17$ array. The calculations of the Dynamic Impact Effects on Spent Fuel Assemblies ${ }^{[26]}$ show that the static load on a fuel assembly is taken equally by each fuel rod in the assembly. The same approach is taken for the analysis of static load on the fuel assemblies. ${ }^{[14]}$

Having the mass of all the components of the WP (tubes, plates, side guide, inner barrier, and outer barrier), the fuel assemblies, and the backfill calculated, a total mass of approximately $7,602 \mathrm{~kg}$ $(16,760 \mathrm{lb})$ is determined to be resting on the bottom fuel assembly on the WP symmetry plane. Beam theory is applied to one fuel rod in order to calculate the resulting maximum bending moment and stresses. ${ }^{[2]}$ Thus, a maximum bending stress of $57.2 \mathrm{MPa}$ is determined for one fuel rod. Comparing this value with an allowable bending stress of $348.2 \mathrm{MPa},{ }^{[26]}$ it is concluded that the margin of safety is 5.1 and there is no failure in the fuel assembly due to a static load of a completely degraded WP.

The fuel rod flattening is also analyzed by using the equation of critical bending moment which is expressed in terms of the Young's Modulus, nominal radius, and thickness of the fuel rod. The results show that the moment required to cause a flattening of the rod is much higher than the moment calculated on a fuel rod due to the static weight above the fuel assembly. Therefore, it is also concluded that there is no flattening of the fuel rods because of this loading condition.

\subsection{Relation of Degradation to Time}

Available general corrosion models and information have been applied to estimate the thickness of barrier and basket components as a function of time for the purpose of determining failure times based on the results of the analyses presented in Sections 3.2, 3.3, and 3.4.

\section{Outer Barrier Degradation}

In Reference 31, the Total System Performance Assessment (TSPA)-95 ${ }^{[28]}$ general corrosion models for carbon steel (Equations 3.6-1 and 3.6-2) were used to estimate the outer barrier thickness as a function of time for the purposes of determining when inner barrier pitting will begin and showing how the rockfall mass required to breach the WP changes with time. This study was performed for the 83 MTU/acre, low infiltration, no backfill case only. This is acceptable because for the static loading cases, the only differences in corrosion rate are due to differences in temperature and relative humidity in the early years, so long term effects are minimal. For the rock fall cases, rock fall would not be expected to be a concern for the backfill case (most if not all of the space above the waste package would be filled with backfill, thus preventing the rock from contacting the WP). 
The TSPA-95 model for humid-air general corrosion of carbon steel ${ }^{[28, p .5-25]}$ is given by:

$$
D_{g}(t, R H, T)=\exp \left[16.984+0.6113 \ln (t)-\frac{893.55}{R H}-\frac{833.27}{T}\right], \quad \text { Equation 3.6-1 }
$$

where: $\quad D_{g} \quad=$ general corrosion depth $(\mu \mathrm{m})$

$t \quad=$ exposure time (years)

$\mathrm{RH}=$ relative humidity $(\%)$

$T \quad=$ temperature $(\mathrm{K})$

The TSPA-95 model for aqueous general corrosion ${ }^{[28, \text { p.5-26] }}$ is given by:

$$
D_{g}(t, T)=\exp \left[111.5+0.5320 \ln (t)-\frac{23300}{T}-3.193 E-4 T^{2}\right], \quad \text { Equation 3.6-2 }
$$

where the variable definitions are the same as for Equation 3.6-1.

For this estimate, the WP surface temperature and humidity curves for the TSPA-95 83 MTU/acre, low infiltration case without backfill (Ref. 28, Fig. 4.2-8) were used. Humid-air corrosion was assumed to initiate when the relative humidity was greater than $70 \%$ (middle of the TSPA-95 range of $65-75 \%),{ }^{[28, \text { p. } 5-23]}$ and aqueous corrosion was assumed to initiate when the relative humidity was greater then $90 \%$ (middle of the TSPA-95 range of $85-95 \%$ ), ${ }^{[28, ~ p . ~ 5-23] ~}$ and the temperature was less than $100^{\circ} \mathrm{C}$. The outer barrier thickness was determined in two-year time steps using Mathcad+ v5.0. At time step $t_{i}$, the outer barrier thickness remaining is given by:

$$
L_{i}=L_{i-1}-\frac{d D_{g}\left(t_{i}-t_{0}, R H_{i}, T_{i}\right)}{d t}\left(t_{i}-t_{i-1}\right)
$$

Equation 3.6-3

$$
\begin{aligned}
& \text { Where: } \\
& \begin{array}{ll}
i & \text { indicates time step } \\
t & =\text { outer barrier thickness }(\mu \mathrm{m}) \\
t_{0} & =\text { time since emplacement (years) } \\
R H & =\text { average relative humidity for the time step } \\
T & =\text { average temperature for the time step } \\
D_{g} & \text { is either Equation } 3.6-1 \text { or } 3.6-2 \text { as indicated by the relative humidity } \\
& \text { and temperature rules discussed above. }
\end{array}
\end{aligned}
$$

The estimation is detailed in Attachment II of Ref. 31 and the results are shown in Figure 3.6-1. 


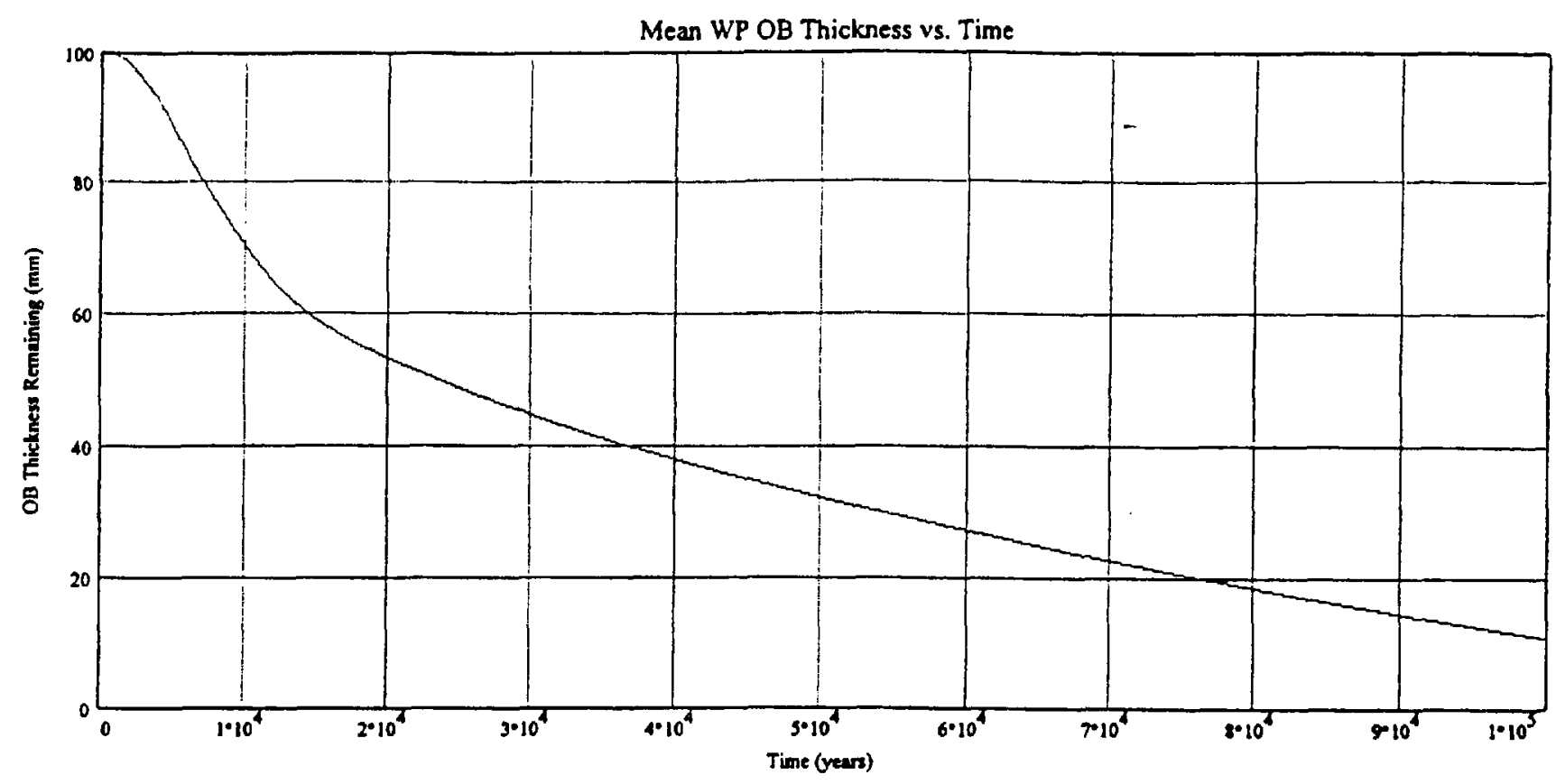

Figure 3.6-1. Outer Barrier Thickness vs. Time

\section{Inner Barrier Degradation}

The waste package inner barrier is made of corrosion resistant material (Alloy 625) which corrodes primarily by pitting. Pitting corrosion affects the structural integrity of the inner barrier in a manner which is proportional to the pitted area multiplied by the average pit depth and divided by the total thickness of the inner barrier. This combined parameter was estimated as a function of time by the following methodology in Ref. 31 .

- The fraction of the inner barrier exposed to aqueous attack at time $t$ is measured by the product of the fraction of the outer barrier surface which is covered by pits $(0.1$ corresponding to the highest most conservative number of pits, based on 10 pits, each 1 $\mathrm{mm}^{2}$, per $\left.\mathrm{cm}^{2}\right)^{[28, p .5 .24]}$ multiplied by the fraction of pits which have penetrated through the entire outer barrier (as a function of time).

$$
\text { Inner barrier exposed fraction }=0.1[1-F(100,4 \mu(t), \sigma(t))]
$$

where $F$ is the cumulative distribution function of the normal distribution with the arguments representing, respectively, the total thickness to be penetrated, the mean penetration depth for a pit, and the standard deviation of that distribution. The particular values to be used are as follows: $\mu(t)$ is the time dependent mean corrosion depth of the outer barrier caused by general corrosion, as computed by the above methodology; the factor of 4 is applied to account for the acceleration of pitting corrosion compared with general corrosion, $\sigma(\mathrm{t})$ is the time dependent standard deviation which is taken to be $90 \%$ of the 
mean, $4 \mu(t)$, which is approximately consistent with the covariance matrices given in Ref. 28 for the parameters of the formulas for the outer barrier corrosion depth used above. The details of this study are given in Attachment III of Ref. 31, where it is seen that the fraction is completely insignificant (less than $10^{-8}$ ) before 5,000 years and is only 0.08 after 100,000 years.

- The average inner barrier pit penetration at time $t_{i}$ is the sum of all the penetrations from earlier time steps, $t_{j}$, multiplied by the fraction of surface area which just became exposed at that earlier time step (the difference between the inner barrier exposed fractions computed from Equation 3.6-4 at times $t_{j}$ and $t_{-1}$ ). For each time step the average penetration is computed by multiplying the penetration rate,

$$
R_{p}=\exp (50.37-19656 / T),
$$

Equation 3.6-5

(taken from Ref. 28, p. 5-17), by the time step length $\left(t_{j}-t_{j-1}\right)$, which is taken to be 1000 years for the numerical estimations described in Attachment III of Ref. 31. These estimations show that because of the decreasing temperature with time, $R_{p}$ decreases very rapidly with time, falling below $0.001 \mathrm{~mm} / \mathrm{yr}$ by 17,000 years and thereafter becoming insignificant.

The net result of the fact that the exposed inner barrier surface area does not become significant until after 5000 years and the rapid decrease of $R_{p}$ combine to give only a few years of significant increase in effective thinning, which reaches a fraction of 0.00009 at 12,000 years and is no higher than 0.00011 at 100,000 years. The effective thinning of the inner barrier with respect to time is listed in Table 3.6-1.

Table 3.6-1. Inner Barrier Thickness with Respect to Time

\begin{tabular}{||c|c|c|c|c||}
\hline $\begin{array}{c}\text { Time } \\
\text { (years) }\end{array}$ & $\begin{array}{c}\text { Original Inner } \\
\text { Barrier Thickness } \\
(\mathrm{mm})\end{array}$ & Corrosion Fraction & $\begin{array}{c}\text { Thinning } \\
(\mathrm{mm})\end{array}$ & $\begin{array}{c}\text { Thickness } \\
\text { Remaining } \\
(\mathrm{mm})\end{array}$ \\
\hline 5,000 & 20 & 0 & 0 & 20 \\
\hline 10,000 & 20 & 0.000077 & 0.00154 & 19.99846 \\
\hline 12,000 & 20 & 0.000090 & 0.00180 & 19.99820 \\
\hline 20,000 & 20 & 0.000097 & 0.00194 & 19.99806 \\
\hline 50,000 & 20 & 0.000103 & 0.00206 & 19.99794 \\
\hline 100,000 & 20 & 0.000110 & 0.00220 & 19.99780 \\
\hline
\end{tabular}

Based on the data in Table 3.6-1, it is determined that it will be well over 100,000 years before the inner barrier has thinned to the critical thicknesses determined for static loads, $6.5 \mathrm{~mm}$ without backfill present and $9.5 \mathrm{~mm}$ with backfill present. Thus, the repository will be well into the isolation phase before static loads on the WP result in barrier failure. 
Using Figure 3.6-1, Table 3.6-2 has been generated, relating critical rock masses with the times that the barriers will have thinned to those dimensions.

Table 3.6-2. Critical Rock Mass With Respect to Time

\begin{tabular}{||l|c|c|}
\hline Degradation Level & Time (years) & Critical Rock Mass (kg) \\
\hline $0 \%$ Outer Barrier Degradation & 0 & 8000 \\
\hline $50 \%$ Outer Barrier Degradation & 23,000 & 2500 \\
\hline $75 \%$ Outer Barrier Degradation & 54,000 & 1000 \\
\hline $100 \%$ Outer Barrier Degradation & $>100,000$ & 350 \\
\hline
\end{tabular}

Thus, it is evident that in the operations and substantially complete containment phases of the repository, the critical rock mass will remain around $8000 \mathrm{~kg}$. Later, in the isolation phase of the repository, the critical rock mass will decrease.

\section{Basket Component Degradation}

\section{$\underline{\text { Side Guides }}$}

The AUCF WP side guides are fabricated from $10 \mathrm{~mm}$ thick carbon steel plates. During WP closure, the interior of the WP will be inerted with a He/Ar fill gas, so prior to WP breach, no degradation of the side guides or other internal components is expected. To estimate the thickness of the side guides as a function of time following WP breach, the carbon steel general corrosion models in equations 3.6-1 and 3.6-2 are used.

The estimation was performed using Mathcad+ v5.0 in a manner similar to that as performed previously in Section 3.6 for the outer barrier. The primary differences involve: 1) use of a 0.5 year time step, 2) multiplying the rate at each time step by two because both sides are exposed, and 3) exposure starts at the time of first pit penetration of the inner barrier.

For this estimate, the WP surface temperature and humidity curves for the TSPA-95 83 MTU/acre, low infiltration cases with and without backfill were used. ${ }^{[28, \text { Fig. } 4.2-8]}$ The side guide surface temperature and relative humidity were assumed to be the same as the WP surface temperature for the time frame being considered. Side guide degradation was initiated at the time of WP breach. For each case, no-backfill and backfill, five WP breach times were used. These times were read from Fig. 5.7-3a of Ref. 28 for the no-backfill case and Fig. 5.7-5a of Ref. 28 for the backfill case. These times correspond to the time of first WP breach, the median WP breach time, and the times when $70 \%, 80 \%$, and $90 \%$ of the WPs had breached. The breach times used here are the times of first pit penetration of both containment barriers. These times are not the times of barrier failure due to static loading previously determined in Section 3.6. In addition, for the backfill case, the WP failure distribution did not reach $90 \%$ before 100,000 years, so 50,000 years was assumed for purposes of estimating the side guide failure time because the temperature and relative humidity appear to have stabilized by this time. The side guide thickness at times following WP breach was 
determined in half-year time steps using Mathcad+ v5.0. At time step $t_{i}$, the side guide thickness remaining is given by the following modified version of Equation 3.6-3

$$
L_{i}=L_{i-1}-2 \frac{d D_{g}\left(t_{i}-t_{0}, R H_{i}, T_{i}\right)}{d t}\left(t_{i}-t_{i-1}\right)
$$

where the rate is multiplied by two because both sides of the side guide are exposed. The results are presented in the table below. The estimation is detailed in Attachment I of Ref. 31.

Table 3.6-3. Side guide thickness as a function of WP breach time and time since WP breach for the TSPA-95 83 MTU/acre, low infiltration, no-backfill case

\begin{tabular}{|c|c|c|c|c|c|c|c|c|c|}
\hline \multicolumn{2}{|c|}{$\begin{array}{c}\text { WP breach at } 2200 \\
\text { years } \\
(0.003 \% \text { WPs } \\
\text { breached })\end{array}$} & \multicolumn{2}{|c|}{$\begin{array}{c}\text { WP breach at } 3200 \\
\text { years } \\
\text { (50\% WPs breached) }\end{array}$} & \multicolumn{2}{|c|}{$\begin{array}{c}\text { WP breach at } 4000 \\
\text { years } \\
\text { (70\% WPs } \\
\text { breached) }\end{array}$} & \multicolumn{2}{|c|}{$\begin{array}{c}\text { WP breach at } 4600 \\
\text { years } \\
\text { (80\% WPs breached) }\end{array}$} & \multicolumn{2}{|c|}{$\begin{array}{c}\text { WP breach at } 10000 \\
\text { years } \\
\text { (90\% WPs breached) }\end{array}$} \\
\hline $\begin{array}{l}\text { Time } \\
\text { Since } \\
\text { WP } \\
\text { Breach } \\
\text { (years) }\end{array}$ & $\begin{array}{c}\text { Side } \\
\text { Guide } \\
\text { thickness } \\
\text { (mm) }\end{array}$ & $\begin{array}{c}\text { Time } \\
\text { Since } \\
\text { WP } \\
\text { Breach } \\
\text { (years) }\end{array}$ & $\begin{array}{c}\text { Side } \\
\text { Guide } \\
\text { thickness } \\
(\mathrm{mm})\end{array}$ & $\begin{array}{c}\text { Time } \\
\text { Since } \\
\text { WP } \\
\text { Breach } \\
\text { (years) }\end{array}$ & $\begin{array}{l}\text { Side } \\
\text { Guide } \\
\text { thickness } \\
(\mathrm{mm})\end{array}$ & $\begin{array}{c}\text { Time } \\
\text { Since } \\
\text { WP } \\
\text { Breach } \\
\text { (years) }\end{array}$ & $\begin{array}{l}\text { Side } \\
\text { Guide } \\
\text { thickness } \\
(\mathrm{mm})\end{array}$ & $\begin{array}{c}\text { Time } \\
\text { Since } \\
\text { WP } \\
\text { Breach } \\
\text { (years) }\end{array}$ & $\begin{array}{l}\text { Side } \\
\text { Guide } \\
\text { thickness } \\
(\mathrm{mm})\end{array}$ \\
\hline 0 & 10 & 0 & 10 & 0 & 10 & 0 & 10 & 0 & 10 \\
\hline 100 & 6.202 & 100 & 6.617 & 25 & 6.425 & 25 & 5.892 & 25 & 5.793 \\
\hline 200 & 4.113 & 200 & 4.805 & 50 & 4.677 & 50 & 3.889 & 50 & 3.754 \\
\hline 300 & 2.401 & 300 & 3.384 & 75 & 3.299 & 75 & 2.317 & 75 & 2.162 \\
\hline 400 & 1.195 & 400 & 2.138 & 100 & 2.117 & 100 & 0.971 & 100 & 0.806 \\
\hline 500 & 0.211 & 500 & 1.006 & 125 & 1.062 & 125 & 0 & 125 & 0 \\
\hline 600 & 0 & 600 & 0 & 150 & 0.093 & 150 & 0 & 150 & 0 \\
\hline
\end{tabular}


Table 3.6-4. Side guide thickness as a function of WP breach time and time since WP breach for the TSPA-95 83 MTU/acre, low infiltration, backfill case

\begin{tabular}{|c|c|c|c|c|c|c|c|c|c|}
\hline \multicolumn{2}{|c|}{$\begin{array}{c}\text { WP breach at } 2300 \\
\text { years } \\
\text { (.003\% WPs failed) }\end{array}$} & \multicolumn{2}{|c|}{$\begin{array}{c}\text { WP breach at } 4000 \\
\text { years } \\
\text { (50\% WPs failed) }\end{array}$} & \multicolumn{2}{|c|}{$\begin{array}{c}\text { WP breach at } 5700 \\
\text { years } \\
\text { (70\% WPs failed) }\end{array}$} & \multicolumn{2}{|c|}{$\begin{array}{c}\text { WP breach at } 12000 \\
\text { years } \\
\text { (80\% WPs failed) }\end{array}$} & \multicolumn{2}{|c|}{$\begin{array}{c}\text { WP breach at } 50000 \\
\text { years } \\
\text { (>80\% WPs failed) }\end{array}$} \\
\hline $\begin{array}{l}\text { Time } \\
\text { Since } \\
\text { WP } \\
\text { Breach } \\
\text { (years) }\end{array}$ & $\begin{array}{c}\text { Side } \\
\text { Guide } \\
\text { thickness } \\
(\mathrm{mm})\end{array}$ & $\begin{array}{l}\text { Time } \\
\text { Since } \\
\text { WP } \\
\text { Breach } \\
\text { (years) }\end{array}$ & $\begin{array}{l}\text { Side } \\
\text { Guide } \\
\text { thickness } \\
(\mathrm{mm})\end{array}$ & $\begin{array}{l}\text { Time } \\
\text { Since } \\
\text { WP } \\
\text { Breach } \\
\text { (years) }\end{array}$ & $\begin{array}{c}\text { Side } \\
\text { Guide } \\
\text { thickness } \\
(\mathrm{mm})\end{array}$ & $\begin{array}{c}\text { Time } \\
\text { Since } \\
\text { WP } \\
\text { Breach } \\
\text { (years) }\end{array}$ & $\begin{array}{c}\text { Side } \\
\text { Guide } \\
\text { thicknes } \\
\mathrm{s}(\mathrm{mm})\end{array}$ & $\begin{array}{l}\text { Time } \\
\text { Since } \\
\text { WP } \\
\text { Breach } \\
\text { (years) }\end{array}$ & $\begin{array}{c}\text { Side } \\
\text { Guide } \\
\text { thickness } \\
(\mathrm{mm})\end{array}$ \\
\hline 0 & 10 & 0 & 10 & 0 & 10 & 0 & 10 & 0 & 10 \\
\hline 100 & 8 & 100 & 7.082 & 25 & 5.471 & 25 & 6.185 & 100 & 6.478 \\
\hline 200 & 6.686 & 200 & 5.504 & 50 & 3.271 & 50 & 4.338 & 200 & 4.842 \\
\hline 300 & 5.459 & 300 & 4.203 & 75 & 1.549 & 75 & 2.898 & 300 & 3.564 \\
\hline 400 & 4.367 & 400 & 3.056 & 100 & 0.078 & 100 & 1.672 & 400 & 2.476 \\
\hline 500 & 3.414 & 500 & 2.017 & 125 & 0 & 125 & 0.585 & 500 & 1.51 \\
\hline 600 & 2.572 & 600 & 1.056 & 150 & 0 & 150 & 0 & 600 & 0.631 \\
\hline
\end{tabular}

As calculated in Section 3.2.2.1, the side guide will fail by bending at a thickness of $2.9 \mathrm{~mm}$ if there is no backfill, and at a thickness of $3.8 \mathrm{~mm}$ if there is backfill present. The seismic analysis presented in Section 3.4 indicated failure in the side guide after thinning to $5 \mathrm{~mm}$. Using Tables 3.6-3 and 3.6-4, the times at which the side guides fail can be determined for the static loading (no backfill and backfill cases, respectively) and the seismic loading. These failure times are provided in Table 3.6-5. The more rapid side guide corrosion at higher barrier breach times are a result of the switch from humid air to aqueous corrosion when the relative humidity exceeds $90 \%$ and the surface temperature is still above $30^{\circ} \mathrm{C}$. 
Table 3.6-5. Failure Times for Side Guides

\begin{tabular}{|c|c|c|c|}
\hline Loading Conditions & $\begin{array}{l}\text { Critical Thickness } \\
(\mathrm{mm})\end{array}$ & $\begin{array}{c}\text { Barrier Breach Time } \\
\text { (years) }\end{array}$ & $\begin{array}{c}\text { Side Guide Failure } \\
\text { Time Following } \\
\text { Penetration of } \\
\text { Barriers (years) }\end{array}$ \\
\hline \multirow{5}{*}{ Static, No Backfill } & 2.9 & 2200 & 270 \\
\hline & 2.9 & 3200 & 340 \\
\hline & 2.9 & 4000 & 84 \\
\hline & 2.9 & 4600 & 66 \\
\hline & 2.9 & 10000 & 63 \\
\hline \multirow{5}{*}{ Static, Backfill } & $3.8(2.9)^{*}$ & 2300 & $460(560)^{*}$ \\
\hline & $3.8(2.9)^{*}$ & 4000 & $330(420)^{*}$ \\
\hline & $3.8(2.9)^{*}$ & 5700 & $44(55)^{*}$ \\
\hline & $3.8(2.9)^{*}$ & 12,000 & $59(75)^{*}$ \\
\hline & $3.8(2.9)^{*}$ & 50,000 & $280(360)^{*}$ \\
\hline \multirow{5}{*}{ Seismic, Backfill } & 5 & 2300 & 340 \\
\hline & 5 & 4000 & 238 \\
\hline & 5 & 5700 & 30 \\
\hline & 5 & 12,000 & 41 \\
\hline & 5 & 50,000 & 189 \\
\hline
\end{tabular}

*Barrier failure times indicate that the barriers will not fail under static loads within the first 100,000 years. Therefore, the loads on the side guide are more likely to be those calculated for the no backfill case even if backfill is present. The values given in parentheses are the critical side guide thickness under the no backfill load and the failure time with backfill present.

\section{Criticality Control Plates}

The AUCF WP criticality control plates are fabricated from $7 \mathrm{~mm}$ thick borated Type $316 \mathrm{~L}$ stainless steel plates (316B6A), Table 3.1-1. Since long-term corrosion testing of this material in repository type environments is just beginning, specific corrosion models are not yet available. However, a preliminary evaluation can be made by using previous data collected for 316 stainless steels (Ref. 30 ), and scoping corrosion tests which compared borated and unborated stainless steels (Ref. 29). For J-13 well water in the temperature range expected after WP breach for the 83 MTU/acre cases, Reference 30 found that the general corrosion rate of 316L stainless steel ranged from $0.037 \mu \mathrm{m} / \mathrm{yr}$ at $100^{\circ} \mathrm{C}$ to $0.154 \mu \mathrm{m} / \mathrm{yr}$ at $50^{\circ} \mathrm{C}$. Scoping corrosion tests (Ref. 29) of borated and unborated Type 
304L stainless steels in an extremely aggressive environment $(\mathrm{pH}=3.8)$ found that the borated stainless steel had a corrosion rate that was approximately 4 times higher than that of the unborated stainless steel. Using the above $316 \mathrm{~L}$ rates, multiplied by an adjustment factor of 4 , suggests that it will take 2,000 to 8,500 years following breach of the WP for general corrosion of both sides of the neutron absorber plates to remove the $2.5 \mathrm{~mm}$ of material that would be required for bending to occur, Section 3.2.2.2. It will take 4,000 to 17,000 years following breach of the WP for general corrosion of both sides of the neutron absorber plates to remove the $5.05 \mathrm{~mm}$ of material that would be required for buckling of the vertical plates to occur if backfill is present, and 4,300 to 18,000 years to remove the $5.36 \mathrm{~mm}$ of material that would be required for buckling if backfill is not present, Section 3.2.2.2. These failure times are tabulated in Table 3.6-3.

Table 3.6-6. Criticality Control Plate Times to Failure

\begin{tabular}{||c|c|c||}
\hline Failure Mode & Critical Corrosion Depth & $\begin{array}{c}\text { Time of Critical Corrosion } \\
\text { Depth Following Breach of } \\
\text { Barriers }\end{array}$ \\
\hline Buckling without Backfill & $5.36 \mathrm{~mm}$ & $4,300-18,000$ years \\
\hline Buckling with Backfill & $5.05 \mathrm{~mm}$ & $4,000-17,000$ years \\
\hline Bending & $2.5 \mathrm{~mm}$ & $2,000-8,500$ years \\
\hline
\end{tabular}




\subsection{Summary of Results}

\section{Static Analyses of Barriers}

Static analyses of the waste package barriers were performed with and without structural support from the basket assembly. With structural support from the basket assembly, inner barrier failure was not observed until the inner barrier had thinned to only a few millimeters and basket thinning had begun. Levels of basket degradation required to cause failure were dependent on the remaining thickness of inner barrier, whether on not backfill was present, and whether of not the mass difference between degradation products and original materials was modeled. When no structural credit is taken for the basket, inner barrier failure occurred at much lower levels of inner barrier thinning. These results are all summarized in Table 3.7-1. The condition which produced the earliest barrier failure was analyzing the barrier with backfill present and no structural support from the basket components. Even these loading conditions did not produce barrier failure due to static loading until well after 100,000 years. 
Table 3.7-1. Summary of Results, Barrier Static Analyses

\begin{tabular}{|c|c|c|c|c|}
\hline $\begin{array}{c}\text { Structural } \\
\text { Support } \\
\text { from } \\
\text { Basket }\end{array}$ & Backfill & $\begin{array}{c}\text { Increased } \\
\text { Mass of } \\
\text { Degradation } \\
\text { Products }\end{array}$ & $\begin{array}{l}\text { Component Thinning } \\
\text { Required for Failure }\end{array}$ & $\begin{array}{l}\text { Material Thickness } \\
\text {-Remaining at Failure }\end{array}$ \\
\hline \multirow{8}{*}{ Yes } & \multirow{4}{*}{ No } & \multirow{2}{*}{ No } & $\begin{array}{l}100 \mathrm{~mm} \text { Outer Barrier } \\
18 \mathrm{~mm} \text { Inner Barrier } \\
5 \mathrm{~mm} \text { Tubes } \\
8.4 \mathrm{~mm} \text { Guides } \\
3.4 \mathrm{~mm} \text { Criticality Control Plates }\end{array}$ & $\begin{array}{l}0 \mathrm{~mm} \text { Outer Barrier } \\
2 \mathrm{~mm} \text { Inner Barrier } \\
0 \mathrm{~mm} \text { Tubes } \\
1.6 \mathrm{~mm} \text { Guides } \\
3.6 \mathrm{~mm} \text { Criticality Control Plates }\end{array}$ \\
\hline & & & $\begin{array}{l}100 \mathrm{~mm} \text { Outer Barrier } \\
19 \mathrm{~mm} \text { Inner Barrier } \\
4.2 \mathrm{~mm} \text { Tubes } \\
4.2 \mathrm{~mm} \text { Guides } \\
0 \mathrm{~mm} \text { Criticality Control Plates }\end{array}$ & $\begin{array}{l}0 \mathrm{~mm} \text { Outer Barrier } \\
1 \mathrm{~mm} \text { Inner Barrier } \\
0.8 \mathrm{~mm} \text { Tubes } \\
5.8 \mathrm{~mm} \text { Guides } \\
7 \mathrm{~mm} \text { Criticality Control Plates }\end{array}$ \\
\hline & & \multirow{2}{*}{ Yes } & $\begin{array}{l}100 \mathrm{~mm} \text { Outer Barrier } \\
18 \mathrm{~mm} \text { Inner Barrier } \\
5 \mathrm{~mm} \text { Tubes } \\
7.0 \mathrm{~mm} \text { Guides } \\
2.0 \mathrm{~mm} \text { Criticality Control Plates }\end{array}$ & $\begin{array}{l}0 \mathrm{~mm} \text { Outer Barrier } \\
2 \mathrm{~mm} \text { Inner Barrier } \\
0 \mathrm{~mm} \text { Tubes } \\
\text { 3.0 mm Guides } \\
5.0 \mathrm{~mm} \text { Criticality Control Plates }\end{array}$ \\
\hline & & & $\begin{array}{l}100 \mathrm{~mm} \text { Outer Barrier } \\
19 \mathrm{~mm} \text { Inner Barrier } \\
4.1 \mathrm{~mm} \text { Tubes } \\
4.1 \mathrm{~mm} \text { Guides } \\
0 \mathrm{~mm} \text { Criticality Control Plates }\end{array}$ & $\begin{array}{l}0 \mathrm{~mm} \text { Outer Barrier } \\
1 \mathrm{~mm} \text { Inner Barrier } \\
0.9 \mathrm{~mm} \text { Tubes } \\
5.9 \mathrm{~mm} \text { Guides } \\
7 \mathrm{~mm} \text { Criticality Control Plates }\end{array}$ \\
\hline & \multirow{4}{*}{ Yes } & \multirow{2}{*}{ No } & $\begin{array}{l}100 \mathrm{~mm} \text { Outer Barrier } \\
18 \mathrm{~mm} \text { Inner Barrier } \\
5 \mathrm{~mm} \text { Tubes } \\
8.0 \mathrm{~mm} \text { Guides } \\
3.0 \mathrm{~mm} \text { Criticality Control Plates }\end{array}$ & $\begin{array}{l}0 \mathrm{~mm} \text { Outer Barrier } \\
2 \mathrm{~mm} \text { Inner Barrier } \\
0 \mathrm{~mm} \text { Tubes } \\
2.0 \mathrm{~mm} \text { Guides } \\
4.0 \mathrm{~mm} \text { Criticality Control Plates }\end{array}$ \\
\hline & & & $\begin{array}{l}100 \mathrm{~mm} \text { Outer Barrier } \\
19 \mathrm{~mm} \text { Inner Barrier } \\
4.7 \mathrm{~mm} \text { Tubes } \\
4.7 \mathrm{~mm} \text { Guides } \\
0 \mathrm{~mm} \text { Criticality Control Plates }\end{array}$ & $\begin{array}{l}0 \mathrm{~mm} \text { Outer Barrier } \\
1 \mathrm{~mm} \text { Inner Barrier } \\
0.3 \mathrm{~mm} \text { Tubes } \\
5.3 \mathrm{~mm} \text { Guides } \\
7 \mathrm{~mm} \text { Criticality Control Plates }\end{array}$ \\
\hline & & \multirow{2}{*}{ Yes } & $\begin{array}{l}100 \mathrm{~mm} \text { Outer Barrier } \\
18 \mathrm{~mm} \text { Inner Barrier } \\
5 \mathrm{~mm} \text { Tubes } \\
7.0 \mathrm{~mm} \text { Guides } \\
2.0 \mathrm{~mm} \text { Criticality Control Plates }\end{array}$ & $\begin{array}{l}0 \mathrm{~mm} \text { Outer Barrier } \\
2 \mathrm{~mm} \text { Inner Barrier } \\
0 \mathrm{~mm} \text { Tubes } \\
3.0 \mathrm{~mm} \text { Guides } \\
5.0 \mathrm{~mm} \text { Criticality Control Plates }\end{array}$ \\
\hline & & & $\begin{array}{l}100 \mathrm{~mm} \text { Outer Barrier } \\
19 \mathrm{~mm} \text { Inner Barrier } \\
4.6 \mathrm{~mm} \text { Tubes } \\
4.6 \mathrm{~mm} \text { Guides } \\
0 \mathrm{~mm} \text { Criticality Control Plates }\end{array}$ & $\begin{array}{l}0 \mathrm{~mm} \text { Outer Barrier } \\
1 \mathrm{~mm} \text { Inner Barrier } \\
0.4 \mathrm{~mm} \text { Tubes } \\
5.4 \mathrm{~mm} \text { Guides } \\
7 \mathrm{~mm} \text { Criticality Control Plates }\end{array}$ \\
\hline
\end{tabular}


Table 3.7-1. Summary of Results, Barrier Static Analyses (Continued)

\begin{tabular}{|c|c|c|c|c|}
\hline $\begin{array}{c}\text { Structural } \\
\text { Support } \\
\text { from } \\
\text { Basket }\end{array}$ & Backfill & $\begin{array}{c}\text { Increased } \\
\text { Mass of } \\
\text { Degradation } \\
\text { Products }\end{array}$ & $\begin{array}{l}\text { Component Thinning } \\
\text { Required for Failure }\end{array}$ & $\begin{array}{l}\text { Material Thickness } \\
\text { - Remaining at Failure }\end{array}$ \\
\hline \multirow{3}{*}{ No } & No & No & $\begin{array}{l}100 \mathrm{~mm} \text { Outer Barrier } \\
13.5 \mathrm{~mm} \text { Inner Barrier }\end{array}$ & $\begin{array}{l}0 \mathrm{~mm} \text { Outer Barrier } \\
6.5 \mathrm{~mm} \text { Inner Barrier }\end{array}$ \\
\hline & \multirow{2}{*}{ Yes } & No & $\begin{array}{l}100 \mathrm{~mm} \text { Outer Barrier } \\
11.2 \mathrm{~mm} \text { Inner Barrier }\end{array}$ & $\begin{array}{l}0 \mathrm{~mm} \text { Outer Barrier } \\
8.8 \mathrm{~mm} \text { Inner Barrier }\end{array}$ \\
\hline & & Yes & $\begin{array}{l}100 \mathrm{~mm} \text { Outer Barrier } \\
10.5 \mathrm{~mm} \text { Inner Barrier }\end{array}$ & $\begin{array}{l}0 \mathrm{~mm} \text { Outer Barrier } \\
9.5 \mathrm{~mm} \text { Inner Barrier }\end{array}$ \\
\hline
\end{tabular}

\section{Static Analysis of Basket Components}

Four separate components of the basket can be analyzed. However, static structural analysis of the tubes is not necessary since the criticality control plates can withstand static basket loads without support from the tubes. Static structural analysis of the corner guides is also unnecessary because they are made of the same material and have the same thickness as the side guides, but are under lower loading. Thus, the critical components of the basket for static analysis are the criticality control plates and the side guides. The results of the analyses performed on these components are presented in Table 3.7-2.

Table 3.7-2. Summary of Results, Basket Component Static Analyses

\begin{tabular}{|c|c|c|c|c|}
\hline Component & Backfill & $\begin{array}{l}\text { Increased } \\
\text { Mass of } \\
\text { Degradation } \\
\text { Products }\end{array}$ & $\begin{array}{c}\text { Thinning of } \\
\text { Component } \\
\text { Required } \\
\text { for Failure }\end{array}$ & $\begin{array}{l}\text { Thickness of } \\
\text { Component } \\
\text { Remaining } \\
\text { at Failure }\end{array}$ \\
\hline \multirow{4}{*}{ Side Guide } & \multirow{2}{*}{ No } & No & $7.2 \mathrm{~mm}$ & $2.8 \mathrm{~mm}$ \\
\hline & & Yes & $7.1 \mathrm{~mm}$ & $2.9 \mathrm{~mm}$ \\
\hline & \multirow{2}{*}{ Yes } & No & $6.6 \mathrm{~mm}$ & $3.4 \mathrm{~mm}$ \\
\hline & & Yes & $6.2 \mathrm{~mm}$ & $3.8 \mathrm{~mm}$ \\
\hline \multirow{4}{*}{$\begin{array}{l}\text { Criticality Control Plate } \\
\text { (Vertical/Buckling) }\end{array}$} & \multirow{2}{*}{ No } & No & $5.45 \mathrm{~mm}$ & $1.55 \mathrm{~mm}$ \\
\hline & & Yes & $5.36 \mathrm{~mm}$ & $1.64 \mathrm{~mm}$ \\
\hline & \multirow{2}{*}{ Yes } & No & $5.17 \mathrm{~mm}$ & $1.83 \mathrm{~mm}$ \\
\hline & & Yes & $5.05 \mathrm{~mm}$ & $1.95 \mathrm{~mm}$ \\
\hline \multirow{2}{*}{$\begin{array}{l}\text { Criticality Control Plate } \\
\text { (Horizontal/Bending) }\end{array}$} & \multirow{2}{*}{ N/A } & No & $2.7 \mathrm{~mm}$ & $4.3 \mathrm{~mm}$ \\
\hline & & Yes & $2.5 \mathrm{~mm}$ & $4.5 \mathrm{~mm}$ \\
\hline
\end{tabular}

It was determined that these levels of degradation would be reached for the side guide between 44 years and 560 years following the first pit penetration in the barriers. The time for side guide failure 
following the first pit penetration in the barriers is strongly dependent on the time at which the first pit penetration occurs. Bending of the criticality control plates can be expected to occur between 2000 and 8500 years following the first penetration of the barriers. Buckling of the criticality control plates can be expected to occur between 4000 and 18,000 years following the first penetration of the barriers.

\section{Rock Fall Analyses}

The maximum stresses from the ANSYS solution are compared to the stress allowables in order to determine the critical rock sizes for different degradation levels in the WP containment barriers. The allowable rock size and mass values are summarized in Table 3.7-3.

Table 3.7-3. Summary of Results, Rock Fall Analyses

\begin{tabular}{||l|c|c|c|c|c||}
\hline $\begin{array}{l}\text { Barrier Analysis at Different Levels } \\
\text { of Degradation }\end{array}$ & \multicolumn{5}{|c||}{ Percent Degradation } \\
\hline Outer Barrier Degradation & $0 \%$ & $50 \%$ & $75 \%$ & $100 \%$ & $100 \%$ \\
\hline Inner Barrier Degradation & $0 \%$ & $0 \%$ & $0 \%$ & $0 \%$ & $50 \%$ \\
\hline $\begin{array}{l}\text { Allowable Rock Mass that does not } \\
\text { Breach Containment Barriers (kg) }\end{array}$ & 8,000 & 2,500 & 1,000 & 350 & 50 \\
\hline $\begin{array}{l}\text { Rock Size Diameter for Allowable } \\
\text { Rock Mass Values (m) }\end{array}$ & 1.90 & 1.29 & 0.95 & 0.67 & 0.35 \\
\hline $\begin{array}{l}\text { Time to Reach Degradation Level } \\
\text { (Years) }\end{array}$ & 0 & 23,000 & 54,000 & $>100,000$ & $» 100,000$ \\
\hline
\end{tabular}

\section{Seismic Analysis}

It is determined that a degradation level of $100 \%$ in the outer barrier, $90 \%$ in the inner barrier, $100 \%$ in the tubes, $50 \%$ in the guides, and $0 \%$ in the SS-B plates will not cause failure in any component of the WP which is subjected to a seismic load of $0.66 \mathrm{~g}$ peak ground acceleration. The side guide is the WP component which is closest to failure for this degraded WP configuration with a margin of safety value of $16 \%$. The critical component in terms of degradation is the side guide. It can be expected to reach this level of degradation 30 to 340 years following the first full penetration of the barriers. The results of the fatigue analysis also show that there is no failure in the WP for a seismic input for a time duration of 50 seconds per seismic event. Thus, these degradation levels are considered to be acceptable in terms of the WP performance subjected to the previously described seismic load. 


\section{Fuel Assembly Analysis}

The dimensions of the fuel rod, guide tubes, and instrument tube are used to determine the volume per unit length of the fuel assembly. The calculations showed that the available volume is larger than the total volume of the fuel assembly in the tubes. Therefore, it is concluded that degradation products do not cause any load on the fuel assemblies.

The second calculation is performed to determine the effect of a static load on the fuel assemblies after the WP has completely degraded. A maximum bending stress of $57.2 \mathrm{MPa}$ is determined for one fuel rod. Comparing this value with an allowable bending stress of $348.2 \mathrm{MPa}$, it is concluded that the margin of safety is 5.1 and there is no failure in the fuel assembly due to a static load of a completely degraded WP. 


\subsection{Conclusions and Recommendations}

\section{Static Analyses of Barriers}

The results of static analyses of the WP barriers vary greatly depending on whether or not the basket assembly provides structural support to the barriers. When the basket assembly provides structural support, barrier stresses do not exceed allowables until the outer barrier has completely degraded and the inner barrier has thinned to one or two millimeters. Even then, barrier failure does not occur until the basket assembly begins thinning and losing strength. If the barrier is analyzed with no structural support from the basket assembly, barrier stresses reach the allowable limits sooner, but still not until the outer barrier has completely degraded and the inner barrier has thinned to less than half of its original thickness.

Manufacturing tolerances in the final design may leave gaps between the barrier and the basket assembly. With gaps between the barrier and basket, significant deformations in the barriers could occur before contact is made with the basket. Therefore, the evaluations in which the basket assembly does not provide structural support to the barriers are more realistic analyses than those in which the basket assembly provides structural support to the barrier. It is the conclusion of these analyses that barrier failures due to static loading will begin occurring when the outer barrier has completely degraded and the inner barrier has thinned to $9.5 \mathrm{~mm}$ from its original thickness of 20 $\mathrm{mm}$, a condition that will take well over 100,000 years to occur.

Additional studies which would benefit the development of the waste package and emplacement method would be an analysis of the sensitivity of waste package barrier stresses to emplacement support spacing, shape, and size.

\section{Static Analyses of Basket Components}

The results of the static analyses of the individual basket components can be used to predict the order in which failure of the basket components will occur and what basket configurations may be expected during and following basket failure.

The first component to fail will be the tubes. They are the thinnest components in the basket assembly at $5 \mathrm{~mm}$ and are made of A 516 Grade 70 carbon steel, the first material to degrade. However, the interlocking stainless steel-boron plate array in which the tubes are located is capable of maintaining the basket configuration without support from the tubes, so the tubes are not critical components of the basket assembly when the only loads are static weight.

The limiting components are the side guides on the bottom side of the WP. They are made of the same material as the tubes, but have an original thickness twice that of the tubes, $10 \mathrm{~mm}$. They are under loading from the basket components, SNF assemblies, and depending on the barrier thickness remaining, possibly barrier and backfill loads. The side guides are capable of supporting this load until nearly two thirds of the thickness is removed, a condition that will take 44 to 560 years following breach of the containment barriers. When side guide failure occurs, there will be a general downward shift of the basket assembly, allowing the array of stainless steel-boron plates and fuel to rest on the bottom of the inner barrier. 
The next failure to occur will be either in the corner guides or the stainless steel-boron plates. The changes in basket loading due to the prior side guide failure make this determination difficult. However, failure of the corner guide would have an effect similar to failure of the side guide, but with less severity because a smaller portion of the basket assembly is dependent on the corner guide for support. Therefore, the next component failure of interest is that of the stainless steel-boron plates. The analyses of the plates indicate that the bending load is more critical than the buckling load. The stainless steel-boron plates are capable of supporting the load from the peripheral SNF assemblies until one third of the material has degraded, a condition that will take between 2000 and 8500 years following breach of the containment barriers. With more than one third of the material removed, the plates will bend until they contact the fuel assembly below (the tubes have completely degraded by this time). With the plates now under a bending load of multiple fuel assemblies, it is likely that the basket will collapse.

To improve predictions on the order of basket collapse, more information on corrosion rates and interactions between basket materials, SNF, and barrier materials is required.

\section{Dynamic Analyses of Rock Falls}

In the results of the rock fall analyses, the stresses in the WP barriers are nearly equal to the allowable stresses. Thus, it is concluded that for each case analyzed, the critical rock size for which the barriers are capable of withstanding an impact during a rock fall in the emplacement drift has been determined. When there is no degradation of the barriers, the WP is capable of withstanding the fall of an $8000 \mathrm{~kg}$ rock without breaching. When half of the outer barrier is removed, about 23,000 years of degradation, the capability of the WP to withstand a rock fall is reduced to a 2500 $\mathrm{kg}$ rock. With three fourths of the outer barrier removed, 54,000 years of degradation, the critical rock size drops to $1000 \mathrm{~kg}$. When the outer barrier has completely degraded, greater than 100,000 years of degradation, the WP is still capable of withstanding the fall of a $350 \mathrm{~kg}$ rock without breaching. When half of the inner barrier is removed, much greater than 100,000 years of degradation, the critical rock size becomes small, $50 \mathrm{~kg}$.

\section{Seismic Analyses of Waste Packages}

It is observed from the results of seismic analysis that a WP with degradations of $100 \%$ in the outer barrier, $90 \%$ in the inner barrier, $100 \%$ in the tubes and $50 \%$ in the guides is still capable of withstanding a seismic load of $0.66 \mathrm{~g}$ peak ground acceleration. For this condition, the side guide is an important component. Thinning of the side guide can be expected to reach this level of degradation between 30 and 340 years following breach of the containment barriers. As it was noted in Assumption 2.3.2, the PGA value of $0.66 \mathrm{~g}$ is higher than the $0.4 \mathrm{~g}$ PGA currently specified as the design basis earthquake for the WP in CDA Assumption EBDRD 3.7.1.1.G; therefore, $0.66 \mathrm{~g}$ provides additional conservatism to this analysis. The results of fatigue analysis also show that there is no fatigue failure in the WP when this seismic load is applied for a duration of 50 seconds. Seismic failure occurred when there is 50\% degradation of the SS-B plates. Therefore, the critical level of degradation for seismic loading is bounded by these two cases. 


\section{Analysis of Loads on Spent Nuclear Fuel Assemblies}

The evaluations on the effect of degradation products on the fuel assemblies showed that degradation products do not cause loading on the fuel rods. It is also concluded from these evaluations that the static loads on an SNF assembly following complete collapse of the basket assembly will not cause rupturing of the fuel rods.

\section{Failure Through Time}

From the evaluations presented in this document, the overall waste package/engineered barrier design concepts are appropriate. The engineered barrier segment does contain the waste for a long time, but as noted earlier, the TSPA-95 models are being updated to include realistic corrosion rates and failure mechanisms. It is anticipated that as the models are refined, the time to component failure will decrease. Therefore, as the corrosion models and the waste package/engineered barrier designs mature, additional evaluations will be performed using the methodology developed in this report. 


\section{References}

1. Seismic Design Inputs for the Exploratory Studies Facility at Yucca Mountain, Document Identifier Number (DI\#): BAB000000-01717-5705-00001 REV 02, (Civilian Radioactive Waste Management System) CRWMS M\&O.

2. Waste Package Development Technical Document, DI\#: BBA000000-01717-5705-00009 REV 01, CRWMS M\&O.

3. Q-List, YMP/90-55Q, REV 03, YMP (Yucca Mountain Site Characterization Project).

4. Develop Technical Documents, DI\#: BB0000000-01717-2200-00007 REV 02, CRWMS M\&O.

5. Formal Review of Technical Documents, DI\#: BB0000000-01717-2200-00009 REV 03, CRWMS M\&O.

6. Perform Criticality, Thermal, Structural, and Shielding Analyses, DI\#: BB0000000-017172200-00025 REV 02, CRWMS M\&O.

7. Quality Assurance Requirements and Description, DOE/RW-0333P REV 05, DOE (U.S. Department of Energy).

8. Technical Document Preparation Plan (TDPP) for the Emplaced Waste Package Structural Capability Through Time Report, DI\#: BBAA00000-01717-4600-00001 REV 01, CRWMS M\&O.

9. Engineered Barrier Design Requirements Document, YMP/CM-0024 Rev. 0, ICN 1, YMP.

10. 1992 ASME Boiler and Pressure Vessel Code. Section III, Division 1, Subsection NB, American Society of Mechanical Engineers.

11. 1992 ASME Boiler and Pressure Vessel Code. Section III, Division 1, Subsection NG, American Society of Mechanical Engineers.

12. 1992 ASME Boiler and Pressure Vessel Code. Section III, Division 1, Appendices, American Society of Mechanical Engineers.

13. Controlled Design Assumptions Document, DI\#: B00000000-01717-4600-00032 REV 02, CRWMS M\&O. (TBV-221-DD)

14. Static Structural Analyses of Waste Package in Degraded States, DI\#: BBAA00000-017170200-00014 REV 00, CRWMS M\&O. 
15. Rock Size Required to Breach Barriers at Different Levels of Degradation, DI\#: BBAA00000-01717-0200-00012 REV 00, CRWMS M\&O.

16. Seismic Analysis of Waste Package at Different Levels of Degradation, DI\#: BBAA0000001717-0200-00013 REV 00, CRWMS M\&O.

17. Material of 21 PWR AUCF Waste Container, H. Wang, Interoffice Correspondence, M\&O Correspondence Number: LV.WP.HW.03/96.059, March 13, 1996, CRWMS M\&O.

18. 1992 ASME Boiler and Pressure Vessel Code, Section II, Part D, Subpart 2, American Society of Mechanical Engineers.

19. Mechanics of Materials, SI Metric Edition, F. P. Beer and E. R. Johnston Jr., McGraw-Hill Ryerson Ltd., Toronto Canada, 1987.

20. Manual of Steel Construction, Load \& Resistance Factor Design, First Edition, American Institute of Steel Construction, Inc., 1986.

21. Recommended Layout Concepts Report, DI\#: BCAA00000-01717-5705-00001 REV 00, CRWMS M\&O.

22. Emplacement Equipment/Concept Development Report, DI\#: BC0000000-01717-570500015 REV 00, CRWMS M\&O.

23. Standard Specification Pressure Vessel Plates, Carbon Steel, for Moderate and Lower Temperature Service, ASTM Designation: A 516 / A 516M - 90, American Society for Testing and Materials.

24. Standard Specification for Nickel-Chromium-Molybdenum-Columbium Alloy (UNS N06625) Plate, Sheet, and Strip, ASTM Designation: B 443 - 93, American Society for Testing and Materials.

25. Mechanical Engineering Design, First Metric Edition, J. E. Shigley, McGraw-Hill Book Company, New York, NY, 1986.

26. Dynamic Impact Effects on Spent Fuel Assemblies, Lawrence Livermore National Laboratory (LLNL), UCID-21246, October 1987.

27. Modeling of Gaseous $\mathrm{CO}_{2}$ Release from Perforations in Spent Fuel Disposal Containers, Brookhaven National Laboratory, BNL 52308, November 1991.

28. Total System Performance Assessment 1995: An Evaluation of the Potential Yucca Mountain Repository, DI\#: B00000000-01717-2200-00136, REV 01, CRWMS M\&O. 
29. Scoping Corrosion Tests on Candidate Waste Package Basket Materials for The Yucca Mountain Project, Summary Acct. OL252 AJD, R. A. Van Konynenburg and P. G. Curtis, LLNL, August 31, 1995.

30. Progress Report on the Results of Testing advanced conceptual Design Metal Barrier Materials Under Relevant Environmental Conditions For A Tuff Repository, LLNL, UCID21044, December 1987.

31. Study of the Degradation of WP Barrier and Basket Components, J. R. Massari, Interoffice Correspondence, M\&O Correspondence Number: LV.WP.JRM.06/96.142, June 14, 1996, CRWMS M\&O. 


\section{Attachments}

I-1. Waste Package Tube Design (21-PWR) Outer Barrier Preliminary Sketch.

I-2. Waste Package Tube Design (21-PWR) Outer Barrier Lid Preliminary Sketch

I-3. Waste Package Tube Design (21-PWR) Inner Barrier Preliminary Sketch

I-4. Waste Package Tube Design (21-PWR) Inner Barrier Lid Preliminary Sketch

I-5. Waste Package Tube Design (21-PWR) A-Plate Preliminary Sketch

I-6. Waste Package Tube Design (21-PWR) B-Plate Preliminary Sketch

I-7. Waste Package Tube Design (21-PWR) C-Plate Preliminary Sketch

I-8. Waste Package Tube Design (21-PWR) A-Guide Preliminary Sketch

I-9. Waste Package Tube Design (21-PWR) B-Guide Preliminary Sketch

I-10. Waste Package Tube Design (21-PWR) Corner Guide Preliminary Sketch

I-11. Waste Package Tube Design (21-PWR) Stiffener Preliminary Sketch

I-12. Waste Package Tube Design (21-PWR) Side Cover Preliminary Sketch

I-13. Waste Package Tube Design (21-PWR) Tube Preliminary Sketch

I-14. Waste Package Tube Design (21-PWR) Side Guide Weldment Preliminary Sketch 


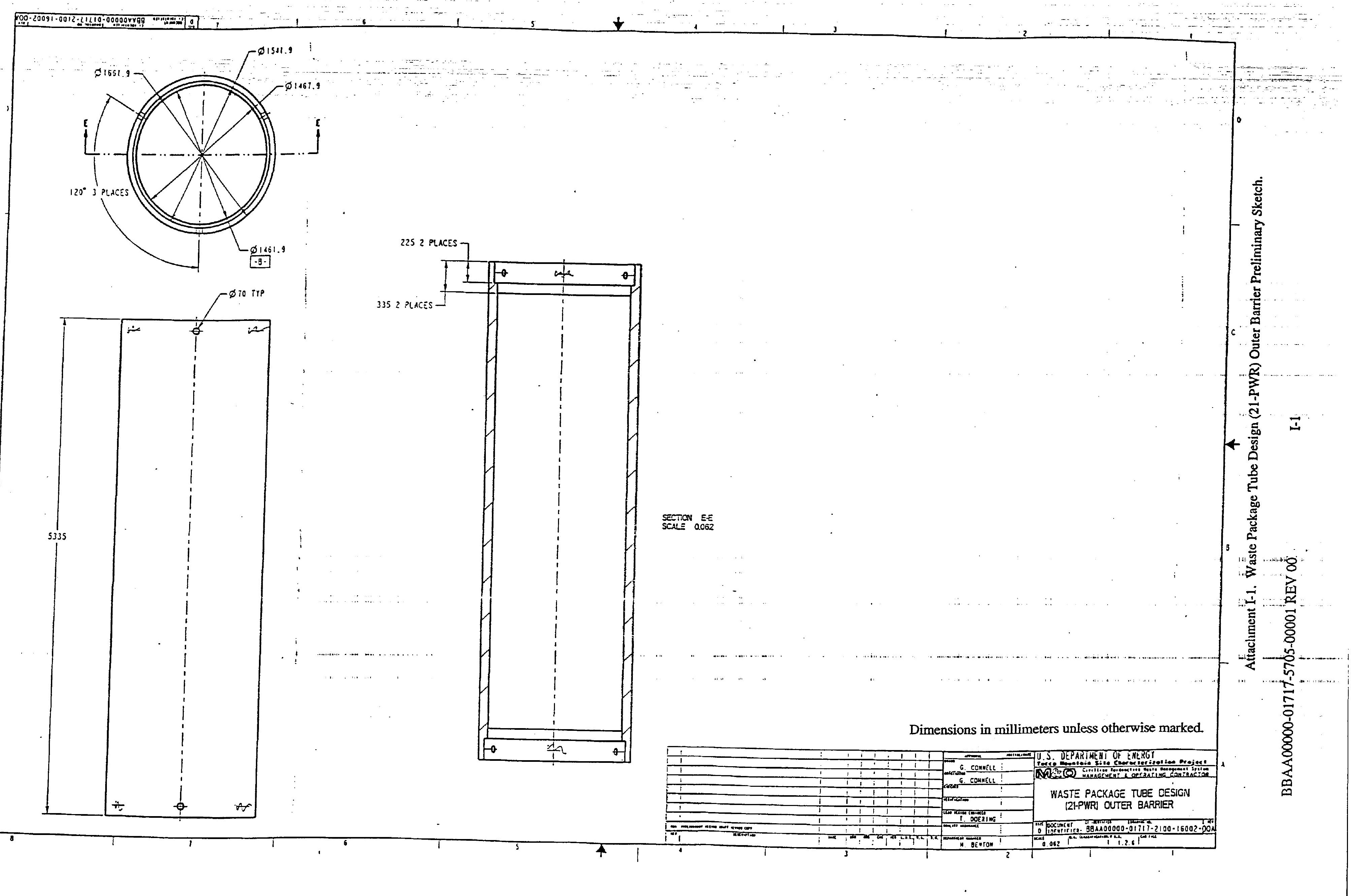




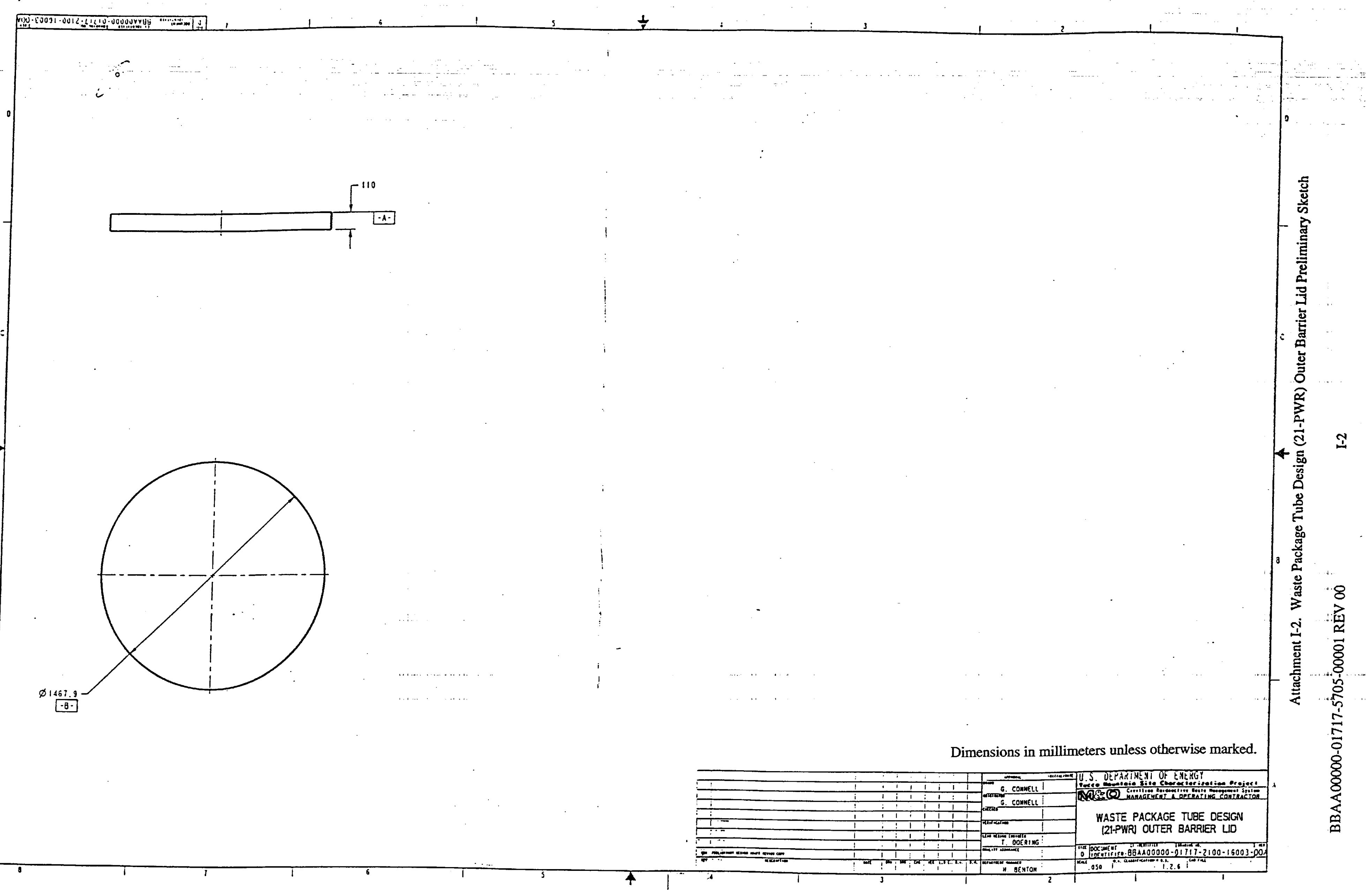




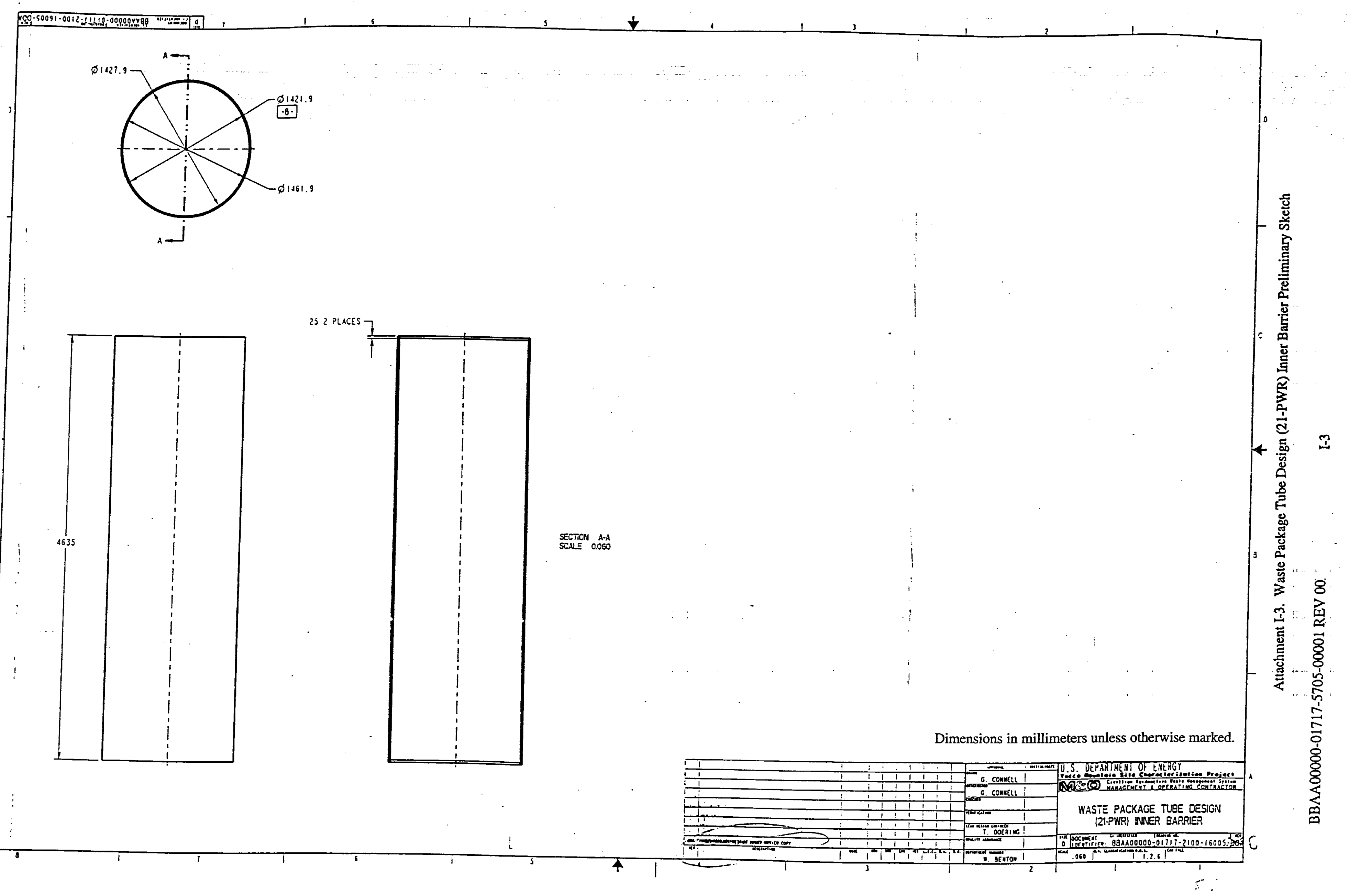




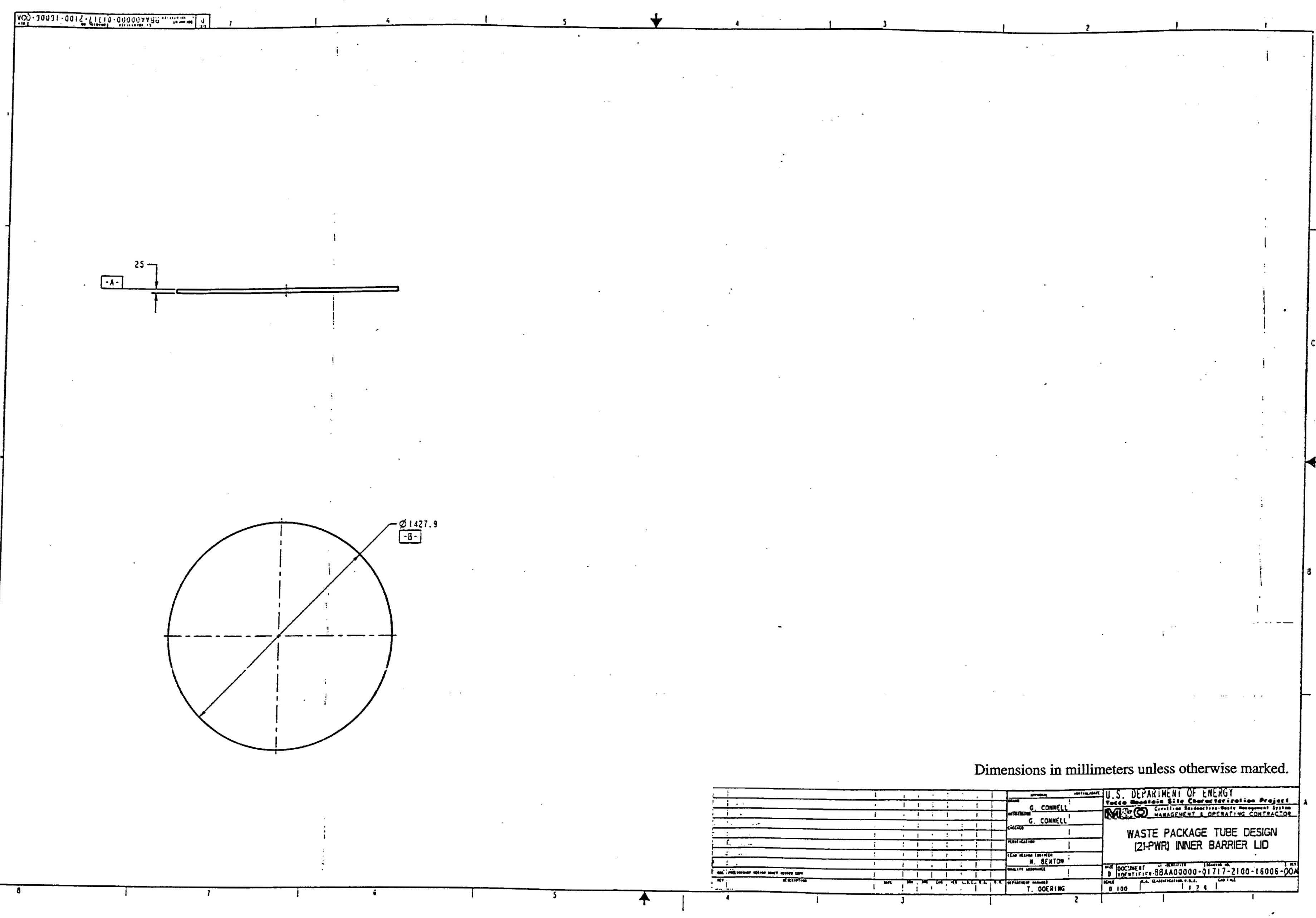




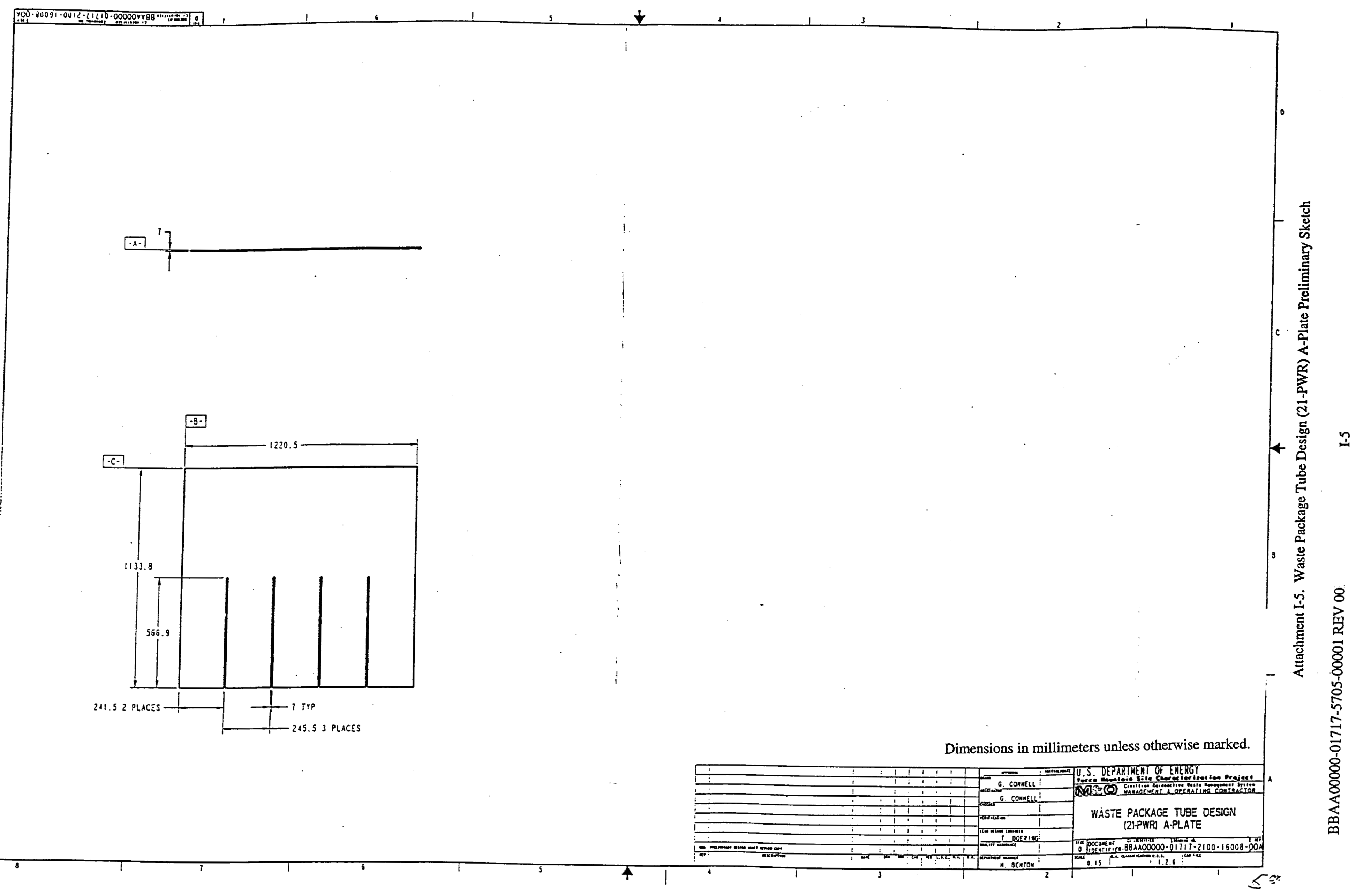




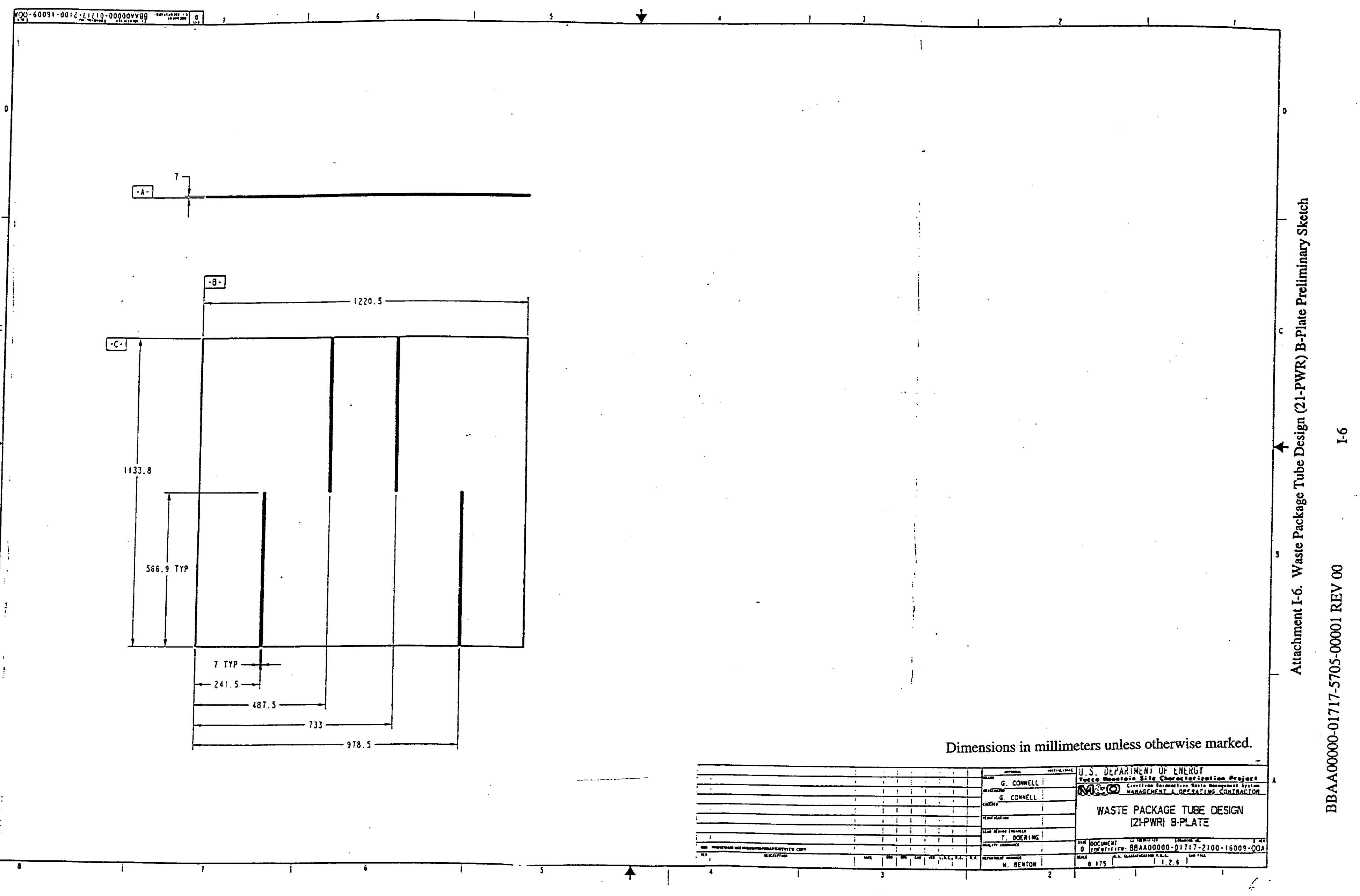



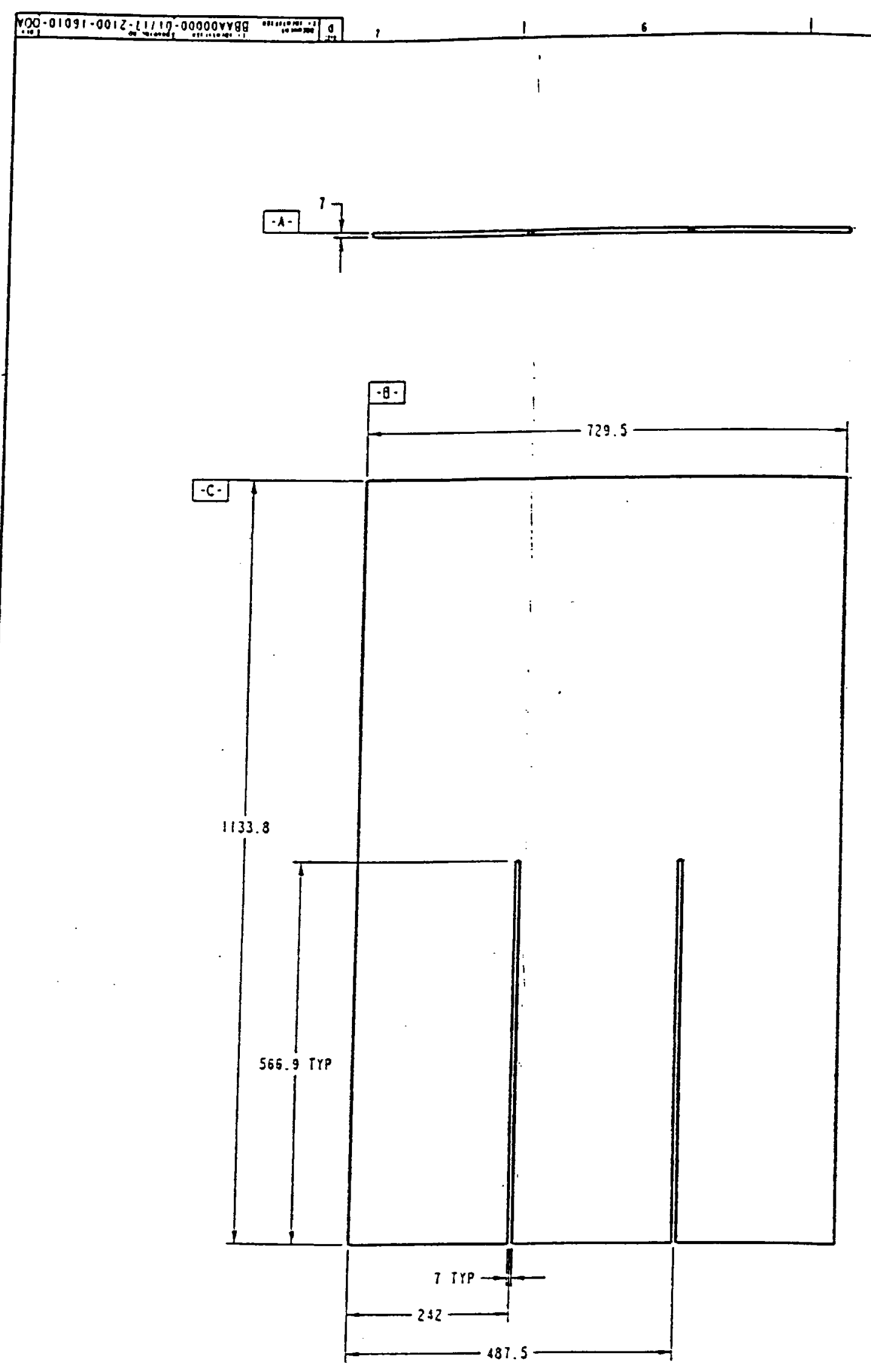

Dimensions in millimeters unless otherwise marked.

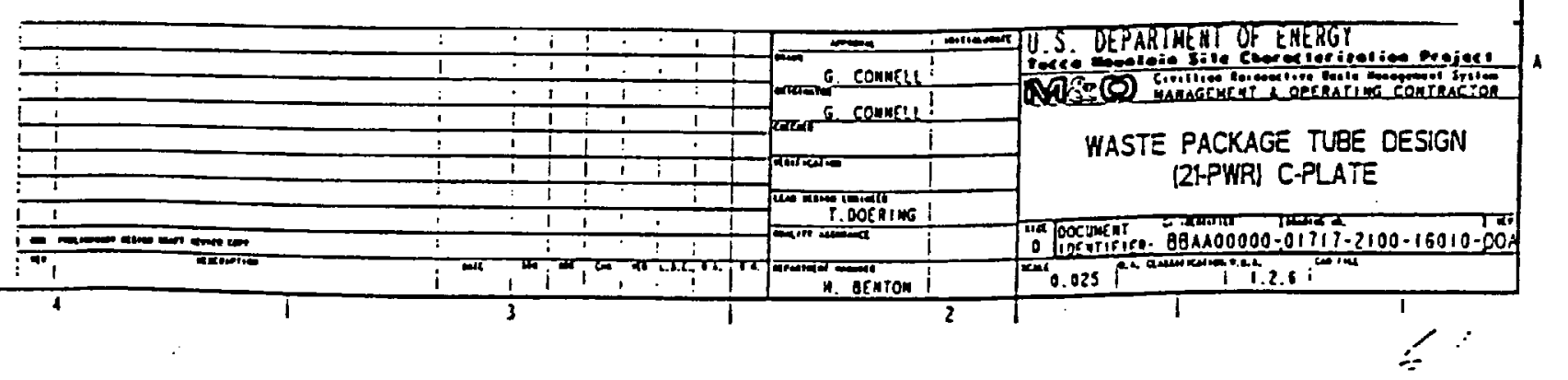




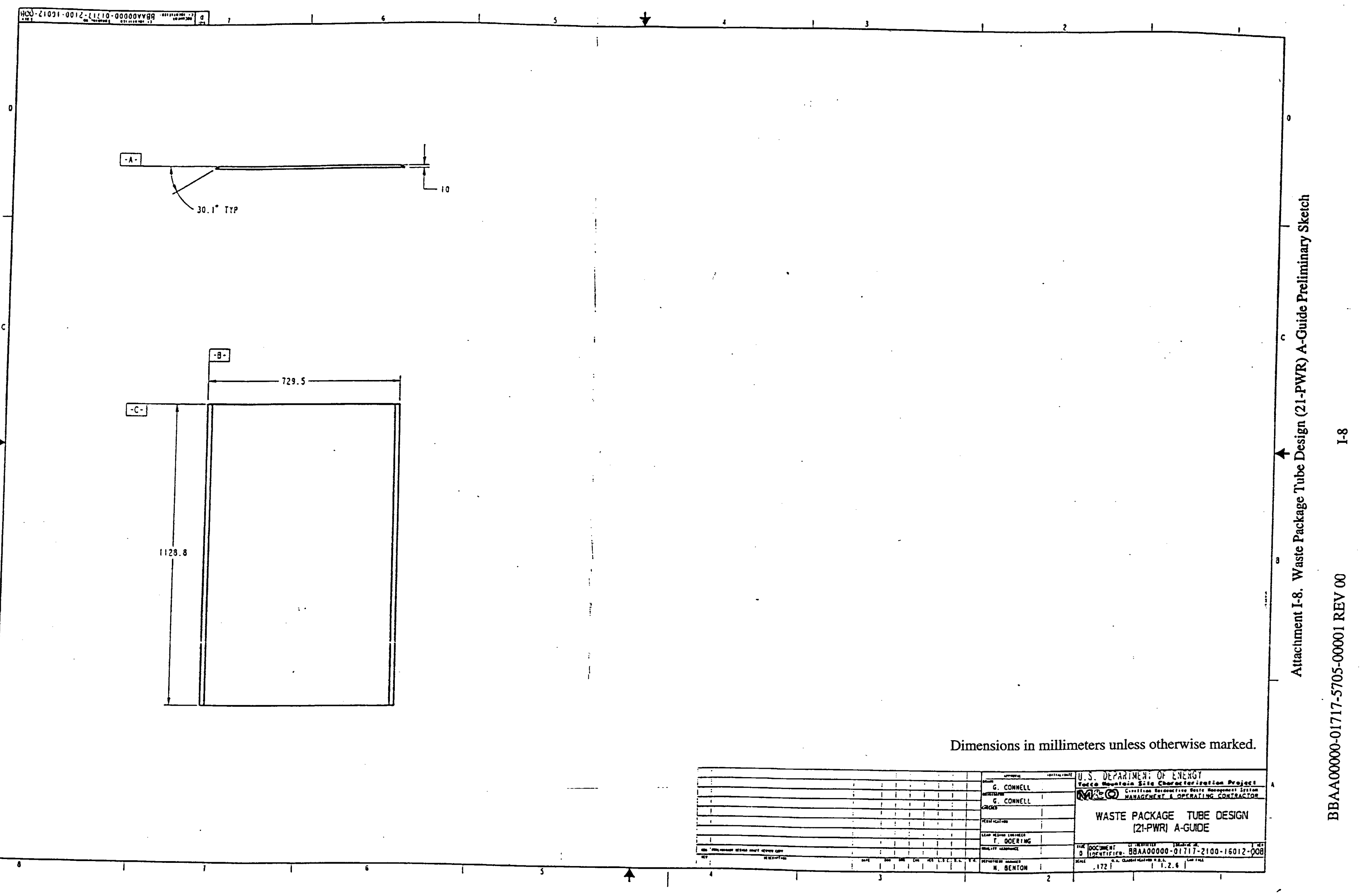




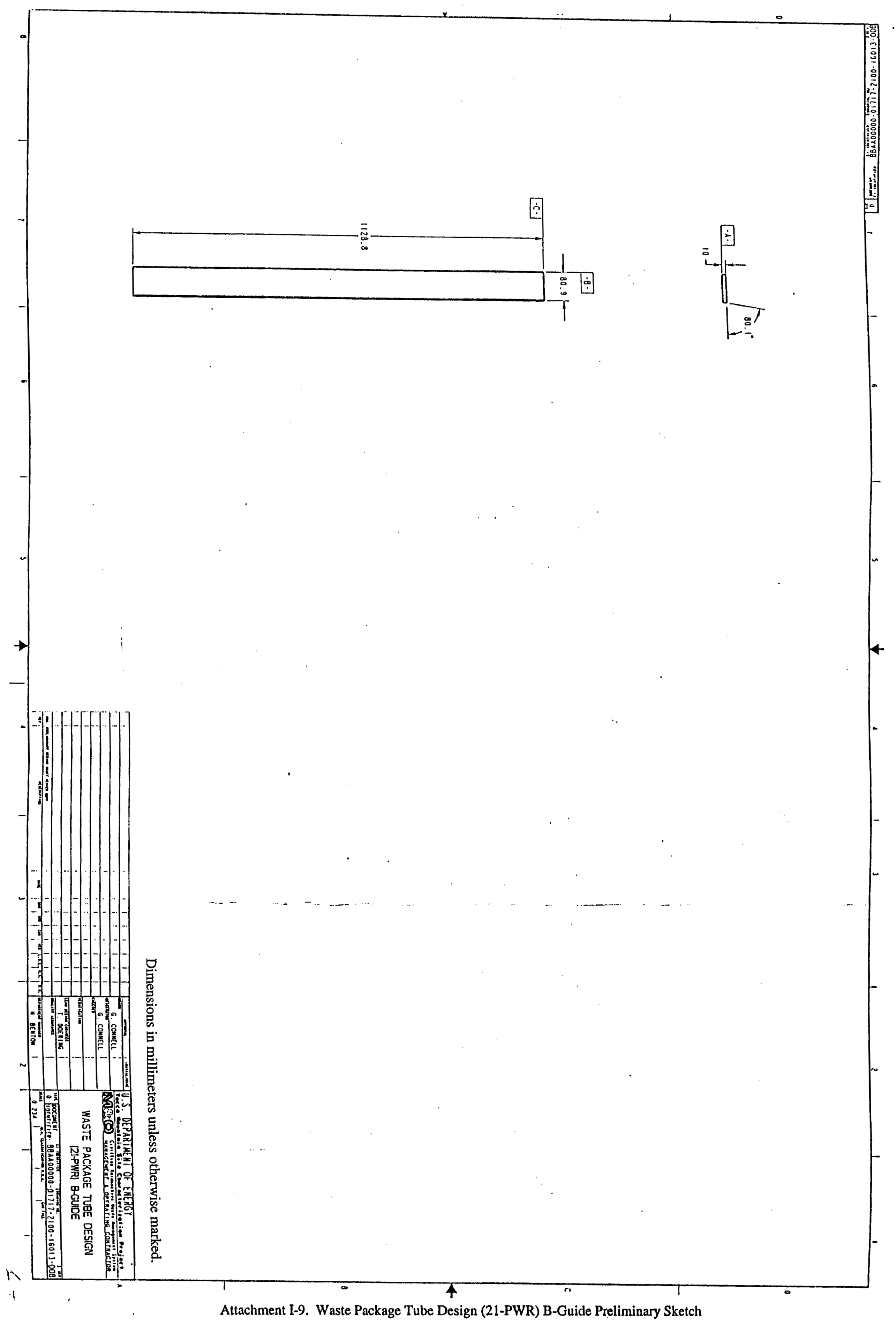




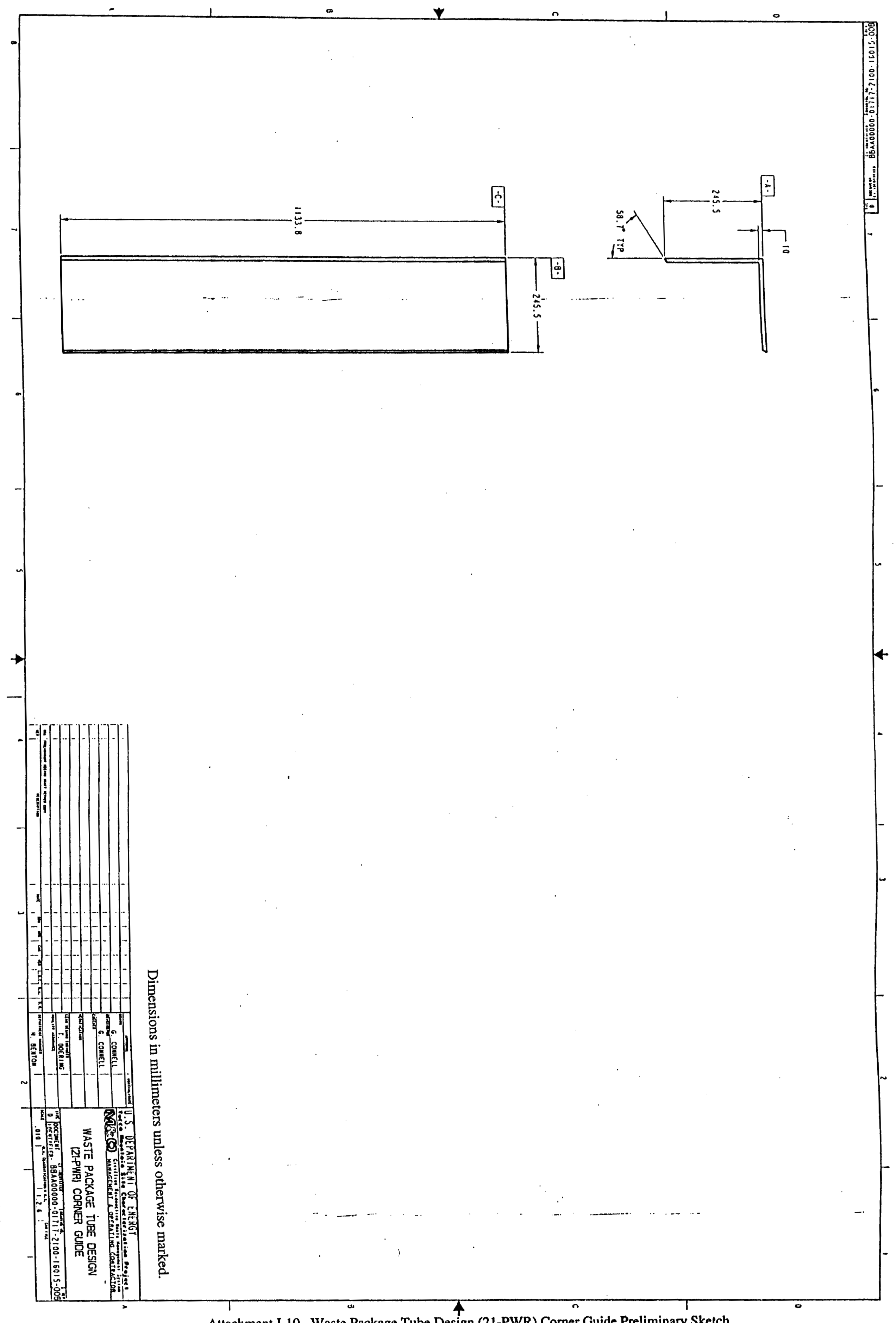

Attachment I-10. Waste Package Tube Design (21-PWR) Corner Guide Preliminary Sketch 


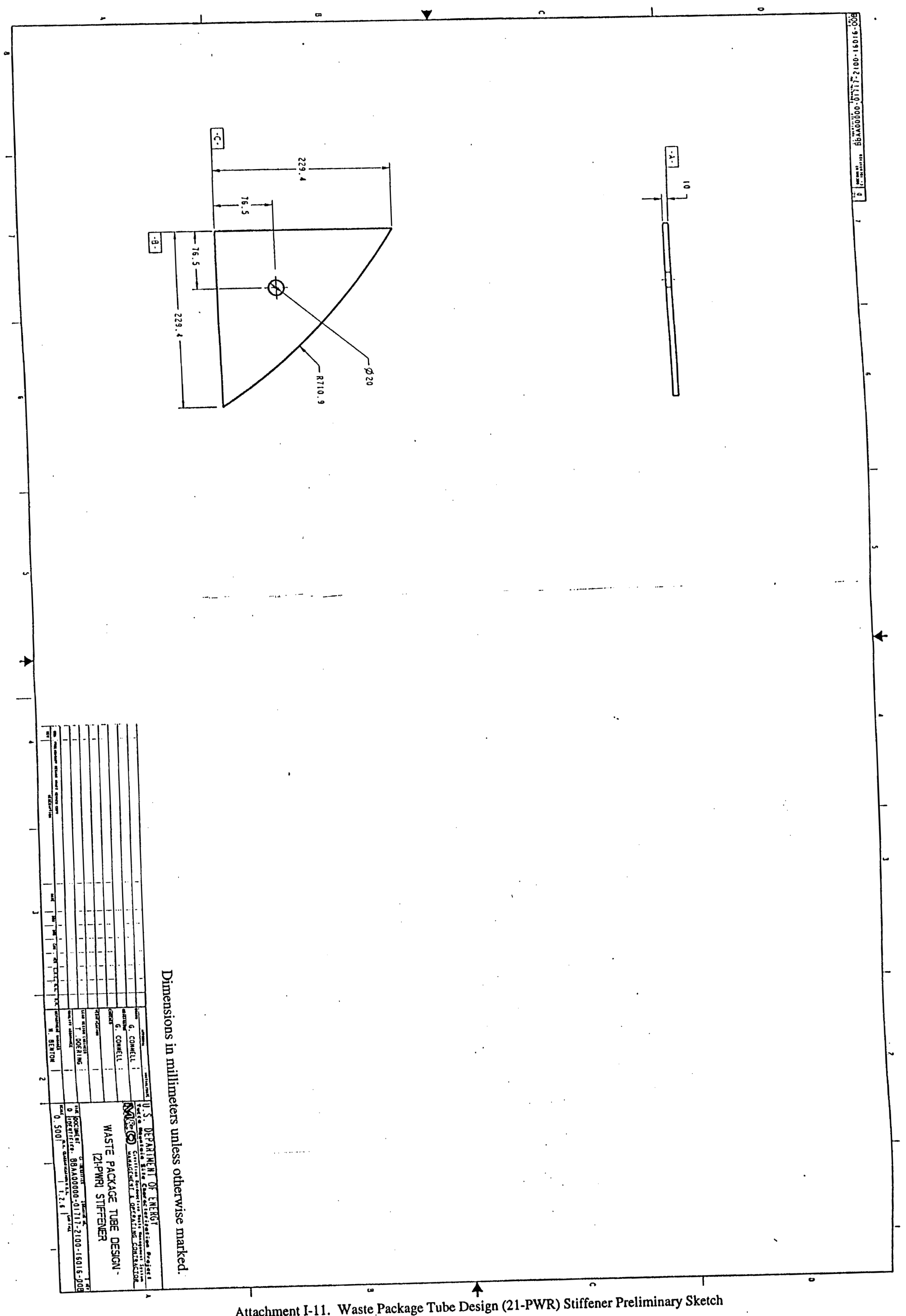




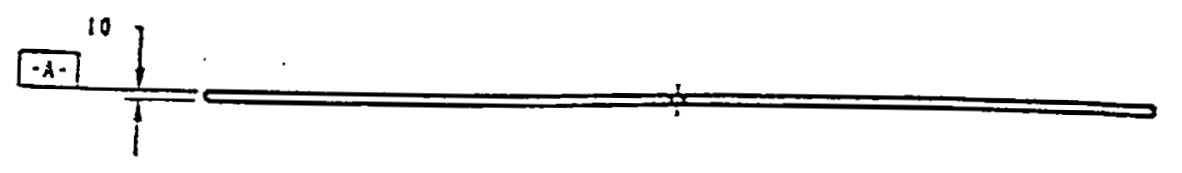

Dimensions in millimeters unless otherwise marked
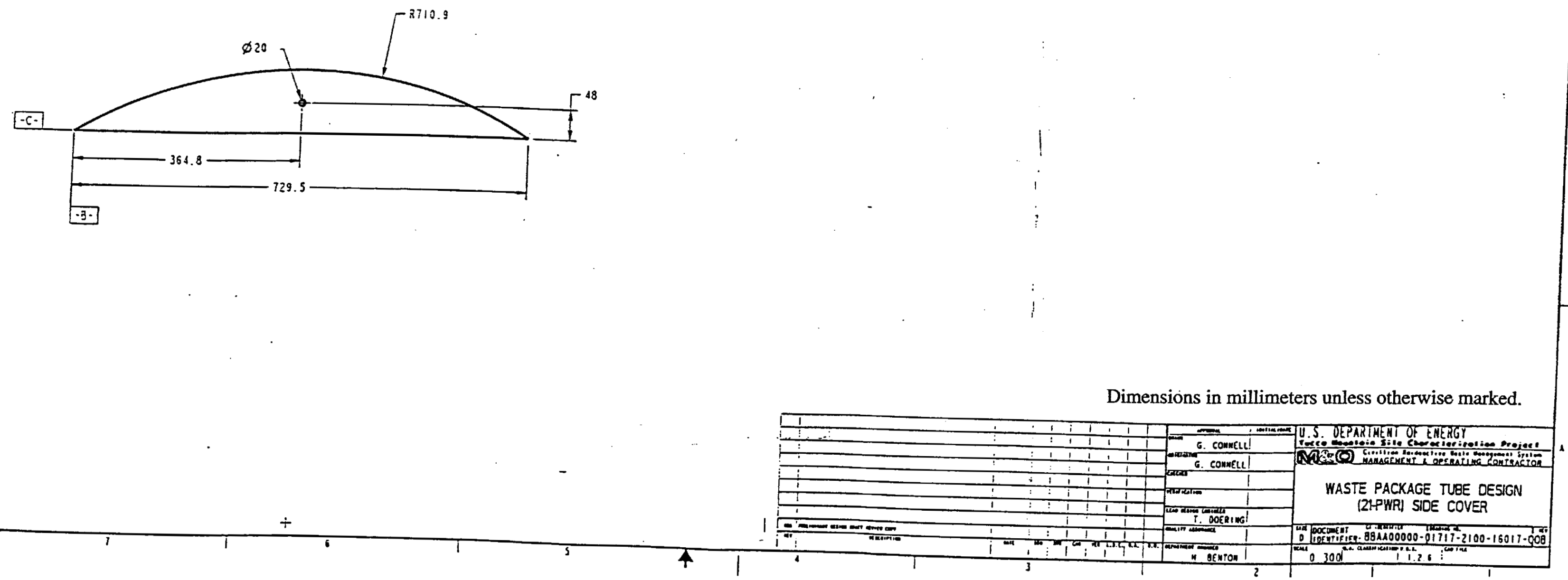


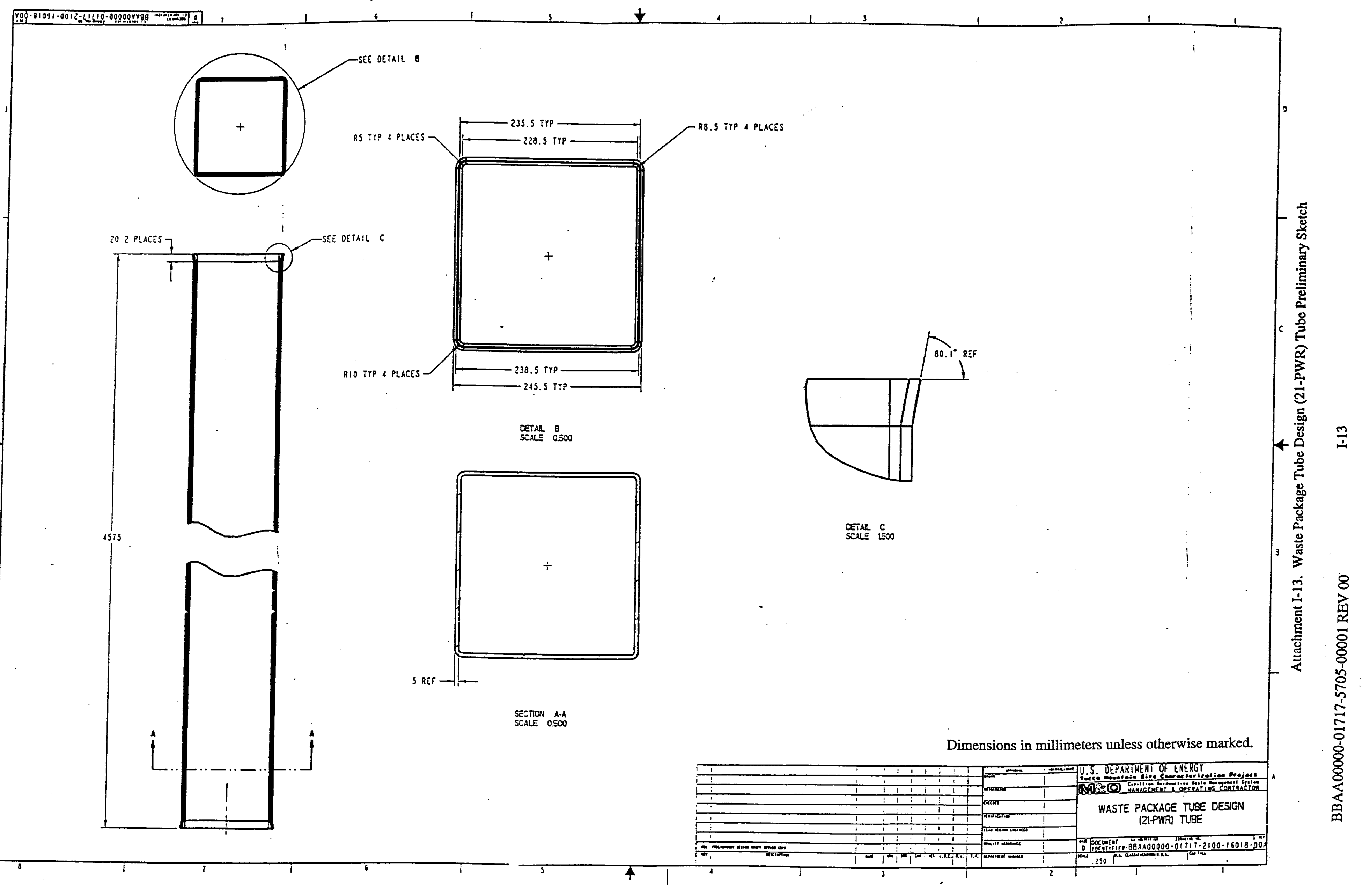




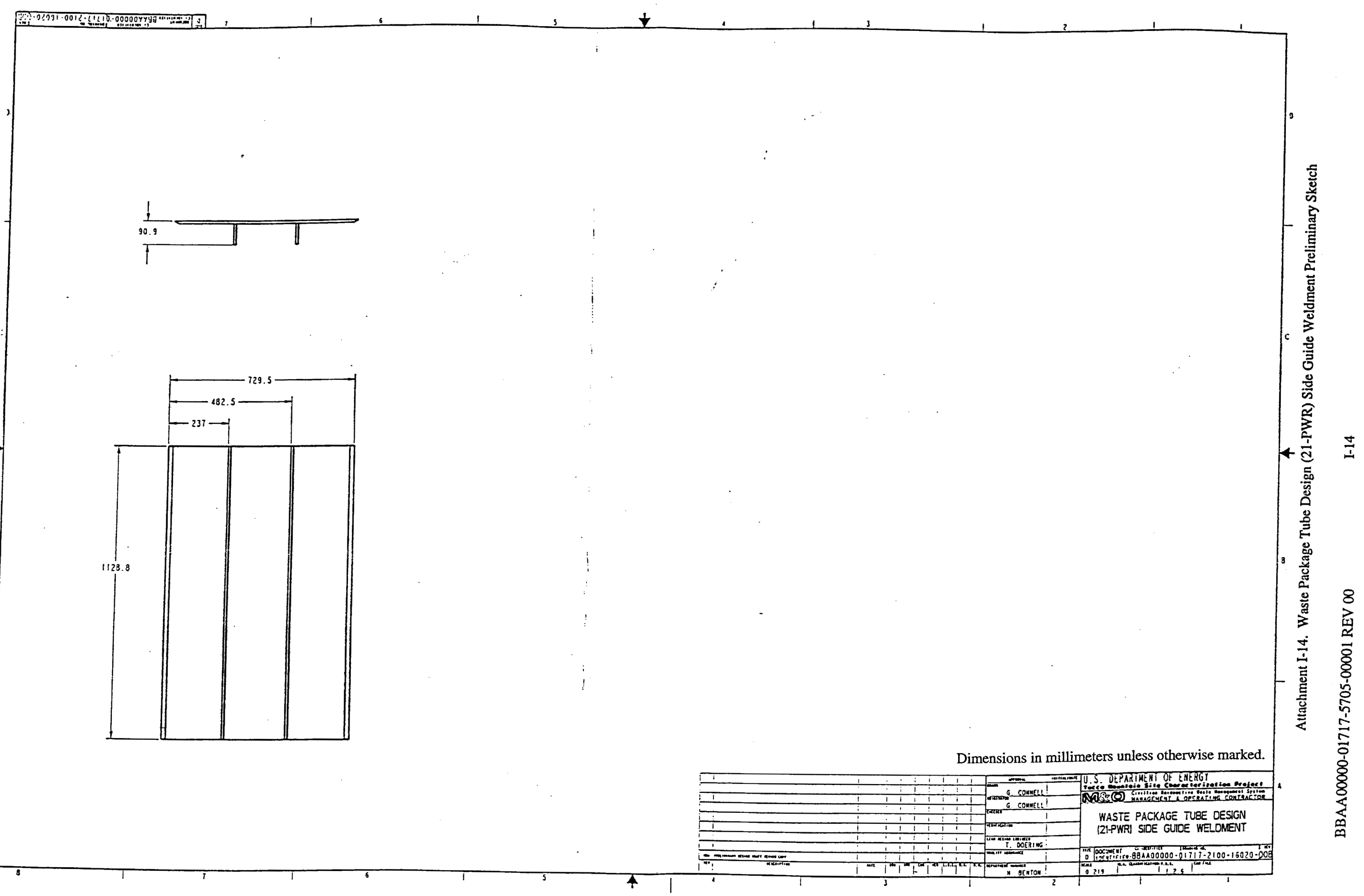

